Illinois State University

ISU ReD: Research and eData

Theses and Dissertations

4-23-2021

\title{
Total Suspended Sediment and Phosphorus Transport in Response to Storm Events in an Agriculturally Dominated Watershed
}

Elijah John William Schukow

Illinois State University, schuke1230@gmail.com

Follow this and additional works at: https://ir.library.illinoisstate.edu/etd

\section{Recommended Citation}

Schukow, Elijah John William, "Total Suspended Sediment and Phosphorus Transport in Response to Storm Events in an Agriculturally Dominated Watershed" (2021). Theses and Dissertations. 1467. https://ir.library.illinoisstate.edu/etd/1467

This Thesis is brought to you for free and open access by ISU ReD: Research and eData. It has been accepted for inclusion in Theses and Dissertations by an authorized administrator of ISU ReD: Research and eData. For more information, please contact ISUReD@ilstu.edu. 
TOTAL SUSPENDED SEDIMENT AND PHOSPHORUS TRANSPORT IN RESPONSE TO STORM EVENTS IN AN AGRICULTURALLY DOMINATED WATERSHED

\section{ELIJAH JOHN WILLIAM SCHUKOW}

99 Pages

Increased sediment introduction and transport in streams negatively impact water quality. Deleterious effects include reservoir filling, water pollution and ecological impairment. Sediment introduction and transport typically takes place during storm events. Phosphorus introduction, generally from loss of agricultural runoff and soil erosion also typically takes place during storm events. When phosphorus is applied for agricultural uses it is preferentially retained by smaller sediments. During storm events, these phosphorus rich sediments are more likely to enter the stream system. A small number of large storms can account for a large percentage of sediment and total phosphorus introduction, leading to elevated levels in waterways. Increased phosphorus introduction into waterways is a main driver of algal blooms and hypoxic conditions such as the dead zone that forms in Lake Erie.

The goal of this study is to determine if turbidity, total suspended sediments, and total phosphorus exhibit similar transport behaviors in an agricultural watershed. Three years of data are available at the Six Mile Creek watershed located in McLean County Illinois. Analysis of total suspended sediments, turbidity, and total phosphorus data show that both total suspended sediments and turbidity display a correlation ranging from weakly to strongly positive with total phosphorus. Hysteresis analysis was conducted to elucidate the similarities in transport mechanisms between total suspended sediments, turbidity, and total phosphorus. Concentration 
discharge relationships observed in the hysteresis patterns were further described by calculating flushing index and hysteresis index values for these events. Evaluation of the hysteresis patterns, flushing index, and hysteresis index allows for further breakdown on an annual, seasonal, or event-based scale.

It was discovered that the hysteresis patterns displayed, the flushing index, and hysteresis index was behaving similarly for both turbidity and total phosphorus on a seasonal, annual, and event-based basis in the Six Mile Creek Watershed. Farmers and agricultural managers may be able to better develop sustainable land management practices if there is a consideration of the correlations between turbidity, total suspended sediments and total phosphorus and the timing of their introduction. This could ultimately mitigate the excessive amount of total suspended sediments, and total phosphorus introduced into surface waters.

KEYWORDS: Adsorption; Agriculture; Concentration; Discharge; Hysteresis; Hysteresis Index; Nutrients; Phosphorus; Turbidity; Total Suspended Sediments 
TOTAL SUSPENDED SEDIMENT AND PHOSPHORUS TRANSPORT IN RESPONSE TO STORM EVENTS IN AN AGRICULTURALLY DOMINATED WATERSHED

\author{
ELIJAH JOHN WILLIAM SCHUKOW
}

\author{
A Thesis Submitted in Partial \\ Fulfillment of the Requirements \\ for the Degree of \\ MASTER OF SCIENCE \\ Department of Geography, Geology, and the Environment \\ ILLINOIS STATE UNIVERSITY
}

2021 
(C) 2021 Elijah John William Schukow 
TOTAL SUSPENDED SEDIMENT AND PHOSPHORUS TRANSPORT IN RESPONSE TO STORM EVENTS IN AN AGRICULTURALLY DOMINATED WATERSHED

\author{
ELIJAH JOHN WILLIAM SCHUKOW
}

COMMITTEE MEMBERS:

Eric Peterson, Chair

William Perry

Catherine O'Reilly 


\section{ACKNOWLEDGMENTS}

I would like to thank Dr. Eric Peterson for serving as my thesis advisor and providing me with excellent insight, motivation, and support throughout the thesis process. I would also like to thank Dr. William Perry for serving on my thesis committee and having the time and the patience to teach me how to use RStudio. This process caused many headaches but saved me an untold amount of time, it is truly a skill I hope to bring with me to the next chapter of my life. I would also to thank Dr. Catherine O'Reilly for serving on my thesis committee and teaching me the ins and outs of conducting a research project. Without the knowledge that you passed onto me going about this process would have been exponentially harder. To all my thesis committee members, thank you so much for helping me design and create this research project, I never would have been able to do this without your help and guidance. The three of you have made my time here at Illinois State University exceptionally great.

I would also like to thank the City of Bloomington, Joe Darter, Jill Mayes, and Rick Twait for funding the Six Mile Creek research site and my research assistantship. I would like to thank and acknowledge Jack Wang, the LEA lab, and the other students involved in data collection for this project prior to myself. I would like to give a special thanks to Illinois State University’s Department of Geography, Geology, and the Environment for all of the opportunities that were available to me as a graduate student and providing me with all of the resources I needed to succeed.

I would like to thank my friends that I have made during my time here at Illinois State University. From all the late nights in the office, countless hours spent studying and writing, and an endless amount of laughter and great times, you know who you are. 
Finally, I would also like to thank my family for always being supportive of me and pushing me to achieve my goals. I would not be where I am today if it was not for your love, support, and guidance. You have truly pushed me to excel throughout phases of my life, including my time here at Illinois State University and for that I will be forever grateful.

E.J.W.S 


\section{CONTENTS}

Page

ACKNOWLEDGMENTS

TABLES

FIGURES - vi

CHAPTER I: INTRODUCTION 1

Sediment/Turbidity 2

$\begin{array}{ll}\text { Phosphorus } & 4\end{array}$

$\begin{array}{ll}\text { Hysteresis } & 6\end{array}$

$\begin{array}{ll}\text { Clockwise loop } & 8\end{array}$

$\begin{array}{ll}\text { Counterclockwise loop } & 10\end{array}$

Figure-eight loop $\quad 11$

Objectives and Research Questions 13

CHAPTER II: METHODS 14

$\begin{array}{ll}\text { Study Site Description } & 14\end{array}$

$\begin{array}{ll}\text { Research Station } & 17\end{array}$

$\begin{array}{ll}\text { Phosphorus Data } & 19\end{array}$

$\begin{array}{ll}\text { Discharge } & 20\end{array}$

$\begin{array}{ll}\text { Storm Event Descriptions } & 20\end{array}$

Hysteresis Index and Flushing Index 20

$\begin{array}{ll}\text { Correlations Statistics } & 22\end{array}$

$\begin{array}{ll}\text { RStudio } & 23\end{array}$

CHAPTER III: RESULTS 25 
Overview

Weather and Yearly Climate Conditions

Storm Events and Values Observed for Variables

Relationship Among Variables

Data as a Whole

Generation of Linear Model

Classification of Single and Double Peaks

Hysteresis Patterns

Hysteresis Index and Flushing Index Comparisons and Statistics

Seasonal Statistics Among Flushing Index and Hysteresis Index

Annual Statistics Among Flushing Index and Hysteresis index

CHAPTER IV: DISCUSSION

Relationship Among Sediment and Total Phosphorus

Watershed Behaviors and Sourcing

Relationships to Discharge

Best Land Management Practices 


\section{TABLES}

Table

Page

1. Turbidity threshold values in NTU used by Six Mile Creek autosamplers

2. Summary Statistics for Storm Parameters Measured in SMC from April 30, 2016, to January 25, 2019

3. Number of Hysteresis Patterns Observed for Single-peak Storm Events for the Entire Study Period, for Individual and for Seasons

4. Flushing Index and Hysteresis Index Values for Turbidity Across Seasons and Years

5. Flushing Index and Hysteresis Index Values for Total Phosphorus Across Seasons and Years 


\section{FIGURES}

Figure

Page

1. Displays how phosphorus can attach to sediments through the process of adsorption 6

2. Displays how clockwise hysteresis patterns can be expected to look for an observed discharge and concentration

3. Displays how counterclockwise hysteresis patterns can be expected to look for an observed discharge and concentration

4. Displays how figure eight hysteresis patterns can be expected to look for an observed discharge and concentration

5. A) Location of SMC watershed within central Illinois, USA

6. Recorded temperature and precipitation for the duration of the study

7. Hydrograph for Six Mile Creek from April 30, 2016 to January 25, 2019

8. Turbidity versus total phosphorus throughout the study period

9. Turbidity versus total suspended sediments throughout the study period

10. Total suspended sediments versus total phosphorus throughout the study period

11. A) Storm data, B) normalized data, and C) clockwise hysteresis patterns generated for turbidity and total phosphorous for storm 10

12. A) Storm data, B) normalized data, and C) counterclockwise hysteresis patterns generated for turbidity and total phosphorous for storm 21

13. A) Storm data, B) normalized data, and C) figure eight hysteresis patterns generated for turbidity and total phosphorous for storm 44

14. Individual storm flushing index (FI) values for turbidity and for total phosphorous 
16. FI for turbidity and FI for TP by season $\quad 45$

17. HI for turbidity and HI for TP by season 45

18. HI for turbidity and HI for TP by season $\quad 46$

19. FI for turbidity and FI for TP by year 47

20. FI for turbidity and FI for TP by year $\quad 48$

21. Displays the relationship observed between peak discharge and the hysteresis index $\begin{array}{ll}\text { across seasons } & 55\end{array}$

22. Displays the relationship observed between peak discharge and the flushing index across seasons 


\section{CHAPTER I: INTRODUCTION}

Increased sediment introduction and transport in streams have a large impact on water quality and ecological diversity. Sediment introduction causes a range of effects including reservoir filling, water pollution, changes in vegetation density, disruption of the food chain, and reduction of channel navigability (Williams 1989; Heathwaite et al., 2005). Increased sedimentation can also have a negative effect on the ecological life found in waterbodies. For example, increased sedimentation decreases visibility in the water and can make it harder for fish to feed. This increase in sediment can also cause abrasion on the gill tissue of fish, negatively affecting their growth rate and reducing the respiratory surface area of the fish (Sutherland et. al., 2007). An additional impact is the link of sediment to nutrients. For example, phosphorus, which is one of the key nutrients for plant growth and biochemical processes, adsorbs onto sediments (Ballantine 2009; Fang et al., 2017; Hart et al., 2004). The adsorption suggests that the mobilization and transport dynamics between sediment and phosphorus are linked. The mobilization and introduction of sediments typically takes place during storm events (Lloyd, et. al., 2016). However, the transport mechanics of sediment have been a challenge to study due to the spatial and temporal variability of storm events (Borah et. al., 2003). Previous studies have used various sampling intervals, ranging from scales of monthly and weekly time frames, with increased sampling during storm events (Gentry et. al., 2007; Schilling et. al., 2020). With the advancements of technology, high-frequency data collection from in-situ sensors can capture very high-resolution data from 0.5 seconds to the 15 -minute intervals. These high-resolution data can be analyzed to highlight temporal relationships between discharge, sediment, and nutrients (Burns et. al., 2019). The use of concentration discharge relationships to gain understanding in 
the introduction and mechanics of both sediments and nutrients into waterways could lead to improved planning and implementation of better watershed management practices.

\section{Sediment /Turbidity}

Total suspended sediments (TSS) are particles that are larger than two microns ( $2 \mu \mathrm{m})$ and are made up of inorganic materials (ISS), such as silt or clay, as well as organic materials like algae, bacteria, and decaying material (OSS). Turbidity is the optical determination of water clarity and is based on the amount of light that is scattered by particles in the water column (Davie-Colley and Smith 2001; Lawler 2005). Waters that are turbid will appear cloudy and colored, while waters that have low turbidity will have high clarity. The measurement of turbidity for a body of water can be used as an indicator for water quality and as an estimate for the total suspended solids in the water column. While turbidity is related to TSS, turbidity is impacted from several sources including algae and colloidal material (Alan and Castillo 2007). Monitoring of turbidity can be used to indicate changes in the amount of total suspended solids in the water.

Suspended sediment is a major water quality issue. In 2000, the Iowa DNR reported sediment as the agricultural pollutant having the greatest effects on water quality (Schilling et. al., 2011). Sediment supply to streams and rivers can have a range of sources such as tile drains, surface runoff, channel, or bank erosion (Kronvang, et. al., 2013). Sediments supplied to the stream from outside its banks can arrive from overland flow, receding flood waters, or even from human influence such as agricultural or construction practices (Williams 1989).

Much of the Midwest is heavily farmed and has streams that drain agricultural watersheds. In Illinois, agriculture has been at the root of water pollution and contamination (Borah et. al., 2003). This is important because sediments introduced into streams can carry with 
them sediment associated contaminants such as phosphorus, ammonium, and organic nitrogen (Lloyd et. al., 2016). One of the key controls on sediment transport in streams is the discharge characteristics. For example, storms of longer duration or greater intensity lead to greater changes in discharge and have higher chances for transporting sediment in the stream, which is attributed to the stream gaining erosional power or because available sediment have been deposited in the stream and is remobilized due to the changing discharge (Borah et al., 2003, Gentry et al., 2007, Lloyd et. al., 2016, Royer et al., 2006, Sherriff et al., 2016, Wymore et al., 2019)

Studies that have investigated sediment transport and dynamics have found and highlighted on some interesting relationships. For example, a study done on a watershed in France found that $85-95 \%$ if the suspended sediment load occurred during storm events (Oeurng et al., 2010). It has also been found that in incised channels large proportions of sediments can be yielded from bank erosion (Neal and Anders 2015; Rinaldi and Simon, 2006). A study conducted in Maryland found that $45 \%$ of sediments were sourced from agricultural lands and $52 \%$ were from streambanks (Gellis et al., 2013). In low-gradient agricultural stream in central Illinois, Peterson et al. (2008) found that it requires less shear stress for mobilization of sediments than in mountain and karst streams given the size of sediments transported. They also found that there was a higher frequency of events capable of entertaining sediment in lowgradient streams versus mountain and karst streams. This is important because it means that lowgradient agricultural streams have hydraulic conditions and sediment sizes that make the streambed highly mobile and something that can be redistributed on a regular or event-based basis. The channel bed is not typically considered a source of sediments but rather a storage of sediments mobilized from upstream sourced (Gellis et al., 2009). Overall sediment sourcing 
occurs from a range of sources including, cropland, pastures, construction sites, streambanks, flood plains and more (Gellis et al., 2015)

\section{Phosphorus}

While a key nutrient for plant growth and development, excess phosphorus in the waterways is one of the main drivers of algal blooms and hypoxic conditions in waterways (Schilling et. al., 2020). Hypoxic conditions form when algae die and decompose; this decomposition by bacteria consumes the available oxygen in the water column and creates a lowoxygen environment, otherwise known as a dead zone (Diaz 2001; Rabalais et. al., 2002). A primary example of a coastal dead zone found in the Gulf of Mexico (Diaz 2001), while a freshwater example is the harmful algal bloom that occurs in Lake Erie (Watson et al., 2016)

Phosphorus can be introduced into watersheds from point sources, such as wastewater treatment plants and from non-point sources, such as runoff from agriculture and soil erosion. The Iowa Nutrient Reduction Strategy (Iowa Department of Agriculture and Land Stewardship, 2012) reported that $79 \%$ of total phosphorus (TP) loads in streams were sourced from non-point sources. Surrounding land use, sediment supply, and slope of the stream were found to be the main drivers in both phosphorus phase, dissolved reactive phosphorus (DRP) or particulate phosphorus (PP), and phosphorus dynamics (Bowes et, al., 2003). Phosphorus loss from agricultural runoff and soil erosion and the introduction of phosphorous into the surrounding environment are primarily driven by episodic events such as storms or snow melt, with the dominant transport mechanism as overland flow. Publications report that a small number of large storms can account for a large percentage of sediment and of TP to be transported (Lloyd et. al., 2016; Ramos et al., 2015; Royer et al 2006). The largest phosphorus mobilization events took place during the first large storm after a drought. Large mobilizations occurring after times of 
low flow or draught is a commonly observed pattern and is due to the increase in remobilized sediment from the streambed and banks during the storm event. When storm events occur in succession, lower levels of sediment and phosphorus are observed because replenishment of materials between events has not occurred (Bowes et. al., 2005; Bowes et.al., 2015).

Tile drainage can also be a key pathway for phosphorus transport (Gentry et. al., 2007). Throughout much of the Midwest, tile drainage is used to drain agricultural fields, and in row crop dominated states such as Illinois and Iowa, up to $85 \%$ of fields are drained using tiles (Sugg 2007). Designed to increase the lands available to be farmed, tile-drainage systems directly introduce nutrient-rich water into local waterways ( Dinnes et. al., 2002, Mastrocicco et. al., 2013). The main source of dissolved reactive phosphorus (DRP) is sourced from these tile drains, especially from late fall to early summer, while particulate phosphorus (PP) is primarily sourced from runoff and erosion (Gentry et. al., 2007).

As the limiting nutrient for primary production in many rivers, phosphorus has been the focus of research exploring sourcing, transportation, and storage. In a northern England watershed, $85 \%$ of the phosphorus exported was generated in the lowland agricultural section of the river with a 20 -fold increase in particulate phosphate concentration from the agricultural section (Bowes et. al., 2003). Large inputs of DRP were observed up stream, but concentrations increased only $4 \%$ downstream. The combination large inputs in the upstream sections but small increases in concentration downstream suggest that DRP was adsorbing on to sediment particles in the river.

The ability for phosphorus to adsorb (Figure 1) onto sediments is a key driver for phosphorus introduction into waterways allowing for the mobilization of sediments to also mobilize phosphorus. For example, smaller and lighter sediments can be transported more easily 
and are more likely to be introduced into waterbodies. When phosphorus is applied for agricultural uses it is preferentially retained by smaller clay size sediment particles (Reedy and DeLaunne 2008). These smaller sediment particles can have elevated phosphorus levels and when a storm event takes place are more likely to be introduced into the stream (House, et.al., 1998). The introduced sediment can drive up PP during these times due to phosphorus being adsorbed onto the finer sediments but a low introduction of DRP. Overall, this trend causes an increase in TP in streams, particularly during storm events.

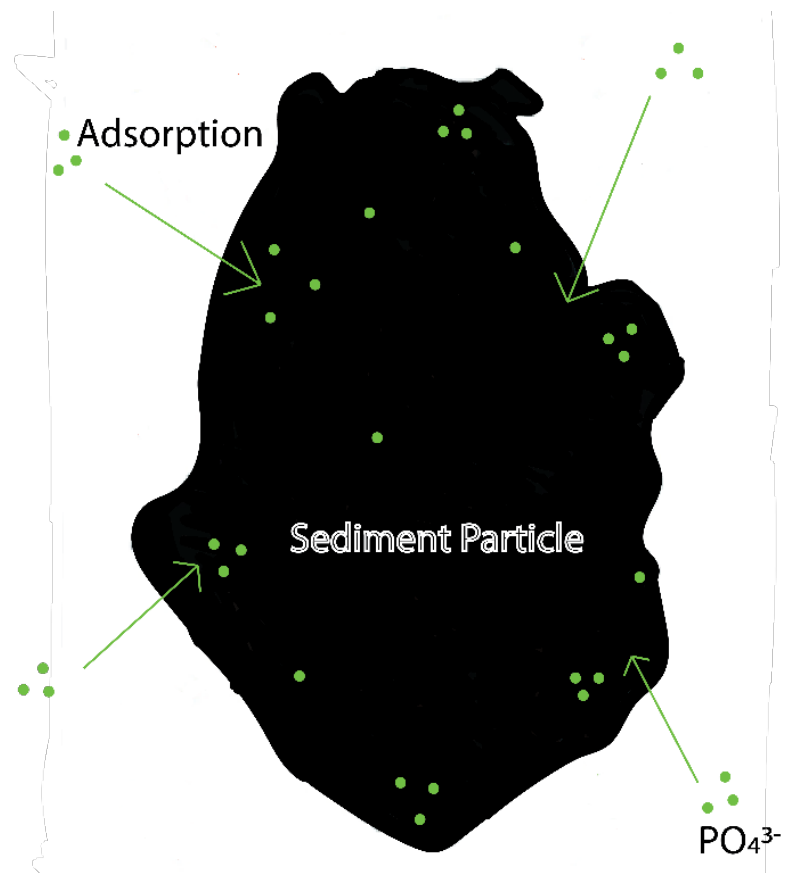

Figure 1: Displays how phosphorus can attach to sediments through the process of adsorption (modified from Fang et al., 2017)

\section{Hysteresis}

Advancements in technology have led to in-situ sensors being able to collect high resolution data. These high-resolution data can be compared to highlight the relationships 
between concentration and discharge and to provide a reliable method for categorizing concentration - discharge dynamics (Williams 1989). When the discharge values are plotted against their corresponding concentrations, a hysteresis loop is generated. Hysteresis occurs when the same discharge value occurs with different concentration values during both the rising and failing limbs of the hydrograph (Figure 3) (Bowes et. al., 2005). The analysis of hysteresis patterns is an effective and valuable tool for assessing the relationship between storm events and the response different hydro chemical parameters have to the storm event in each watershed (Lloyd, et. al., 2016). Concentration and discharge relationships can be used to highlight different variables (turbidity, phosphorus, nitrate, total suspended sediment) and the relationship they have with discharge. However, most work in hysteresis has focused on suspended sediment and discharge relationships where fewer studies have focused on phosphorus discharge and phosphorus and suspended sediment relationships (Bowes et. al., 2015).

The monitoring of nutrient concentrations is important for determining the health of a stream but does not indicate sourcing of the nutrients. A way to do this is to analyze the hysteresis effect produced during a storm event (Bowes et. al, 2005) The relationship between concentration and discharge can be used to infer both source and dynamics on an annual scale, a seasonal scale or on an event-based scale (Bowes et. al., 2015). Depending on the types of patterns observed for a given storm event you can get an idea if the sediments and nutrients being transported are soured from in stream or near bank regions vs introductions from outside the stream such as agricultural runoff.

Hysteresis loops are commonly described based on their loop magnitude and strength of hysteresis occurring during an event and can be represented by a hysteresis index (HI), which is discussed in the following section. Hysteresis loops are also described based on their rotational 
direction. These relationships can be separated into five classes: 1) single valued; 2) clockwise loop; 3) counterclockwise loop; 4) single value plus a loop; and 5) figure-eight. Generally clockwise, counterclockwise, and figure eight loops are most common, with single value and single value plus a loop being very rare (Williams 1989).

\section{Clockwise loop}

Clockwise hysteresis loops occur when the concentration peaks arrive at the stream crosssection before the peak discharge (Figure 2). This means that the concentration of sediment (or parameter of interest) has a higher value on the rising limb than on the falling limb for the same discharge. Clockwise loops represent conditions when the sediment is in limited supply and is transported downstream before peak discharge has arrived (Williams 1989). Clockwise rotational patterns indicate that the sourcing of the concentration variables are from within the stream or found in proximal reaches of the stream (Bowes et al., 2009; Lloyd et al 2016)For phosphorus, clockwise patterns are typically found in intensively farmed sections of the stream (Bowes et. al., 2005) due to the rapid delivery of phosphorus to the sampling location on the rising limb of the hydrograph. To get this pattern and the rapid delivery of phosphorus the source of the phosphorus must be from either from within the stream or near the stream itself such as tile drainage, remobilized bed sediment or erosional runoff (Bowes et. al., 2005, Bowes et. al., 2015). However, it was also noted that after successive storm events the lowland hysteresis loops decreased in magnitude and migrated towards counterclockwise pattern. This is due to a decrease availability of phosphorus from the stream and its banks (Bowes et. al., 2005). 


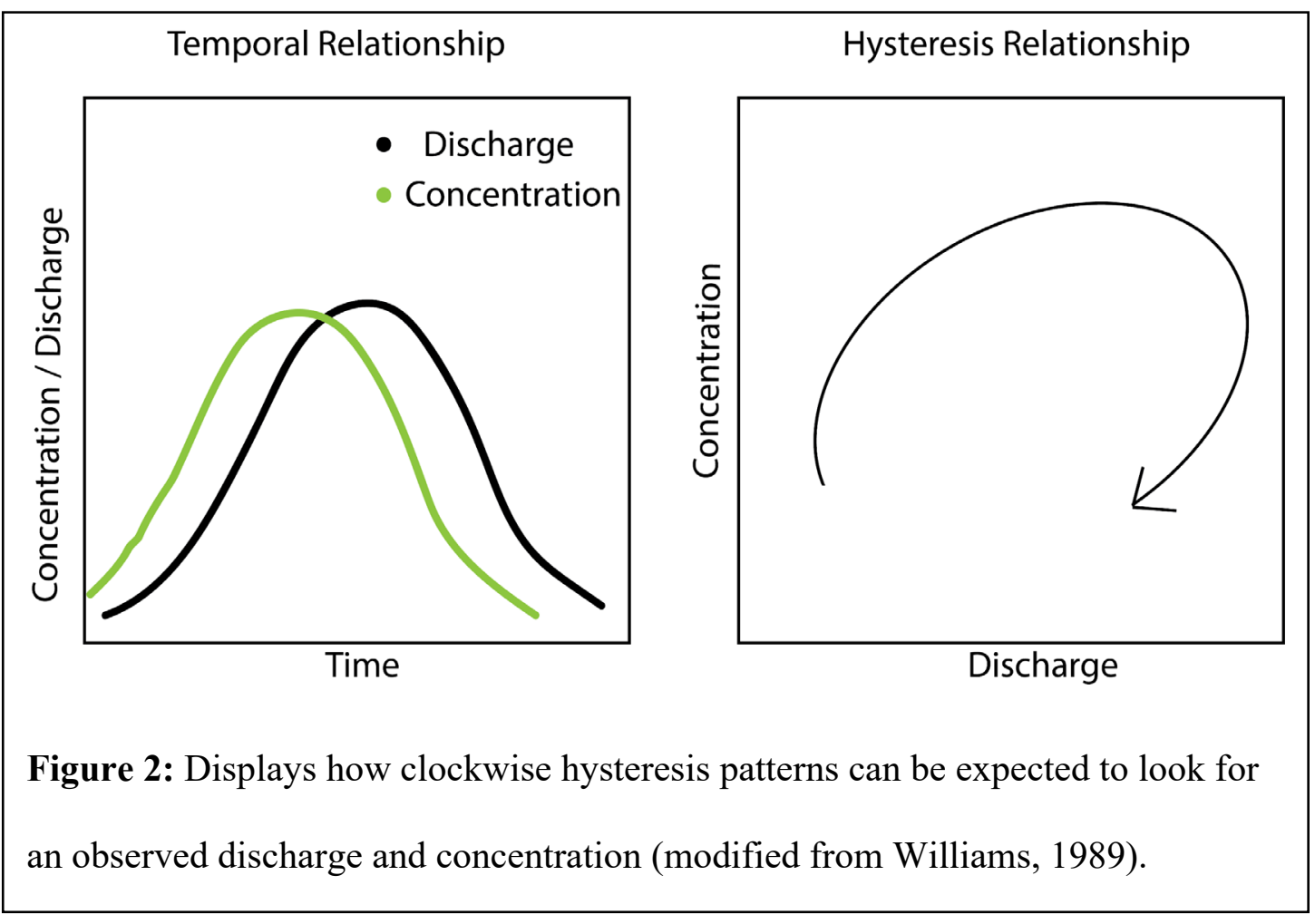




\section{Counterclockwise loop}

Counterclockwise hysteresis loops occur when the concentration peak arrives after the peak discharge (Figure 3), as a result of sediment transport following the mean flow velocity rather than the peak velocity of the stream (Bowes et al., 2009; Lloyd et al., 2016) . This means that the main influx of sediment might get stuck behind the peak discharge of the stream and irregularities in the stream such as meandering can magnify this process. Counterclockwise hysteresis loops indicate that the sourcing of the particulate or concentration variable is from distal sources up stream and out of stream including influence from tributaries and the subsurface (Lawler et al., 2006; Bieroza and Heathwaite 2015). Another cause of counterclockwise loops can be due to high erodible soils combined with a long flood event. Extended flood events allow for sediment to be continuously supplied to the stream during the flood even after the peak discharge has passed (Williams 1989).For phosphorus, counterclockwise patterns were most commonly observed in the upland stream section where agriculture is not as intense (Bowes et. al., 2005). The delay is attributed to phosphorus sourcing most likely introduced from a slow mobilization or from distant reaches from the sampling location (Bowes et. al., 2005, Bowes et. al, 2015). 


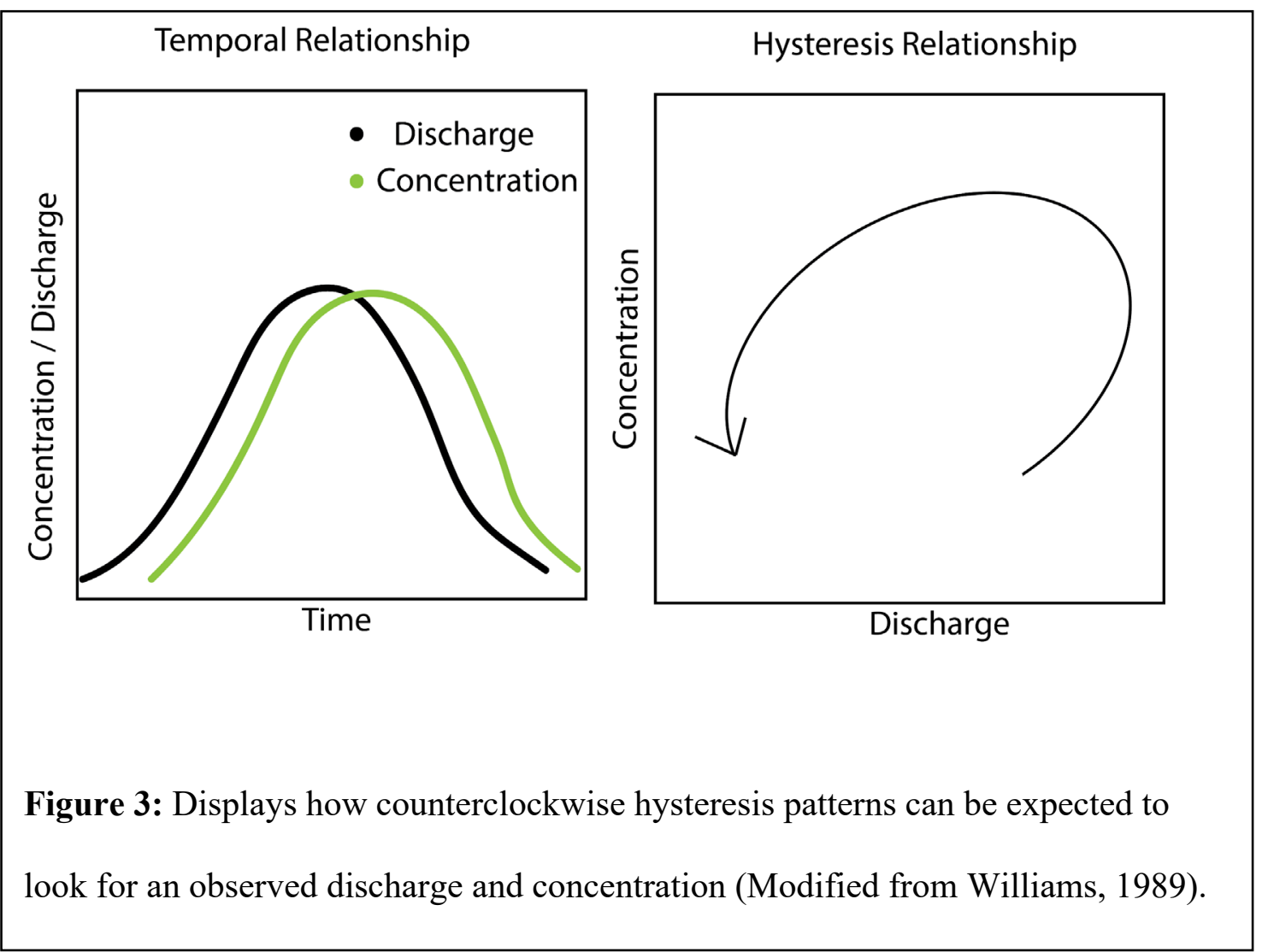

\section{Figure-eight loop}

Figure-eight hysteresis loops (Figure 4) combine parts of both the clockwise and counterclockwise loops due to a shift in the relationship between discharge and the concentration variables during an individual event (Lloyd et al., 2016). The more complex figure-eight hysteresis patterns can be formed as a result of secondary peaks in the concentration variables (Keesstra et al., 2019), or cases where the concentration variables remain at higher levels then discharge on the falling limb (Smith and Dragovich 2009). The Figure-eight hysteresis patterns can also be caused by multiple runoff generation processes (Zabaleta et al., 2007). Clockwise 
figure-eight hysteresis patters can be observed when the concentration variable peaks before the discharge on the rising limb, which produces the first half of the figure eight loop. The second half of the loop forms when the discharge stays at a level higher than the concentration variable on the falling limb of the hydrograph. Counterclockwise figure-eight hysteresis patterns can be observed when the discharge variable reaches its peak before concentration on the rising limb and the concentration variables stays at a higher concentration then the discharge on the falling limb. Overall figure-eight hysteresis patterns are complex and hard to differentiate, therefore one should use careful examination of the data to classify these events (Lloyd et al., 2016).. Figure eight patterns are also thought to be more common in storms that occur in succession of each other (Lloyd et. al., 2016).

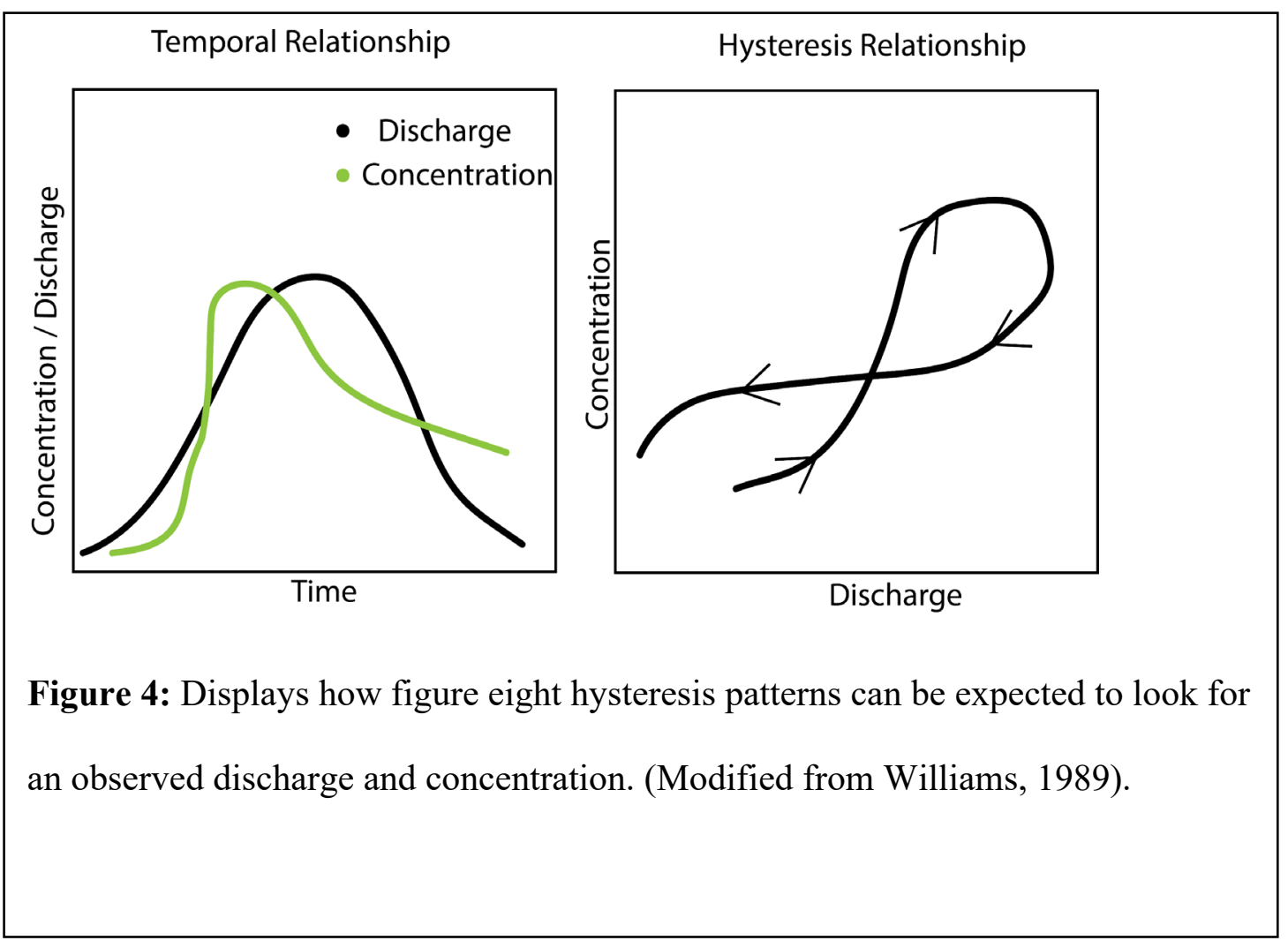




\section{Objectives and Research Questions}

The overarching objective of this study is to determine if turbidity and phosphorus are behaving similarly in the Six Mile Creek Watershed. The objectives of this research are going to be explored through the following research questions:

- Do turbidity and phosphorus follow similar transport behaviors in the Six Mile Creek Watershed?

- Is the flushing index (FI) and the hysteresis index (HI) observed during storm events among turbidity and discharge and phosphorus and discharge similar?

○ How do the flushing index (FI) values and hysteresis index (HI) values compare among water years and among seasons? 


\section{CHAPTER II: METHODS}

\section{Study Site Description}

This study focused on Six Mile Creek (SMC) and its watershed, which are part of the Evergreen Lake watershed located in McLean County, Illinois (Figure 5). This watershed spans $106.5 \mathrm{~km}^{2}$ (Evergreen Lake Watershed Management Plan 2008). Six Mile Creek originates southwest of Towanda flowing northwest and is one of three tributaries that flow into Evergreen Lake. Evergreen Lake serves as a drinking water reservoir for the City of Bloomington and had an original storage capacity of 19,095,22 $\mathrm{m}^{3}$. (Evergreen Lake Watershed Management Plan 2008). The predominant land usage in the Evergreen Lake watershed is agriculture and rural grassland with $87 \%$ of the land in the watershed is covered with row crops (Evergreen Lake Watershed Management Plan 2008). The sampling station on SMC is located about $0.8 \mathrm{~km}$ upstream from Evergreen Lake (Hanna 2013) and is the sole research location for this study.

The SMC watershed resides in a location that has been heavily influenced by multiple glacial advances. About 12,000 years ago the last glaciation took place, and when the glaciers receded, they formed a series of moraines across east-central and northeastern Illinois. The watershed resides within the Till Plains section of the Central Lowland Province, specifically the Bloomington Ridged Plain. This area has low-relief, and the soils are mostly silt loam and silty clay loam. These soils are fertile, have high resistance to drought but are poorly drained due to high clay content (Soil Survey of Mclean County, 2002). McLean County Soil and Water District estimate that $25 \%$ of the watershed has tile drainage (Evergreen Lake Watershed Management Plan 2008). 
The climate of the study area has an average annual high temperature of $16.1^{\circ} \mathrm{C}$ and an annual low temperature of $4.44^{\circ} \mathrm{C}$. The average precipitation for the region is $999.2 \mathrm{~mm}$ per year with an annual snowfall of $508 \mathrm{~mm}$ per year. (US Climate Data 2021). 


\section{Six Mile Creek Study Area}
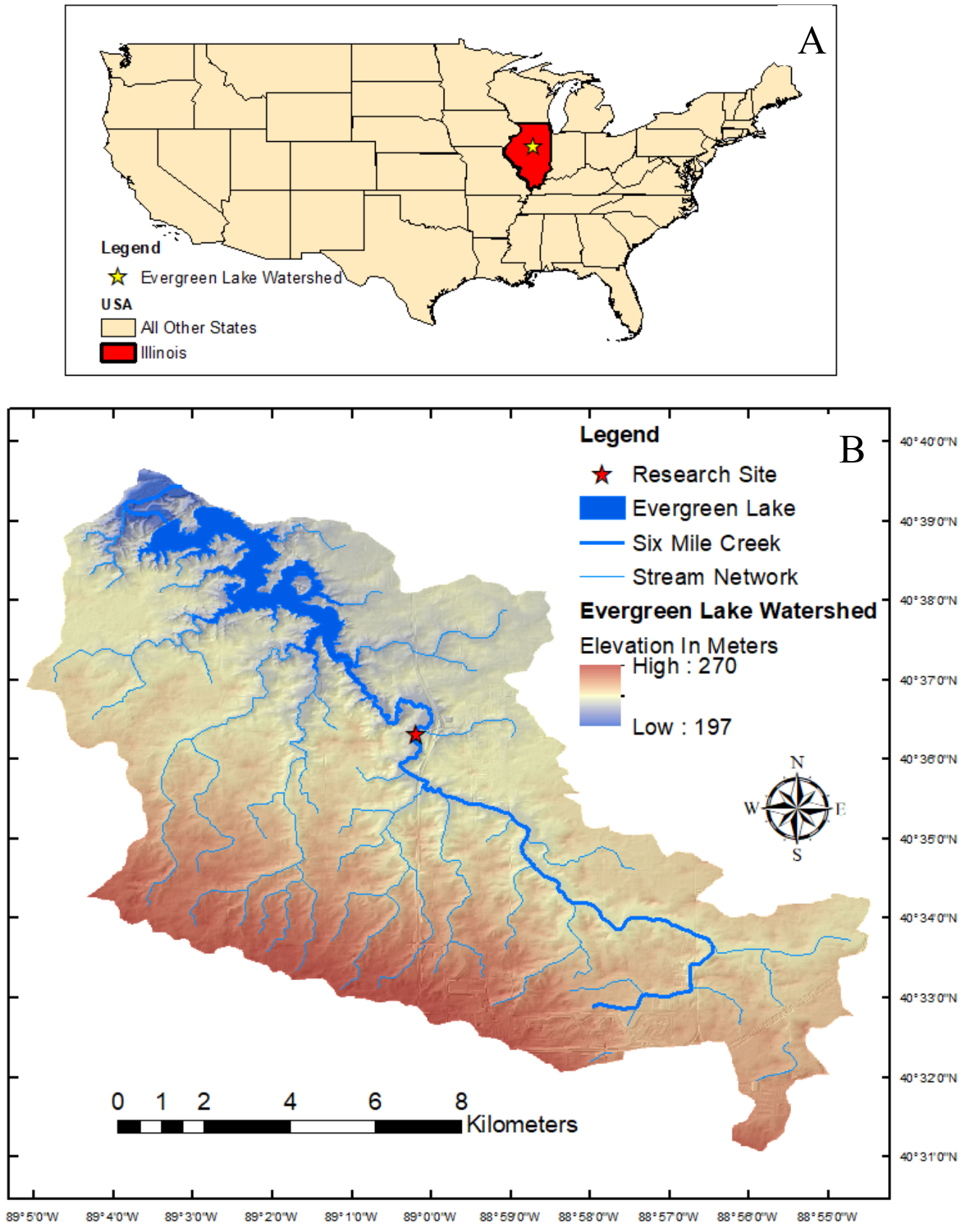

Figure 5: A) Location of SMC watershed within central Illinois, USA. B) Six

Mile Creek sampling location within the Evergreen Lake Watershed. 


\section{Research Station}

The SMC study site is equipped with an automated water sampler (ISCO 6712), a SDI-12 Submersible Pressure Transducer, and an DTS 12 turbidity sensor. The DTS-12 sensor can capture an optical reading between 0 and 1,600 NTU with an accuracy of $+/-2 \%$ of reading ( 0 399 NTU) and an accuracy of $+/-4 \%$ of reading (400-1,600 NTU) at a 0.01 NTU resolution (FTS DTS-12 User Manual). The SDI-12 Submersible Pressure Transducer can capture pressure data between 0 and $274 \mathrm{~m}$ in the water column with an accuracy of $\pm 0.1 \%$ and can collect water temperature within $\pm 0.3^{\circ} \mathrm{C}$ (FTS SDI-12 User Manual). The SDI-12 Submersible Pressure Transducer and DTS-12 sensors collect turbidity, stage, and water temperature data continuously on a 15-minute interval. The data are stored on an FTS Axiom datalogger and transmitted to a lab computer via $4 \mathrm{G}$ connection. The ISCO sampler can hold 241 -liter sized bottles and is programed to collect samples on a percent (\%) change in turbidity (NTU) observed in the stream. The percent change is based off turbidity threshold values for Six Mile Creek (Table 1, Lampo 2017). Data for the study site have been collected since April 2016, providing more than three years of data for the study. Instrument issues occurred on a few occasions during the study period when the sensor was removed from the study site for maintenance. This period created gaps in the data set. 
Table 1: Turbidity threshold values in NTU used by Six Mile Creek autosamplers. (Modified from Lampo 2017)

\begin{tabular}{|l|l|}
\hline \multicolumn{2}{|c|}{$\begin{array}{c}\text { Six Mile Creek Turbidity } \\
\text { Thresholds (NTU) }\end{array}$} \\
\hline Rising & Falling \\
\hline 40 & 1900 \\
\hline 77 & 1698 \\
\hline 115 & 1507 \\
\hline 170 & 1328 \\
\hline 300 & 1160 \\
\hline 467 & 1004 \\
\hline 670 & 858 \\
\hline 820 & 724 \\
\hline 910 & 602 \\
\hline 1187 & 491 \\
\hline 1500 & 391 \\
\hline 1850 & 302 \\
\hline & 225 \\
\hline & 159 \\
\hline & 105 \\
\hline & 32 \\
\hline & 40 \\
\hline
\end{tabular}

The $\%$ change in turbidity triggers samples to be collected from the SMC sampling station, which typically takes place during a storm event. The bottles in the ISCO Sampler are pre-acidified with a $50 \%$ hydrochloric acid to maintain $\mathrm{pH}$ and labeled by number, date, and location to correlate to a point with the same time on a hydrograph for the stream. The ISCO bottles are then replaced and taken to Department of Geography-Geology, Illinois State University for lab analysis. Key samples that capture the main shape of the hydrograph including points from the rising limb, the peak, and the falling limb were chosen for filtration. 
For the chosen samples, the bottles were shaken for $10-15$ seconds to agitate the sediment and water in the bottle and then were measured for their turbidity using a $2100 \mathrm{P}$ Turbidmeter. For each sample chosen, two bottles were collected, one $60 \mathrm{ml}$ unfiltered sample and one $60 \mathrm{ml}$ sample filtered through a Whatman 934-AH, diameter $27 \mathrm{~mm}$, particle retention of $1.5 \mu \mathrm{m}$ filter using a vacuum filter method. Filtering a known volume of the sample allows for sediment to be collected on the filter. The filter was pre-combusted in a muffle furnace oven at $540{ }^{\circ} \mathrm{C}$ for six hours. The filters for each of the samples were stored in a $105^{\circ} \mathrm{C}$ oven for 24 hours. The filters were then transferred to the muffle furnace $540{ }^{\circ} \mathrm{C}$ oven and dried again for 6 hours. The dried weights of the filters were collected after each phase in the oven and recorded manually into a field book. These data were then combined to calculate the total suspended sediment (TSS) using Eqn. 1:

$$
\operatorname{TSS} \frac{\mathrm{mg}}{\mathrm{L}}=\frac{\left(\left(\text { mass of filter }+105^{\circ} \mathrm{Cdried} \mathrm{sediment}(\mathrm{g})\right)-\text { mass of filter }(\mathrm{g})\right)}{(\text { sample volume of water }(\mathrm{ml}))} \times \frac{1000 \mathrm{ml}}{1 \mathrm{~L}} \times \frac{1000 \mathrm{mg}}{1 \mathrm{~g}}
$$

\section{(Eqn. 1)}

\section{Phosphorous Data}

Concentrations of total phosphorus (TP) and dissolved reactive phosphorus (DRP) were provided by the LEA lab in the Department of Geography, Geology, and the Environment, Illinois State University and were not analyzed as part of this study. The data were taken and matched up with the TSS data based on date and time as well as the sample number. Using the total phosphorus (TP) and the dissolved reactive phosphorus (DRP) concentrations the particulate phosphorus (PP) concentration was calculated (Eqn. 2). Cases where the PP concentrations (Eqn. 3) were negative meant that the DRP was recorded as being higher than the $\mathrm{TP}$, which is not physically possible, were not used in further analysis.

$$
\text { TP } \left.\frac{u g}{L}=\text { (Dissolved reactive phosphorus }(u g)+\text { Particulate phosphorus }(u g)\right)
$$


(Eqn. 2)

$$
P P \frac{u g}{L}=(\text { Total phosphorus }(u g)-\text { Dissolved reactive phosphorus }(u g))
$$

(Eqn. 3)

\section{Discharge}

Storm events were chosen to be the focus of this study because they are the main drivers in sediment and nutrient mobilization in streams. Discharge data for the study were provided at SMC and not calculated as part of this research. The discharge data for SMC were fed through a filter in $\mathrm{R}$ to identify values that increased from baseflow over the study period. These storm events were then used to separate out the dataset into individual storms.

\section{Storm Event Descriptions}

Each storm was described by its range of values, and its minimum, maximum, and mean value observed for the variables discharge, stage, phosphorus concentrations, turbidity. Each storm was also described by the year and season the storm took place, the hysteresis pattern that was observed and the recorded HI and FI values observed for turbidity and total phosphorus.

\section{Hysteresis Index and Flushing Index}

Hysteresis patterns were identified by graphing relationships in discharge against total phosphorus, and discharge against turbidity. For each individual storm, data were normalized (Eqn. 4, Eq. 5) before graphing following the methods presented in Lloyd et al. (2016). Normalization does not change the shape, or the type of hysteresis pattern observed for a storm 
but allows for a scale-independent comparison of storms despite differences in discharge or concentration (Lloyd et. al., 2016).

$$
\text { Normalized } Q i=\frac{Q i-Q \min }{Q \max -Q \min }
$$

\section{(Eqn. 4)}

$$
\text { Normalized } C i=\frac{C i-C \min }{C \max -C \min }
$$

\section{(Eqn. 5)}

Where $\mathrm{Q}_{\mathrm{i}}$ is discharge and $\mathrm{C}_{\mathrm{i}}$ is concentration with respect to time interval $i . \mathrm{Q}_{\min }$ and $\mathrm{C}_{\min }$ represent the minimum values for the event, while $\mathrm{Q}_{\max }$ and $\mathrm{C}_{\max }$ represent the maximum values for the event. Comparisons can be made among the storm events by describing them based on their hysteresis index (HI) (Eqn. 6) (Lloyd et. al., 2015, Vaughan et. al., 2017).

$$
H I=C_{R L}-C_{F L}
$$

\section{(Eqn. 6)}

$\mathrm{C}_{\mathrm{RL}}$ and $\mathrm{C}_{\mathrm{FL}}$ represent normalized concentration values for both corresponding to the same discharge on the rising and the falling limbs of the hydrograph. The averaged HI value can be used to describe each of the hysteresis events along with standard deviation for the event. Values of HI can range between -1 and 1 where negative values represent counterclockwise rotation and positive represent clockwise rotation and values of zero represent no hysteresis observed. 
A hysteresis loop can also be described by the slope or gradient of the generated loop, which represents the flushing index (FI) (Eqn. 7).

$$
F I=C_{\text {Qpeaknorm }}-C_{\text {initialnorm }}
$$

\section{(Eqn. 7)}

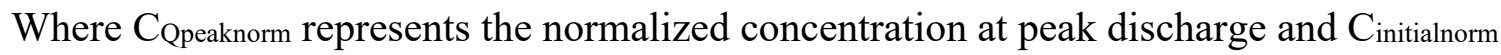
represents the normalized concentration at the beginning of the storm. FI values range from -1 to 1. Negative values represent a dilution effect, while positive values represent a concentration (flushing) effect during the rising limb (Vaughan et. al., 2017).

\section{Correlations and Statistics}

Correlations among the variables of interest were calculated over the entire duration of the study and over subsets of the data for each year. Statistical relationships were generated for TSS and TP, TSS and turbidity, turbidity and TP. For each of the variables, a $R$ and a $\mathrm{R}^{2}$ value were calculated and compared to infer the direction and strength of correlation.

Determination of similarities among FI values for turbidity and TP and HI values for turbidity and TP was addressed through a series of qualitative and statistical analyses. Question one was addressed by plotting and visually comparing individual storm events. The calculated HI and FI values were compared to better assess the transport mechanics of TP and turbidity in the SMC. A paired t-test was performed comparing HI values between turbidity and total phosphorus for collective events. A paired t-test was also be performed comparing the FI values between turbidity and total phosphorus for collective events. The paired t-test was conducted to see if the values were similar throughout the study period and across individual events. Prior to 
running the paired t-test the variables were tested for assumptions of normality and were found to meet or slightly deviate from the criteria, allowing a paired t-test was to be performed.

Question 2 in relation to year was addressed by using a MANOVA test with the two response variables being $\mathrm{HI}$ and FI and the categorical variable being year. Question 2 in relation to season was addressed by using a MANOVA test with the two response variables being HI and FI and the categorical variable being season. All statistical analysis used an $\alpha=0.05$.

\section{RStudio}

Code was written in RStudio to help aid in the analysis and separation of the data available for the study period. The stream discharge, turbidity, ISCO data were joined with the TP and TSS data by date and time. Once the data set were fed into RStudio, ID's were assigned to each of the storm events based on changes in discharge from baseflow. The beginning, peak, and end of each storm were identified using filter and fill commands. Each storm was then assigned a season based on the month that is occurred in. From previous studies that have examined agricultural settings there is a precedent for the following seasons: spring-planting (April - June), summer-growing (July - September), fall-harvest (October - December), and winter-fallow (January - March) (Hanrahan et al., 2018, Piske, 2019). Using mutate statements the points were separated based on the rising and the falling limb of the hydrograph and added as additional columns to the dataset. Then the number of "real" TP and TSS points were calculated in $\mathrm{R}$ to determine how many viable points were available for each storm and the number recorded on each limb. This allowed for easier interpretation of the data for individual storm events. Once a viable dataset for all variables was normalized in RStudio by adding equations 4 and 5 as functions and then applying it to the dataset. The function was applied to the following variables in the dataset: Turbidity, Q, TP. The RStudio version used for this analysis was 4.0.3 
(2020-10-10) - “Bunny-Wunnies Freak Out”. The packages installed for this analysis include tidyverse (Wickham et al., 2019), readxl (Bryan and Wickham, 2019), janitor (Firke, 2021), patchwork (Pedersen, 2020), lubridate ( Grolemund and Wickham , 2011), dplyer (Wickham et al., 2021), zoo (Grothendieck and Zeileis, 2005), skimr (Waring et al., 2021), ggThemeAssist (Gross and Ottolinger, 2016), plotly (Sievert, 2020). 


\section{CHAPTER III: RESULTS}

\section{Overview}

The study period for this research was April 30, 2016 - January 25, 2019. During this period, 54 storm events took place. Five (5) events were removed from the analysis due to lack of data and errors in measurements, creating insufficient data for analysis. The storms removed included ID's $37,38,40,41,43$. Of the remaining 49 events, 21 of these events occurred in 2016 , 15 of these events occurred during 2017, 11 of these occurred during 2018 and 2 of them occurred during 2019. Seasonally, 16 of these storms occurred during the spring, 14 during the summer, 13 during the fall, and 6 during the winter. Single-peak hydrographs occurred during 25 of events, while multi-peak hydrographs were observed in the remaining 24 storms.

\section{Weather and Yearly Climate Conditions}

During the study period, the average annual high temperature was $17.1^{\circ} \mathrm{C}$ and the average annual low temperature was $6.69^{\circ} \mathrm{C}$ (Figure 6). For the study period, the average low temperature was $2.25^{\circ} \mathrm{C}$ above average, and the average high temperature was $1^{\circ} \mathrm{C}$ above average. The average annual precipitation for the study period was $749.5 \mathrm{~mm}$. The precipitation for the study period was $249.7 \mathrm{~mm}$ below average (US Climate Data 2021).

When analyzed by year for the study period, the average high temperature for 2016 was $20.74{ }^{\circ} \mathrm{C}, 4.64$ degrees above normal, and the average low temperature was $10.25^{\circ} \mathrm{C}, 5.81$ degrees above normal. The precipitation during the 2016 year (April to December) measured to be $670.6 \mathrm{~mm}, 328.7$ below the average. The temperatures and precipitation values used for 2016 are only related to the months April through December and therefore could be causing the average low and high temperatures to be higher than reported and the precipitation to be under reported. The average high temperature for 2017 was $17.05^{\circ} \mathrm{C}, 0.95$ degrees above normal, and 
the average low temperature was $6.65^{\circ} \mathrm{C}, 2.21$ degrees above normal. The precipitation during 2017 measured to be $774.7 \mathrm{~mm}, 224.6$ below the average. The average high temperature for $201816.04{ }^{\circ} \mathrm{C}, 0.06$ degrees below average, the average low temperature was $5.47^{\circ} \mathrm{C}, 1.03$ degrees above normal. The precipitation during 2018 measured to be $803.7 \mathrm{~mm}, 195.6$ belove average.

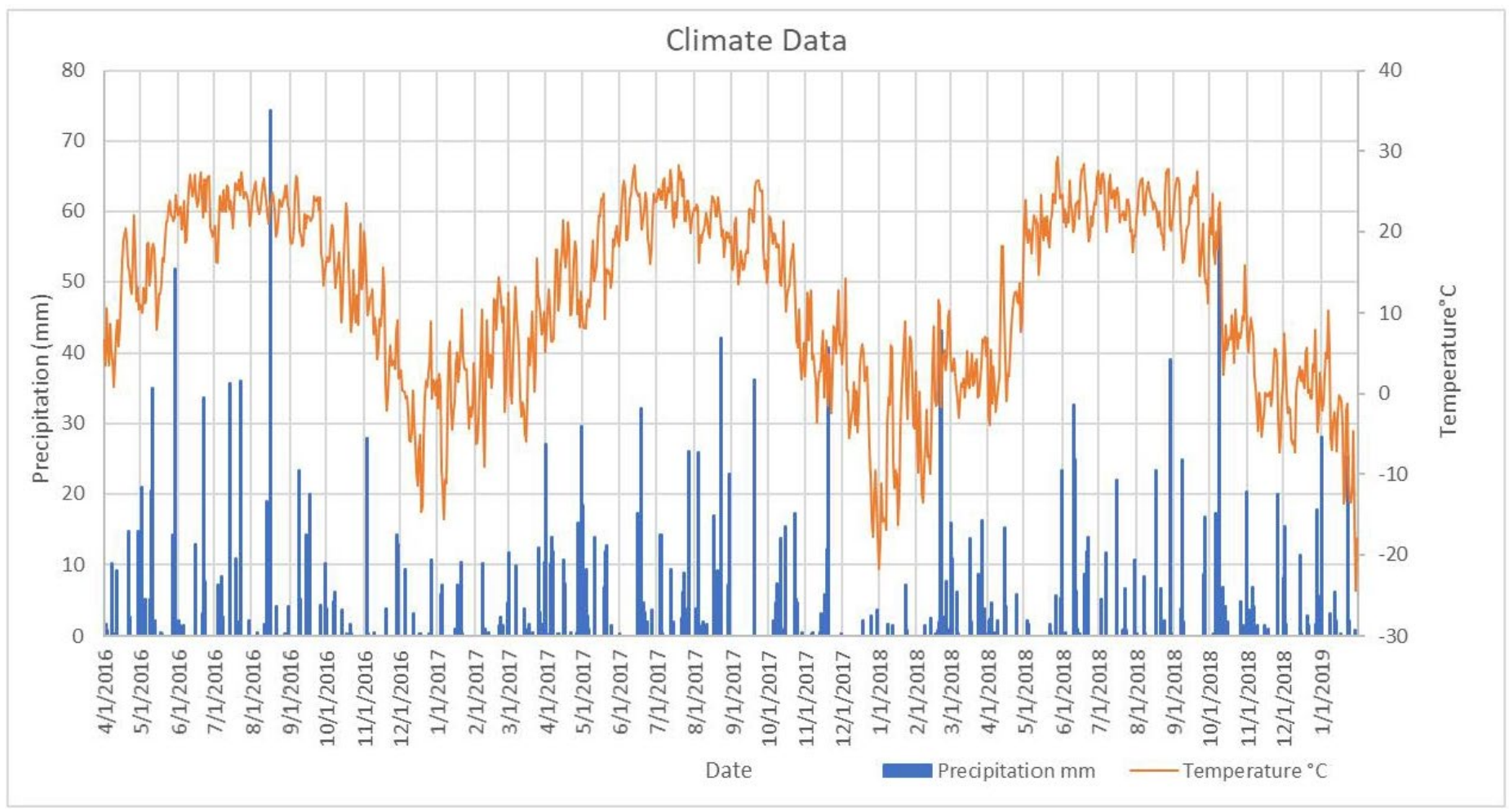

Figure 6: Recorded temperature and precipitation for the duration of the study (data are from US Climate Data 2021). 


\section{Storm Events and Values Observed for Variables}

Storms varied in intensity throughout the study period causing a range of observed responses in the variables of discharge, turbidity, and TP at SMC. Recorded discharge ranged from low flow conditions to large scale flood events (Figure 7). The largest discharge event was observed during the spring season of 2017 occurring from June 17 - June 23 (Event ID 31) with a recorded peak discharge of $44.6 \mathrm{~m}^{3} / \mathrm{s}$ (Table 2 ). The turbidity observed during the study period ranged from non-turbid, less than 40 NTU with higher water clarity to very turbid conditions (NTU up to 2604) with no water clarity (Table 1). In general, larger discharge events related to higher turbidity observations; however, the highest observed turbidity measurement of 2604 NTU was observed in the Fall of 2016 occurring during storm ID 16 and did not correlate to the highest observed discharge. Total phosphorus concentrations also varied throughout the study period (23.2-1280 $\mathrm{g} / \mathrm{L})$, with higher concentrations measured during events that had higher discharge and higher turbidity measurements. The highest observed concentration occurred during the same event as the highest recorded discharge (Event ID 31). 


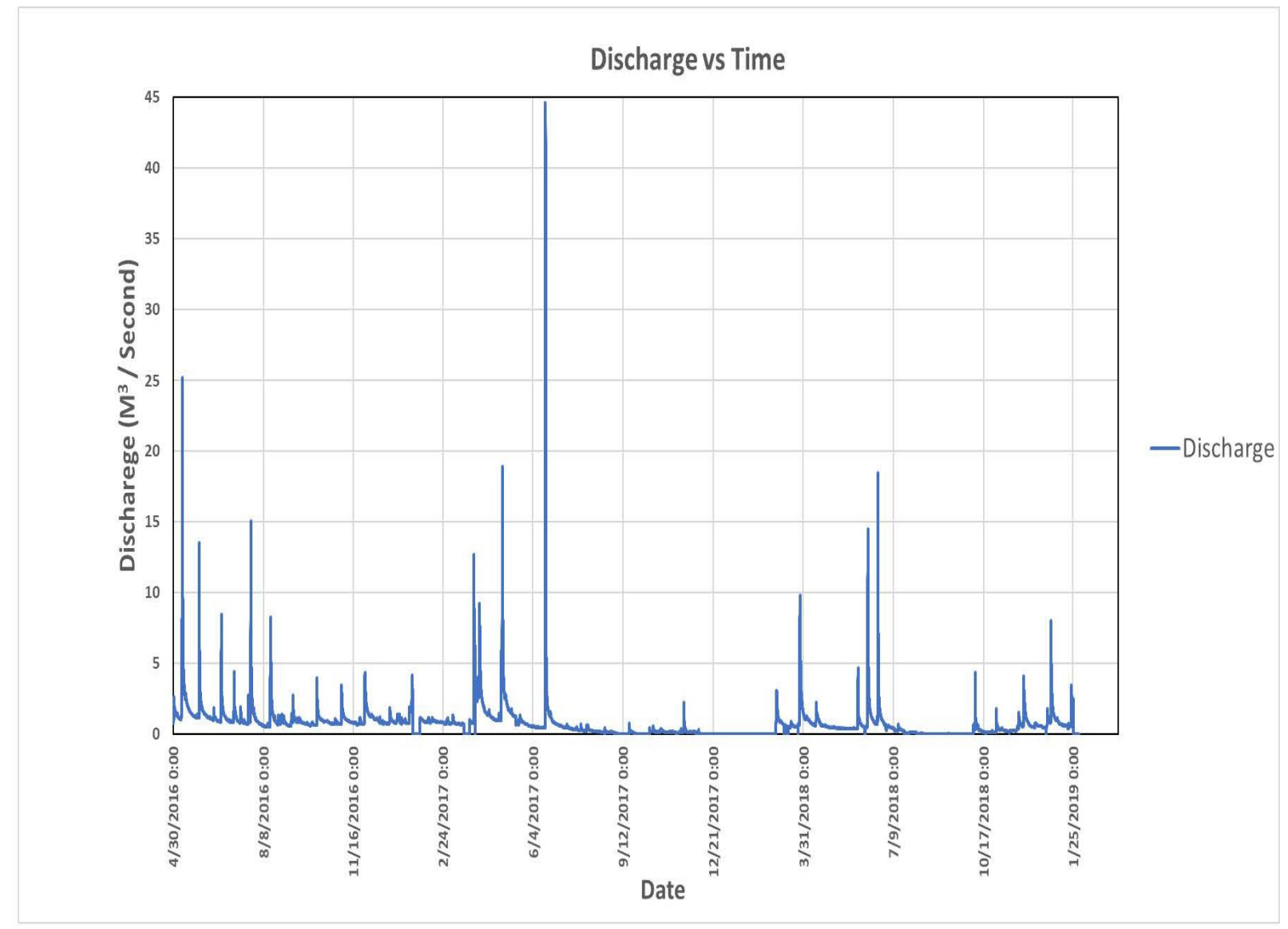

Figure 7: Hydrograph for Six Mile Creek from April 30, 2016 to January 25, 2019. Data were not collected at Six Mile Creek from December 15, 2017 - February 28, 2018 and from August 14, 2018 - September 26, 2018 due to instrument error. 
Table 2: Summary statistics for storm parameters measured in SMC from April 30, 2016 to January 25, 2019.

\begin{tabular}{|l|l|l|l|l|}
\hline Variable & Minimum & Maximum & Mean $( \pm$ standard deviation) & Units \\
\hline Stage & 0.19 & 2.69 & $0.55( \pm 0.24)$ & $\mathrm{m}$ \\
\hline Discharge & 0.14 & 44.63 & $1.78( \pm 2.47)$ & $\mathrm{m} / \mathrm{s}$ \\
\hline Turbidity & 2 & 2604 & $61.59( \pm 141.04)$ & $\mathrm{NTU}$ \\
\hline $\begin{array}{l}\text { Total } \\
\text { Suspended } \\
\text { Sediments }\end{array}$ & 0.002 & 0.452 & $0.0361( \pm 0.035)$ & $\mathrm{g} / \mathrm{L}$ \\
\hline $\begin{array}{l}\text { Total } \\
\text { Phosphorus } \\
\text { (real) }\end{array}$ & 23.2 & 1280.0 & $244.7( \pm 202.7)$ & \\
\hline $\begin{array}{l}\text { Total } \\
\text { Phosphorus } \\
\text { (model) }\end{array}$ & $\mathbf{7 3 . 8}$ & 1428.6 & & $\mu \mathrm{L} / \mathrm{L}$ \\
\hline
\end{tabular}




\section{Relationship among variables}

Relationships between turbidity and TP, turbidity and TSS, and TSS and TP were examined for the collective storm data. Unlike discharge and turbidity data collected every 15minutes, TSS and TP are measured from water samples collected from the autosampler, and the data were not at 15-minute intervals. For the duration of the study, 791 data points with both turbidity and TP were available (Figure 8). The correlation between these variables was found to have an overall $\mathrm{R}^{2}$ value of 0.66 and a r value of 0.81 (Figure 8 ), which can be classified as a strongly positive correlation (Zou, 2003). With turbidity and total suspended sediments, the correlation between the variables generated a $\mathrm{R}^{2}$ of 0.53 and an $\mathrm{r}$ value of 0.73 , a moderately positive correlation (Figure 9). With total phosphorus and total suspended sediments an additional 36 points were available. The additional 36 data points were available because during this period of time the turbidity sensor was not deployed at SMC, but the grab samples were still collected. The samples collected were able to be analyzed for their TSS and TP concentrations and thus, were used in the correlation between these variables. The correlation between TSS and TP had an overall $\mathrm{R}^{2}$ of 0.32 and an $\mathrm{r}$ value of 0.56 , a moderately positive correlation (Figure 10). 


\section{Turbidity vs Total Phosphorus}

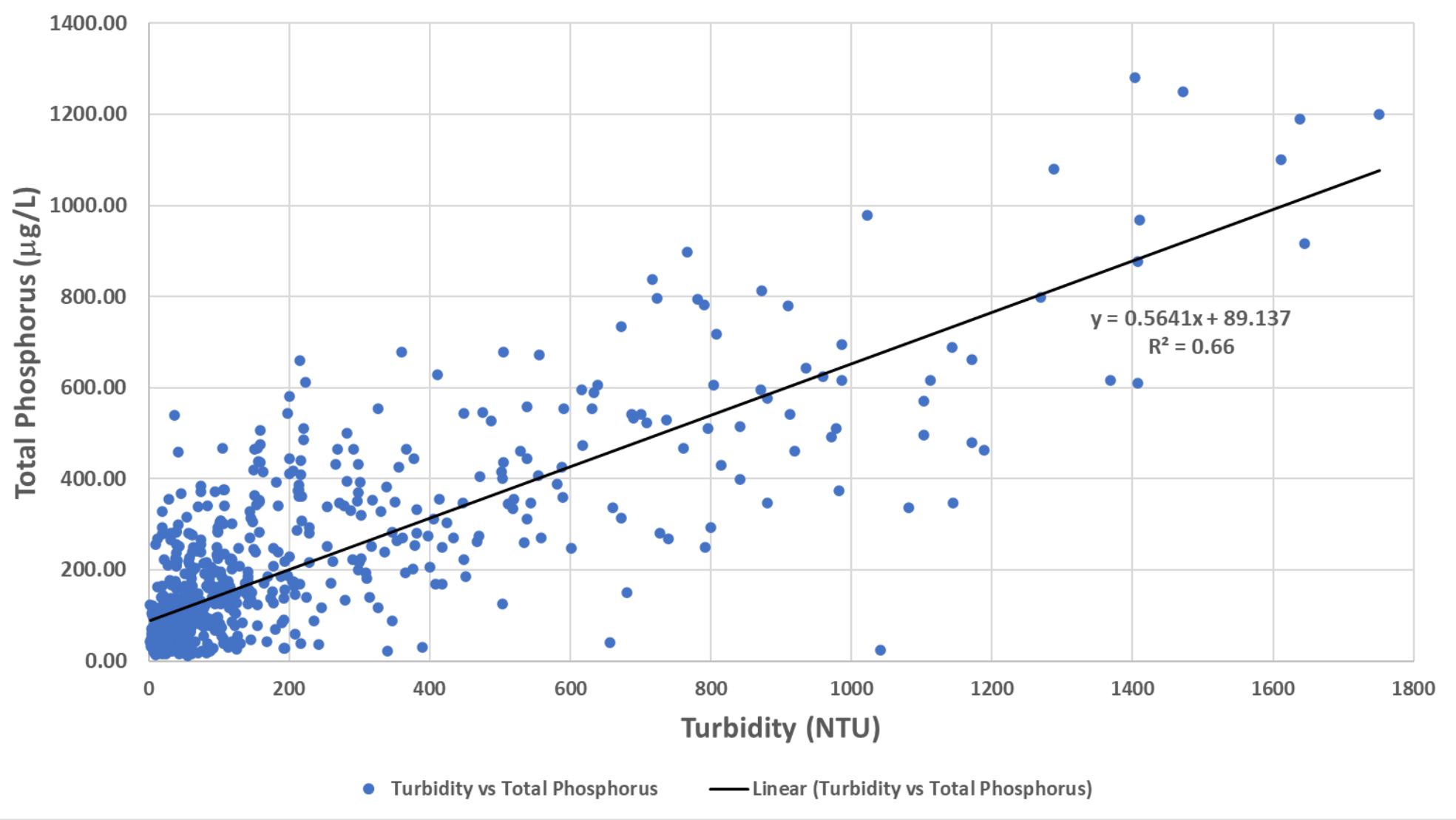

Figure 8: Turbidity versus total phosphorus throughout the study period. 


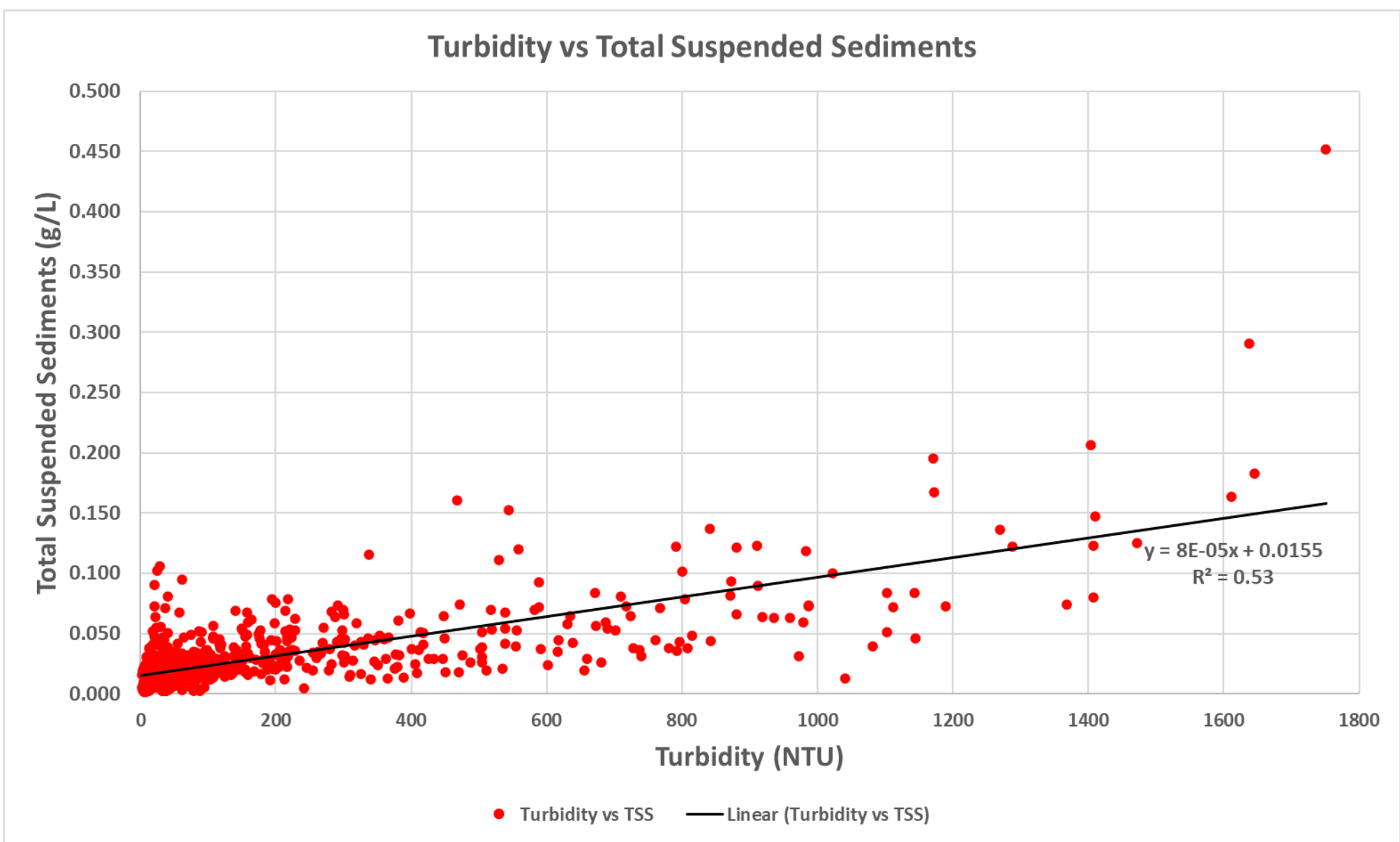

Figure 9: Turbidity versus total suspended sediments throughout the study period. 


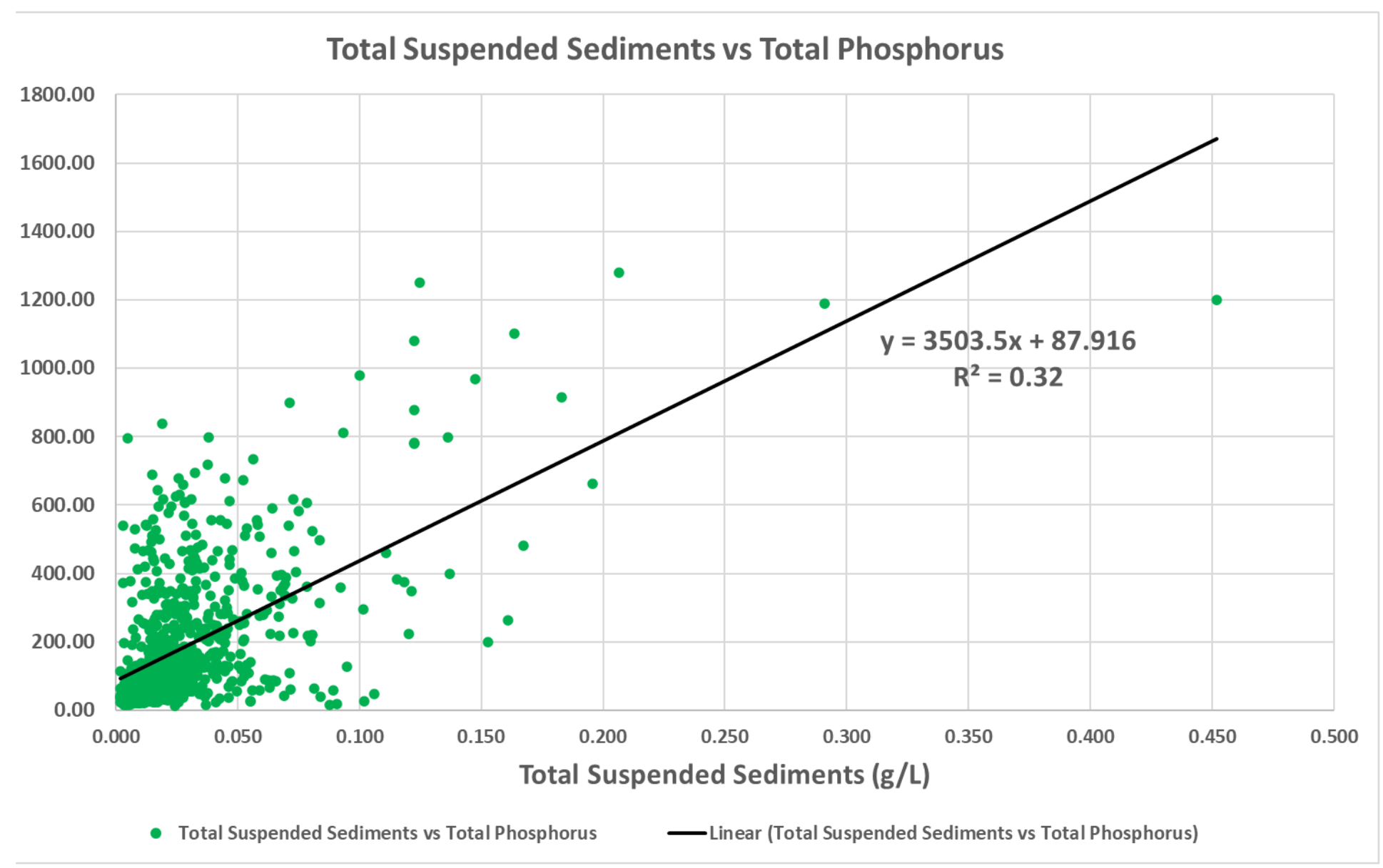

Figure 10: Total suspended sediments versus total phosphorus throughout the study period. 


\section{Data as a Whole}

Overall, there is a large magnitude of data available for the study, with the most detailed data relating to the discharge and turbidity variables. High frequency data for discharge and turbidity were available for every storm event allowing for detailed analysis to be completed. In many instances the variables TSS and TP had data points that were well distributed across the hydrograph for a storm event; however, in some instances the TSS and TP data available for an event were not well distributed across the hydrograph. This was influenced by a couple different factors. In some cases, not as many samples were chosen for filtration for each event. This influenced the number of TSS and TP data points available for a given storm event. For example, in some storm events there would be more data points available on the rising limb than the falling limb of the hydrograph, and in a couple of cases data points were available for only the rising or only the falling limb of the hydrograph. There would also be cases where there was not a sample collected relating to the peak of the hydrograph for a given storm event. Lastly there were a few storms where TP or TSS data were not available due to the sampling station being shut down related to instrument issues or maintenance, but both discharge and turbidity data were still recorded for the given storm events making not all the variables available for comparison.

\section{Generation of Linear Model}

The generation of the linear model was attempted to handle the gaps in the data and allow for better representation of TSS and TP data at 15-minute intervals. Data for both discharge and turbidity were available at 15-minute intervals for the study and allowed for detailed analysis resulting in the generation detailed hysteresis patterns. The use of a linear model to produce high 
frequency 15-minute interval TSS and TP data allows for TSS and TP to be compared to both discharge and turbidity at the same 15 -interval. Having discharge, turbidity, TSS and TP data available on the same interval allows for the generation of hysteresis patterns, HI values, and FI values for these variables to better address the research questions for this project. Based on the correlations between the turbidity and TP (Figure 8) and turbidity and TSS (Figure 9), a linear model using multiple linear regression for both TSS and TP was attempted using RStudio. The total suspended sediment model used independent variables turbidity and discharge to predict the response variable total suspended sediment. The results of this linear model showed that both turbidity and discharge were good predictor variables for total suspended sediments with a $p$ value $=0.000$ for both. The resulting relationship for the model produced an $\mathrm{R}^{2}$ value of 0.57 and a standard error of $0.022 \mathrm{~g} / \mathrm{L}$ with 788 degrees of freedom. Since this linear model did not produce a strongly positive correlation (Zou, 2003), further statistical modeling was not pursued.

The total phosphorus linear model also used the predictor variables turbidity and discharge to predict the response variable total phosphorus. The results of this linear model showed that both turbidity and discharge were good predictor variables for total phosphorus with a $p$-value $=0.000$ for both. The model produced an $\mathrm{R}^{2}$ value of 0.73 and a standard error of 78.02 $\mu \mathrm{g} / \mathrm{L}$ with 788 degrees of freedom. This model produced a strongly positive correlation and was deemed acceptable for use in this research... The linear model is represented by the following equation:

$$
T P \frac{u g}{L}=0.369 * \text { Turbidity }(N T U)+19.62 * \text { Discharge }\left(\frac{m 3}{s}\right)+70.25
$$

\section{(Eqn. 8)}




\section{Classification of Single and Double Peaks}

The 25 single peak storms were able to be used for analyzing the hysteresis and flushing index relationships between turbidity and TP. The 24 multi-peak storms were not included in the hysteresis analysis. These storm events were removed because they were influenced by multiple rain events, which generated complex hysteresis patterns that did not allow for HI and FI values to be calculated. Thus, only single peak events were considered in this work.

\section{Hysteresis Patterns}

Due to the wide range of discharge, turbidity, and TP values measured across the storms (Table 2), the parameter values were normalized for each storm event. When the normalized concentrations of turbidity and TP were plotted against normalized discharge for single peak storm events in the study period many different types of hysteresis patterns were observed (Table 3). The hysteresis patterns produced for this study displayed CW (Figure 11), CCW (Figure 12), figure-eight (Figure 13), and on one occasion complex rotational directions. The types of hysteresis patterns displayed were distributed similarly across years. Seasonally, CW hysteresis patterns were predominantly observed in spring and winter and CCW were only observed in the fall. Figure-eight patterns were observed in all seasons but were more frequent in the summer and the fall. The number and type of hysteresis curves for single peak storms are broken down for all events, by year and by season (Table 3). 
Table 3: Number of hysteresis patterns observed for single-peak storm events for the entire study period, for the individual years, and for the seasons.

\begin{tabular}{|c|c|c|c|c|c|}
\hline Category & $\mathrm{CW}$ & $\mathrm{CCW}$ & Figure-eight CW & Figure-eight $\mathrm{CCW}$ & Complex \\
\hline Total & 8 & 3 & 2 & 11 & 1 \\
\hline Year & & & & & \\
\hline 2016 & 3 & 2 & 1 & 3 & N/A \\
\hline 2017 & 1 & 1 & N/A & 5 & 1 \\
\hline 2018 & 3 & N/A & 1 & 3 & N/A \\
\hline 2019 & 1 & N/A & N/A & N/A & N/A \\
\hline$\underline{\text { Season }}$ & & & & & \\
\hline Spring & 5 & N/A & N/A & 3 & N/A \\
\hline Summer & 1 & N/A & 1 & 4 & N/A \\
\hline Fall & N/A & 3 & 1 & 3 & N/A \\
\hline Winter & 2 & N/A & N/A & 1 & 1 \\
\hline
\end{tabular}



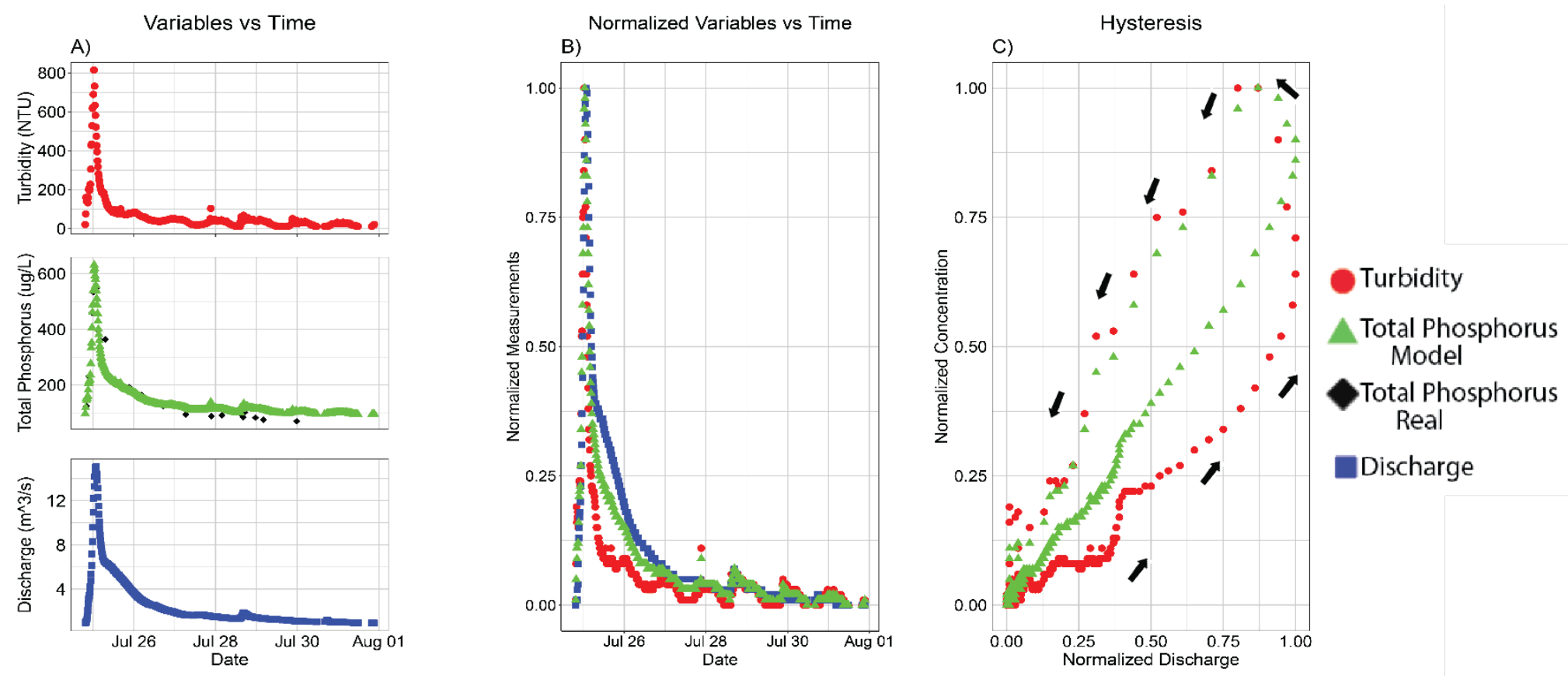

Figure 11: A) Storm data, B) normalized data, and C) clockwise hysteresis patterns generated for turbidity and total phosphorous for storm 10. Turbidity (red), total phosphorous-modeled (green), total phosphorous-actual (black), and discharge data (blue). 

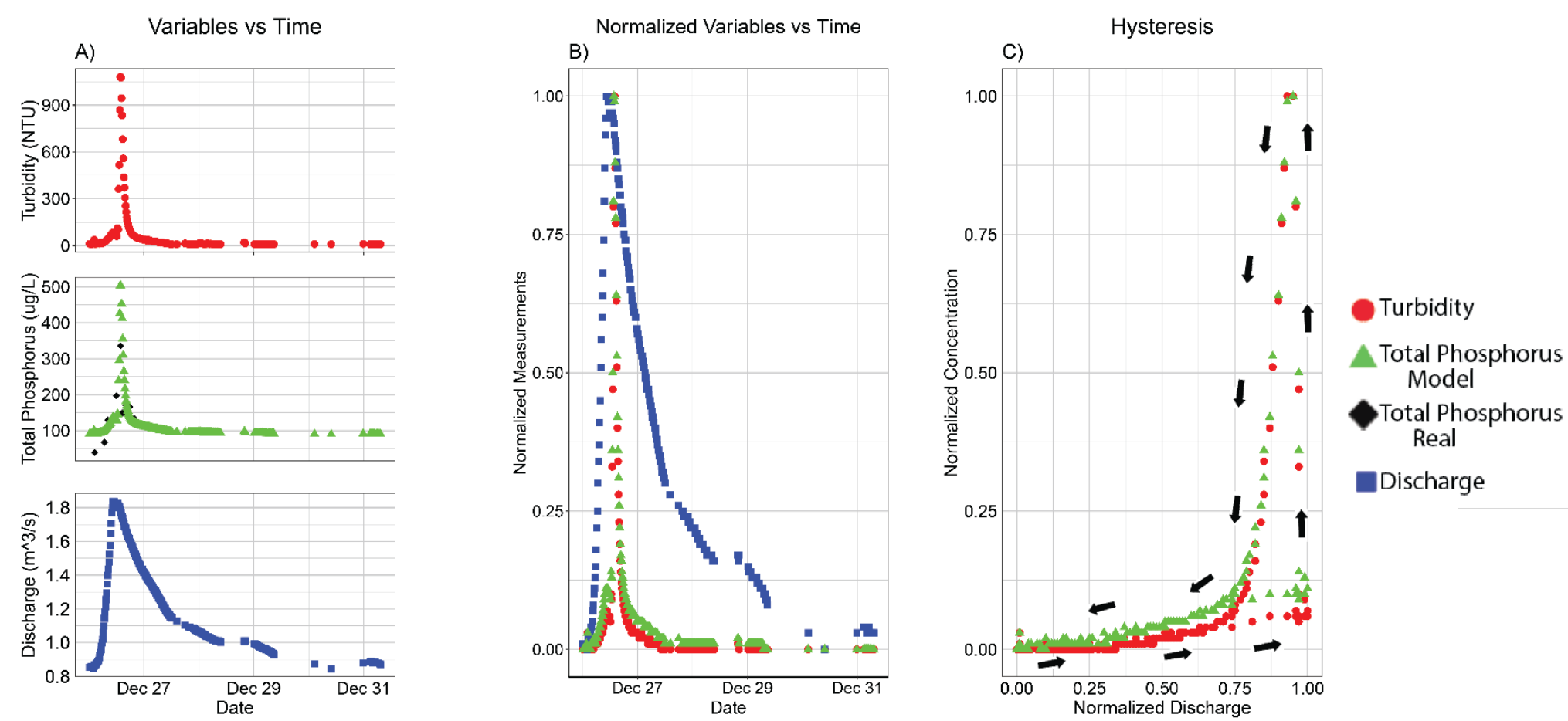

Figure 12: A) Storm data, B) normalized data, and C) counterclockwise hysteresis patterns generated for turbidity and total phosphorous for storm 21. Turbidity (red), total phosphorous-modeled (green), total phosphorous-actual (black), and discharge data (blue).
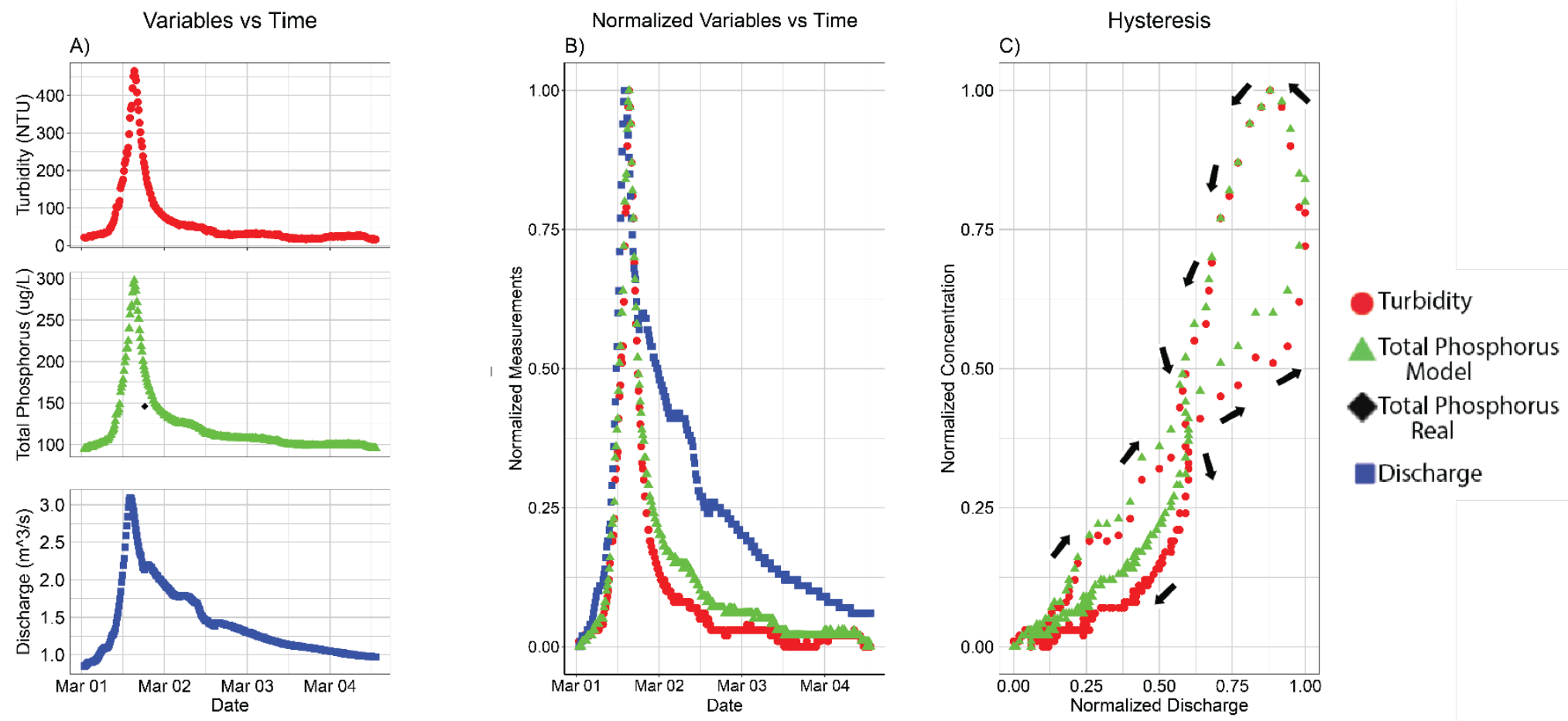

Figure 13: A) Storm data, B) normalized data, and C) figure eight hysteresis patterns generated for turbidity and total phosphorous for storm 44. Turbidity (red), total phosphorous-modeled (green), total phosphorous-actual (black), and discharge data (blue). 


\section{Hysteresis Index and Flushing Index Comparisons and Statistics.}

Throughout the study period a range of HI values and FI values were calculated for turbidity and TP. The HI for turbidity ranged from -0.17 to 0.34 with a mean value of 0.05 (Table 4). The HI for TP ranged from -0.16 to 0.24 with a mean value of 0.03 (Table 5). The largest HI value for both turbidity and TP was observed in the winter of 2018 (Event ID 45). The smallest HI value for turbidity was observed in the fall of 2017 (Event ID 42), while the smallest HI value for TP was observed in the winter of 2017 (Event ID 23). The FI value for turbidity ranged from -0.01 to 1.00 with a mean value of 0.50 (Table 5). The FI value for TP ranged from 0.01 to 1.00 with a mean value of 0.63 (Table 6 ). The largest FI value for both turbidity and TP was observed in the fall of 2018 (Event ID 54). The smallest FI value for both turbidity and TP was observed in the winter of 2017 (Event ID 23). The FI values for turbidity and TP and the HI values for turbidity and TP were compared using a paired t-test. The results of the paired t-test indicated that there was no significant difference in the FI values observed for turbidity ( $\mathrm{M}=0.5$, $\mathrm{SD}=0.32)$ than for the FI values observed for total phosphorus $(\mathrm{M}=0.63, \mathrm{SD}=0.32) ; \mathrm{t}(24)=-$ $6.608, \mathrm{p}=0.000$ (Figure 14). The results of the paired t-test indicated that there was no significant difference in the $\mathrm{HI}$ values observed for turbidity $(\mathrm{M}=0.05, \mathrm{SD}=0.15)$ as compared to the $\mathrm{HI}$ values observed for total phosphorus $(\mathrm{M}=0.03, \mathrm{SD}=0.11) ; \mathrm{t}(24)=2.138, \mathrm{p}=0.04$ (Figure 15). 
Table 4: Flushing Index and Hysteresis Index values for turbidity Across Seasons and Years

\begin{tabular}{|l|l|l|l|l|l|l|}
\hline \multicolumn{7}{|c|}{ FI HI Turbidity } \\
\hline & FI MIN & FI MAX & FI Mean & HI Min & HI Max & HI Mean \\
\hline$\underline{\text { Total }}$ & -0.01 & 1.00 & 0.50 & -0.17 & 0.34 & 0.05 \\
\hline$\underline{\text { Year }}$ & & & & & & \\
\hline 2016 & 0.05 & 0.81 & 0.44 & -0.16 & 0.27 & 0.04 \\
\hline 2017 & -0.01 & 0.68 & 0.30 & -0.17 & 0.33 & -0.02 \\
\hline 2018 & 0.49 & 1.00 & 0.75 & -0.09 & 0.34 & 0.11 \\
\hline Season & & & & & & \\
\hline Spring & 0.33 & 0.93 & 0.61 & -0.04 & 0.33 & 0.16 \\
\hline Summer & 0.00 & 0.81 & 0.40 & -0.12 & 0.09 & 0.00 \\
\hline Fall & 0.05 & 1.00 & 0.43 & -0.17 & 0.02 & -0.08 \\
\hline Winter & -0.01 & 0.93 & 0.55 & -0.16 & 0.34 & 0.09 \\
\hline
\end{tabular}


Table 5: Flushing Index and Hysteresis Index values for total phosphorous Across Seasons and Years

\begin{tabular}{|l|l|l|l|l|l|l|}
\hline \multicolumn{7}{|c|}{ FI HI Total Phosphorus } \\
\hline \multicolumn{1}{|c|}{ FI MIN } & FI MAX & FI Mean & HI Min & HI Max & HI Mean \\
\hline Total & 0.01 & 1.00 & 0.63 & -0.16 & 0.24 & 0.03 \\
\hline$\underline{\text { Year }}$ & & & & & & \\
\hline 2016 & 0.11 & 0.90 & 0.57 & -0.13 & 0.23 & 0.03 \\
\hline 2017 & 0.01 & 0.98 & 0.46 & -0.16 & 0.16 & -0.04 \\
\hline 2018 & 0.70 & 1.00 & 0.87 & -0.05 & 0.24 & 0.08 \\
\hline Season & & & & & & \\
\hline Spring & 0.51 & 0.98 & 0.81 & -0.03 & 0.23 & 0.11 \\
\hline Summer & 0.06 & 0.90 & 0.54 & -0.11 & 0.07 & 0.00 \\
\hline Fall & 0.11 & 1.00 & 0.51 & -0.15 & 0.02 & -0.06 \\
\hline Winter & 0.01 & 0.95 & 0.63 & -0.16 & 0.24 & 0.05 \\
\hline
\end{tabular}




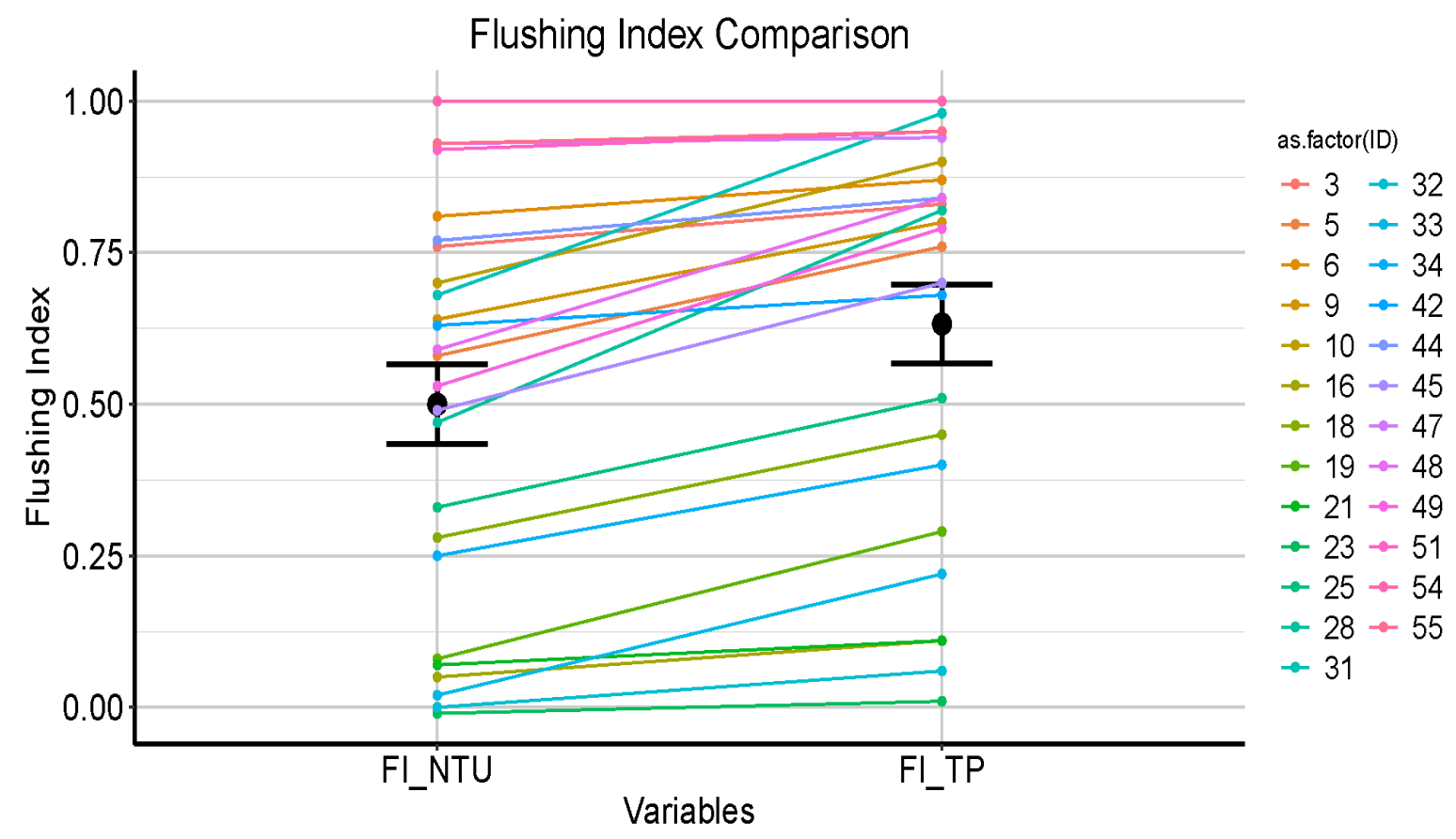

Figure 14: Individual storm flushing index (FI) values for turbidity and for total

phosphorous. The black points with error bars represent mean and standard deviation for the FI values. 


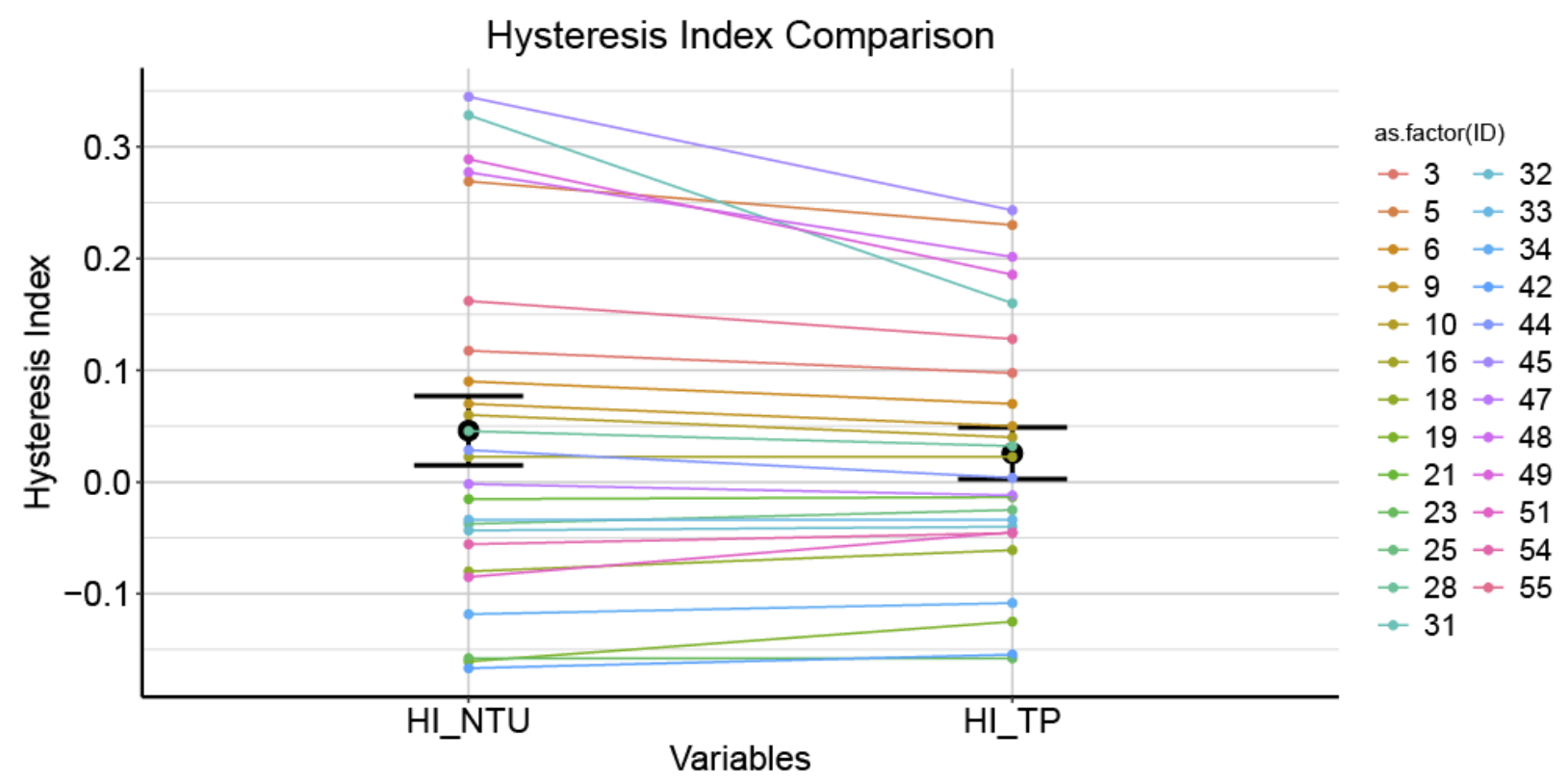

Figure 15: Individual storm flushing index (HI) values for turbidity and for total phosphorous. The black points with error bars represent mean and standard deviation for the HI values.

\section{Seasonal Statistics Among Flushing Index and Hysteresis Index}

One-way MANOVA analysis was performed on the FI values for turbidity and TP compared to season. The one-way MANOVA indicated that there was not a significant difference between the seasons on the combined dependent variables (FI turbidity, and FI TP), F $(6,42)=1.7185, \mathrm{p}$-value $=0.140($ Figure 16$)$. Since the $\mathrm{p}$-value was greater than 0.05 the null hypothesis was rejected, and no further examination was conducted. The one-way MANOVA performed on the HI value for turbidity and TP indicated that there was not a significant difference between the seasons on the combined dependent variables (HI turbidity, and HI TP), F $(6,42)=1.8948, \mathrm{p}$-value $=0.104$ (Figure 15). Since the $\mathrm{p}$-value was greater than 0.05 the null hypothesis is rejected, and no further examination was conducted. 


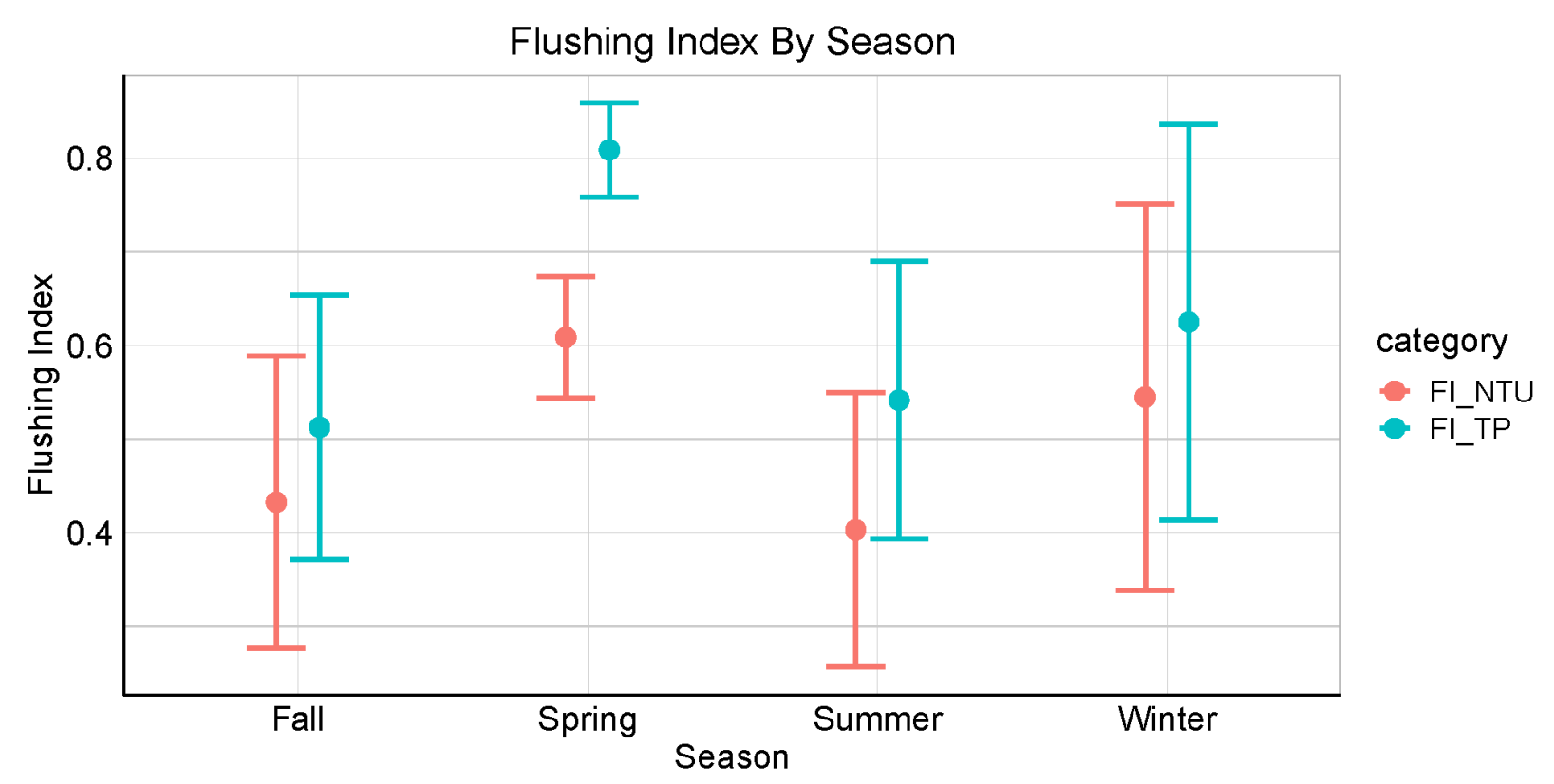

Figure 16: FI for turbidity and FI for TP by season. Red points represent the mean FI values for turbidity while the green points represent TP. The error bars attached to the points represent the standard deviation for each season.

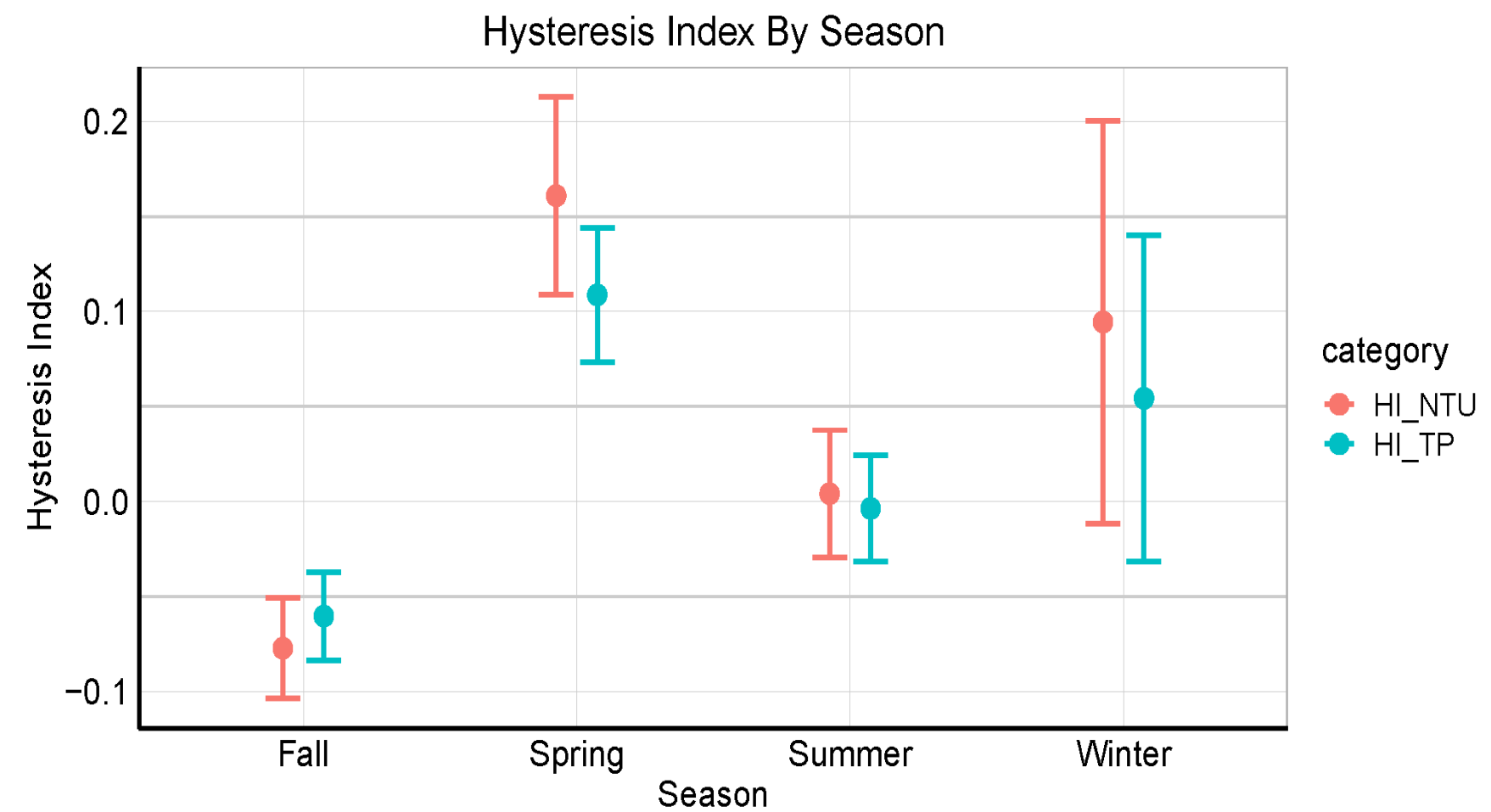

Figure 17: HI for turbidity and HI for TP by season. Red points represent the mean HI values for turbidity while the green points represent TP. The error bars attached to the points represent the standard deviation for each season. 


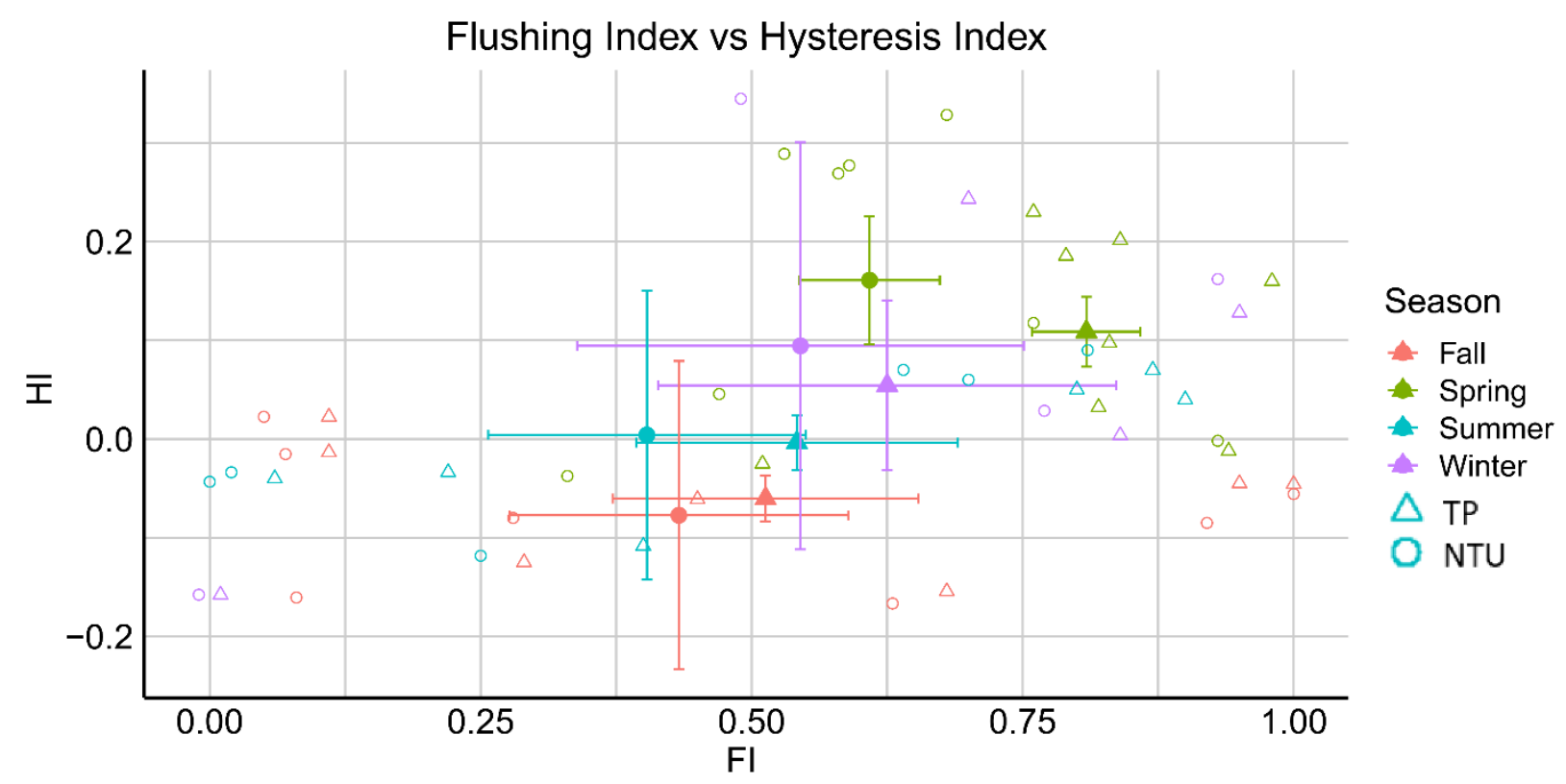

Figure 18: HI vs FI for turbidity (triangles) and for TP (circles) by season. The open shapes represent the variables over the study period. The filled shapes represent the mean HI vs FI values for the variables by season. While the error bars represent the standard deviation for $\mathrm{HI}$ and FI values for the variables by season.

\section{Annual Statistics among Flushing Index and Hysteresis Index}

The one-way MANOVA performed on the FI values for turbidity and TP indicated that there was not a significant difference between the years on the combined dependent variables (FI turbidity, and FI TP), F $(2,21)=1.569$, p-value $=0.232$ (Figure 19). Since the p-value was greater than 0.05 the null hypothesis is rejected, and no further examination was conducted. The one-way MANOVA performed on the HI values for turbidity and TP indicated that there was not a significant difference between the years on the combined dependent variables (HI turbidity, and HI TP), F $(2,21)=1.044$, $\mathrm{p}$-value $=0.370($ Figure 20). Since the $\mathrm{p}$-value was greater than 0.05 the null hypothesis is rejected, and no further examination was conducted. 


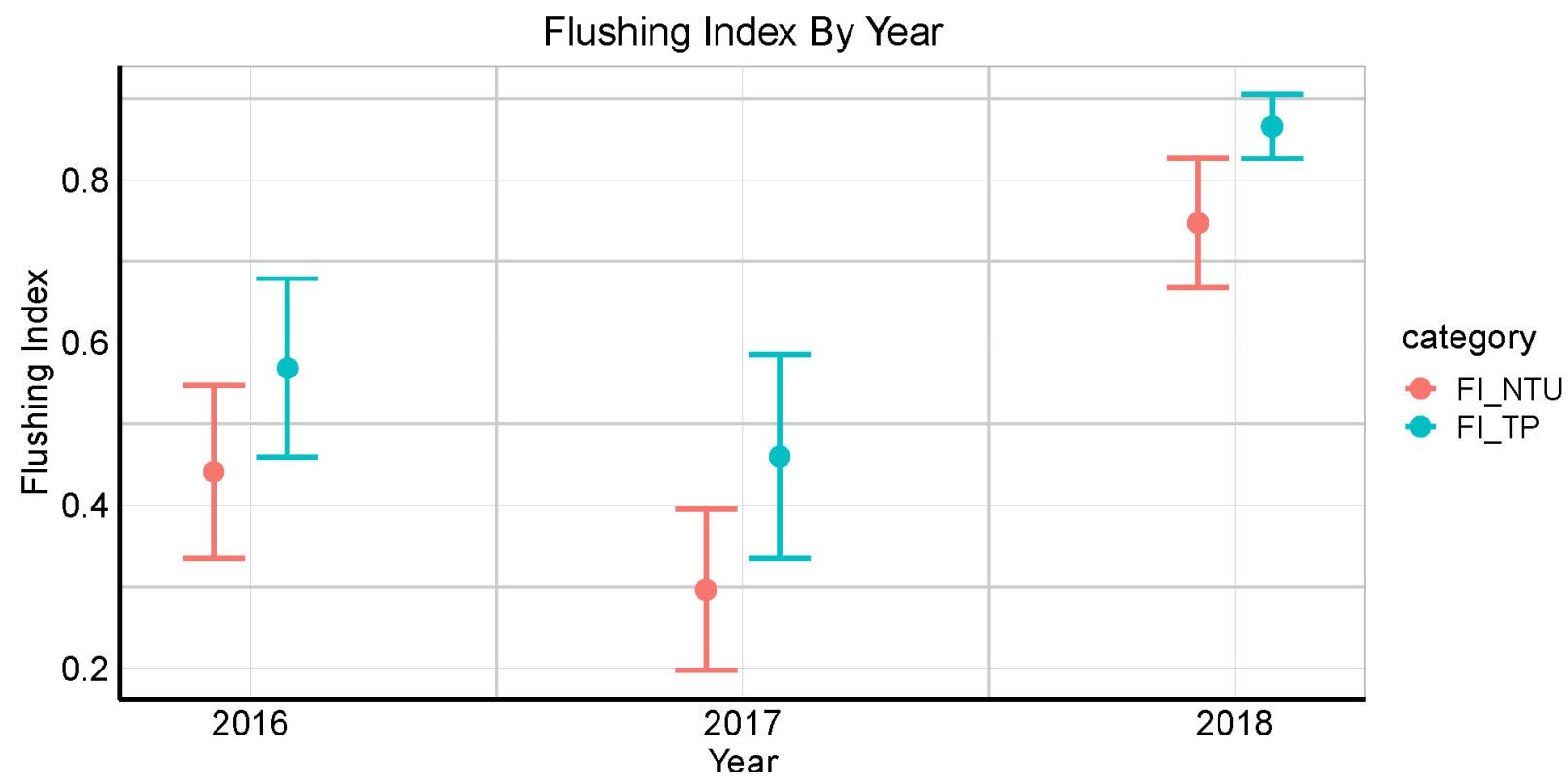

Figure 19: FI for turbidity and FI for TP by year. Red points represent the mean HI values for turbidity while the green points represent TP. The error bars represent the standard deviation for the variables by year. 


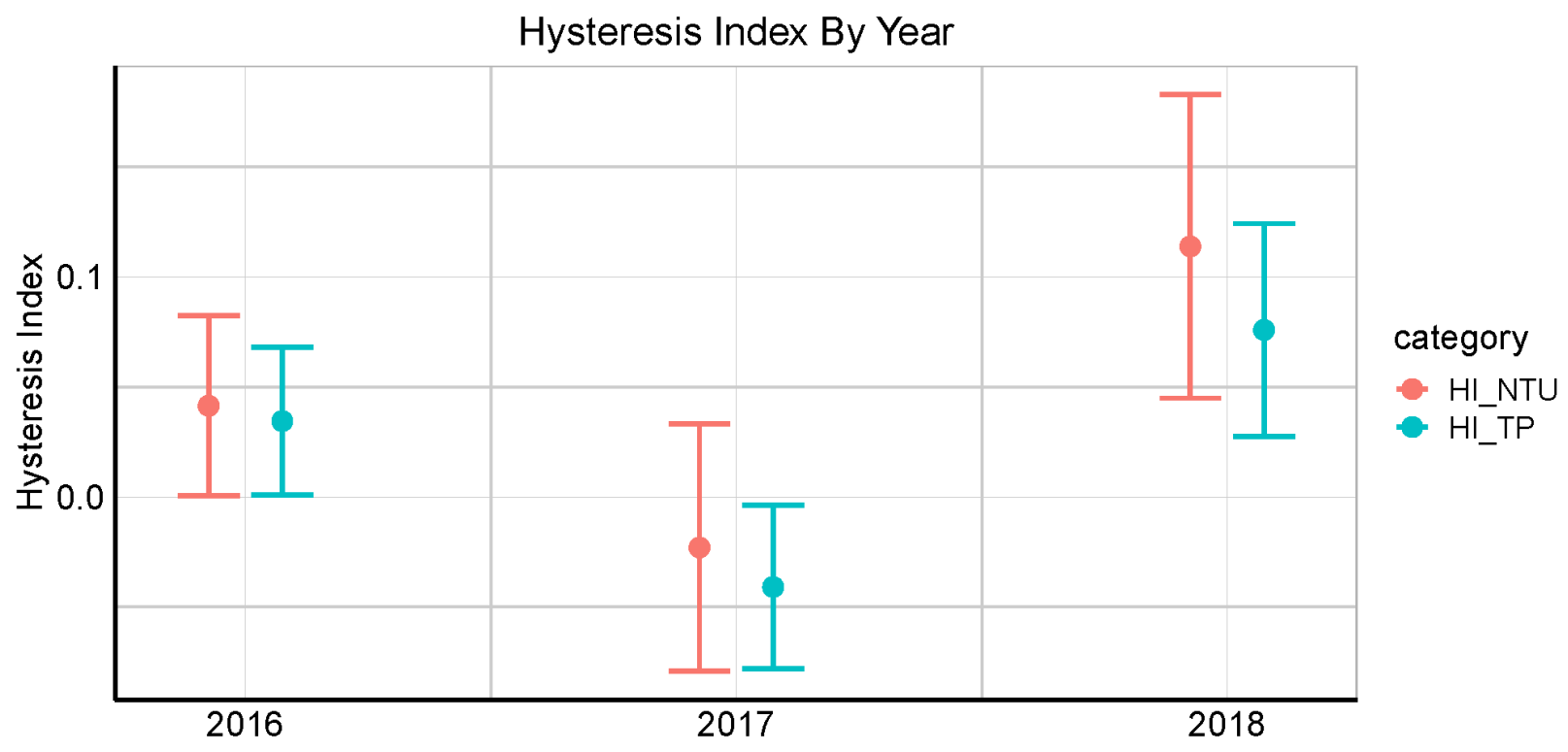

Figure 20: HI for turbidity and HI for TP by year. Red points represent the mean HI values for turbidity while the green points represent TP. The error bars represent the standard deviation for each of the variables by year. 


\section{CHAPTER IV: DISCUSSION}

\section{Relationship Among Sediments and Total Phosphorus}

The introduction and subsequent transport of sediment and phosphorus into streams within agricultural watersheds during storm events are well known. Phosphorus, when in its particulate phase can adsorb onto sediment particles, causing it to be preferentially retained by sediments (Ballantine 2009; Fang et al., 2017 Hart et al., 2004; 2017; King et al., 2015; Sharpley et al., 2008). Sediments and phosphorus are often sourced into waterways from agricultural runoff and soil erosion (Sherriff et al., 2016) and are transported through waterways in similar fashions (Borah et al., 2003). The transport of sediment and of the sediment bound phosphorus has been observed in small scale and large scale agricultural settings in Illinois and Iowa ( Borah et al, 2003, Gentry et al., 2007, Royer et al., 2006, Schilling et al., 2020) and in agricultural settings in Europe and the United Kingdom (Bowes et al., 2015, House and Warwick, 1997, Lloyd et al., 2016, Ramos et al., 2015). The relationships observed between sediments and phosphorus have not only been document in agricultural regions but also in tropical watersheds (Wymore et al., 2019) and in mountainous regions (Emelko et al., 2015, Wymore et al., 2019). The relationship between these variables occurs across landscapes and regardless of setting and is also observed in this study (Figure 8), which takes place in a low gradient agricultural watershed during three dry years.

Turbidity and TP displayed similarities in behavior in the SMC Watershed. Turbidity is strongly related to TSS and have been shown to be great indicators of the amount of TSS in the water column (Lawler et al., 2006; Lenhart et al., 2011; Sherriff et al., 2015). The similarities in behaviors among turbidity being a proxy for TSS and TP is exhibited in this study through several observations. First, observation of these displaying the similarities was the correlations 
found between turbidity and TSS and between turbidity and TP. Turbidity and TSS displayed a moderately positive correlation between each other (Figure 9) and turbidity and TP displayed a strongly positive correlation (Figure 8). The correlations between turbidity and TSS emphasize that these variables are related, and that turbidity is able to serve as proxy for TSS in this study. Furthermore, the correlation observed between turbidity and TP also displays that they are related, and similarities found between turbidity as a proxy for TSS and TP in the SMC watershed is not surprising.

The second observation is among the hysteresis patterns displayed for single peak storm events for both turbidity and total phosphorus (Table 3). For each of the individual storms, the hysteresis patterns for both turbidity and total phosphorus displayed similar shapes and rotational directions. The similar HI values for turbidity and TP further support the like transport mechanisms during the storm events. This is slightly different to the findings found in Lloyd et al. (2016) where six storms exhibited figure-eight hysteresis patterns for total phosphorus, but 25 storms exhibited figure-eight patterns for turbidity. It should be noted that there were 60 available storms for turbidity interpretations but only 41 were available for total phosphorus for that study, which might influence the differences observed. The HI also displayed similarities collectively over the study and is strongly related to the type of pattern observed.

The similarities found between turbidity and total phosphorus are also exhibited across seasons. When looking at the HI values by season no significant difference between the seasons on the combined dependent variables HI turbidity and HI TP was found (Figure 17). The types of hysteresis patterns for both variables displayed primarily clockwise hysteresis patterns (Table 3) and positive HI values during the spring and the winter (Figure 18, Table 4, Table 5). Counterclockwise rotational patterns displayed were predominantly observed during the fall and 
not during any other seasons. This is a trend that has been documented in other literature (Bierozoa and Heathwite 2015; Lampo 2017).

When inspected by year both turbidity and total phosphorus displays similar distributions of hysteresis patterns (Table 3). The HI values observed for the study period were found to have no significant difference among the years on the combined dependent variables of HI turbidity and HI TP (Figure 20). The similarities in behaviors of the HI across years shows that regardless of the climatic conditions observed for the year, the HI for both turbidity and TP behaved in similar fashions. When taking into consideration the climate conditions observed for the study period, all three years were found to have dryer and hotter conditions then an average year for the study area. It has been noted in other studies that during particularly wet years greater phosphorus and sediment loads can be observed (Gentry et a., 2007). The results of this study emphasize similarities in the HI values for both variables between years where all of the years occur during dryer and hotter conditions then average (Figure 6). Due to the hot and dry conditions of the study it would be interesting to see if the same similarities in behavior are exhibited during a year that is wetter than average.

The observed similarities in the hysteresis patterns and HI values between turbidity and TP could potentially be influenced by the fact that a model was used to generate 15-mintue interval total phosphorus data. The linear model uses the variable turbidity as one of the predicting variables, and therefore, it is possible that by using this relationship some bias was introduced and the variables might be appearing to behave more similarly than they actually are in the SMC Watershed. That being said the linear model was able to produce total phosphorus values in line with what was observed in "real" concentrations throughout the study period (Table 2) and is something that has been conducted in other studies (Lannergard et al., 2019). 
The similarities in patterns and HI values between turbidity as a proxy for suspended sediment and total phosphorus suggest that the delivery of phosphorus and sediments occur along similar pathways or come from similar sources (Bierozoa and Heathwite 2015).

\section{Watershed Behaviors and Sourcing}

The similarities observed between the hysteresis patterns and HI values among turbidity and total phosphorus provide insight into how these variables are behaving in the SMC watershed. Predominantly clockwise hysteresis patterns and positive HI values were observed in the spring and winter, while counterclockwise hysteresis patterns and negative HI values were observed in the summer and fall (Figure 18). When the HI value is positive this indicates clockwise a hysteresis pattern for a storm ID and indicates that the mobilization of both sediments and phosphorus is rapidly mobilized and is from proximal sources both in stream and near stream, such as bed mobilization and stream bank erosion (Bowes et al., 2003; Bowes et al., 2005; Bowes et al., 2015, Lloyd et al., 2015; Williams 1989). When the HI value is negative this indicates counterclockwise hysteresis pattern for a storm ID and indicates that both sediments and phosphorus is slowly mobilized and from distal sources either further upstream or out of stream, such as overland runoff from surrounding agricultural fields. A greater number of clockwise events in the spring and winter and counterclockwise in the fall and summer is something that has been observed in other studies (Bierozoa and Heathwite 2015; Lampo 2017, Ramos el al.,2015). The prevalence of clockwise patterns and positive HI values in the spring and winter and counterclockwise patterns with negative HI values in the fall and summer could be driven by a couple factors. The first factor is that there is greater tile drainage influence during the spring and the winter. The greater influence of tile drains would allow for rapid mobilization 
of phosphorus sources in the watershed (Royer et al., 2006). Large FI values observed for TP compared to elevated turbidity, especially during the spring (Figure 16), suggest that there is a large influence of TP coming from the tile drains during these times allowing for higher concentrations and greater coincidence with peak discharge. Larger FI values indicate that there is closer peak alignment taking place between peak discharge and peak TP. This closer peak alignment is likely influenced by the storm event triggering increased tile flow, allowing for the TP to be mobilized at similar times to peak discharge. It has been observed in other studies that there is a correlation between increased flow rates in tile drainage and increased TP concentrations, particularly during the spring season (Kinley, 2007). Another component of to consider is that during the winter and spring the soils are exposed and barren due to tillage and lack of cover crops, which allows for easier transport of the sediments and nutrients during these periods (Ramos et al., 2015, Sherriff et al., 2016). A study investigating nitrate loading into streams in agricultural watershed also observed that the largest exports occurred during the spring and a driving mechanism being bare and exposed soil (Piske and Peterson, 2019). Although they examined nitrate and not phosphorus, the similar behavior provides further insight into why this trend is also occurring in the SMC Watershed. Both the influence of tile drains and lack of ground cover allow for rapid mobilization of sediments and phosphorus and thus produce more clockwise hysteresis patterns and positive HI values. In addition, although there is a tile drainage influence in the fall there is a lack of influence in the summer. There is also increased vegetation in the summer and in the fall. The increased influence and stability provided by plants and crop remnants and the lack of tile drainage influence during the summer and fall would cause slower mobilization of sediments and phosphorus during these seasons. The slower mobilization of these sediment and phosphorus would cause the concentration to peak after peak 
discharge and produce counterclockwise hysteresis patterns and negative HI values for both sediments and total phosphorus.

\section{Relationships to Discharge}

Sediments and phosphorus are not just related to each other, but also have a strong relationship with discharge. The main mobilization of sediments and phosphorus take place during storm events and during times of increased discharge. Heavy and intense rain events lead to higher magnitude discharge, which allows for greater transport capacity of both sediments and phosphorus. Large precipitation and discharge events leading to greater transport of sediments and phosphorus is something that has been observed and is well documented in other studies (Borah et al., 1999, Gentry et al., 2007, Royer et al., 2006, Sherriff et al., 2016, Wymore et al., 2019). Larger mobilizations and introductions of sediments and phosphorus with increased discharge can be observed in this study where it was observed that during periods where stream discharge was at $8.0 \mathrm{~m}^{3} / \mathrm{s}$ or greater the HI was found to be positive and of greater magnitude (Figure 21). 


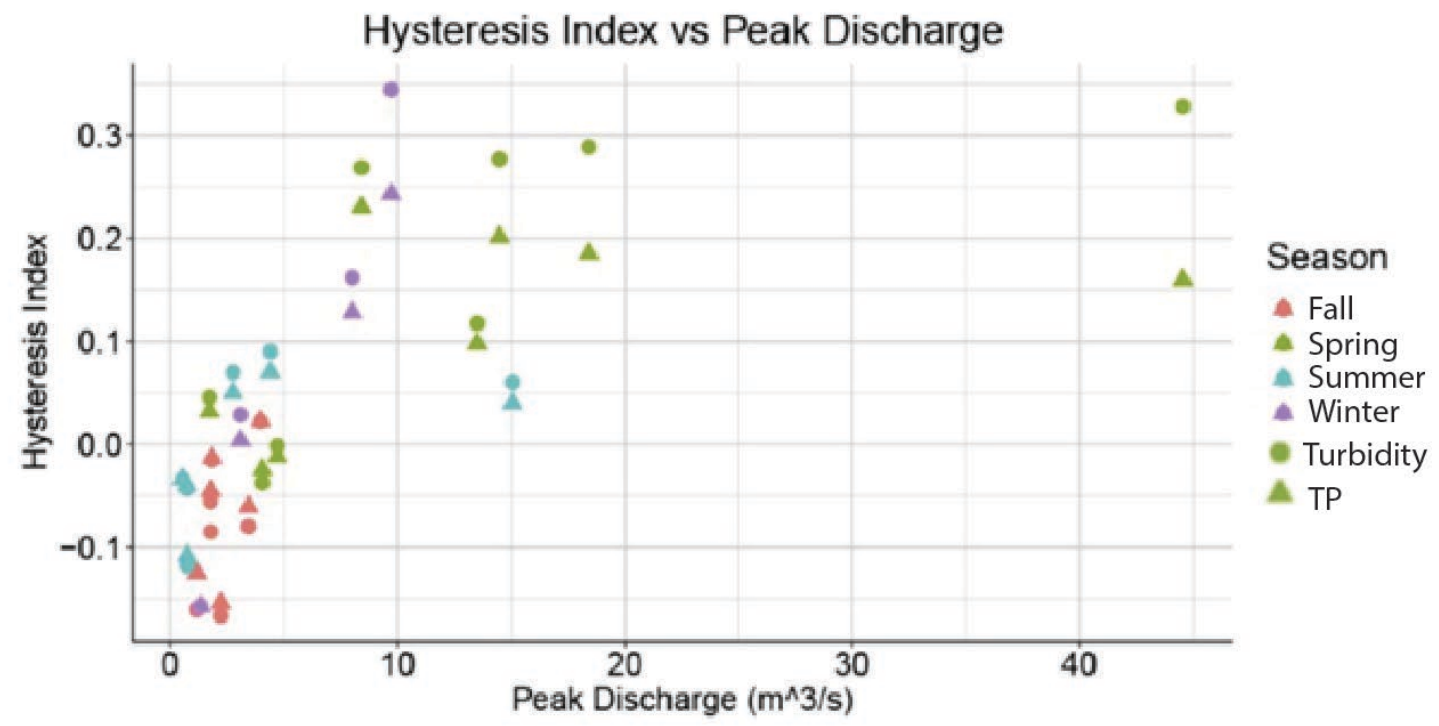

Figure 21: Displays the relationship observed between peak discharge and the hysteresis index across seasons.

Large scale discharge events are found to be large mobilizers of sediment and nutrients and account for large percentages of annual transport in watersheds (Ramos et al., 2015). This is also evident in a study done by (Lampo, 2017), where it was found that $86 \%$ of the cumulative TSS load and 74\% of the TP load for SMC occurred during storm flow during 2016. It can also be observed that seasonally these large-scale discharge events tended to take place during the spring and the winter. The large-scale events occurring during these seasons also correlates with the prevalence of clockwise hysteresis patterns and positive HI values observed during the spring and winter. It is during periods of high flow that have strong correlation with sediment and phosphorus transport in watersheds. The clockwise behavior and positive HI values during these seasons can be caused by the rapid mobilization of sediments and phosphorus in the watershed. The rapid mobilization of sediments and phosphorus in the watershed during these periods of large magnitude discharge events come from the increase in mobilized bed sediments 
as well as from increased stream bank erosion. There is a strong link between the increased bed sediment mobilization and TP mobilization due to the relationship phosphorus exhibits with sediments and its ability to adsorb onto sediments found in the stream bed. Since phosphorus is adsorbed onto the sediments in the stream there is a close alignment between when peak concentrations are occurring between peak turbidity and peak TP. Since discharge reaches its peak after the concentration variables it is likely that during these instances the stream has been able to mobilize and transport the sediments and phosphorus prior to peak discharge and once discharge has reached its peak the majority of available sediments and phosphorus have already been transported downstream. During periods of high flow in midwestern agricultural watersheds, there is also a strong influence of tile drainage, which rapidly mobilize an additional source of sediments and phosphorus (Gentry et al., 2007, Royer et al., 2006). The larger discharge events are main drivers of turbidity and phosphorus and account for most of the sediment and phosphorus loads in streams and overall larger discharge events are accounting for the larger HI values for both turbidity and TP emphasizing that these storms have greater positive differences in their concentration on the rising limb compared to the falling limb of a hydrograph (Bierozoa and Heathwite 2015; Gentry 2007).

There were several occurrences in the SMC Watershed where Clockwise hysteresis patterns and positive HI values for turbidity and total phosphorus observed where a large-scale discharge event took place 10 or more days after the previous events. This is also a trend that has been documented in other literature (Bowes et al., 2015; Bierozoa and Heathwite 2015; Lloyd et al., 2015, Ramos et al., 2015). This pattern can be emphasized by the fact that low gradient agricultural streams have hydraulic conditions and sediment sizes that make the stream bed highly mobile and something that can be redistributed on a regular and event-based basis 
(Peterson et al., 2008). In a watershed similar to SMC, Peterson et al. (2008) found storm events capable of transport $85 \%$ of the bed material occurred every two months and $50 \%$ of the sediment would be transported every month. During periods of low flow in the SMC watershed, sediments are dropped out of suspension and able to build up on the stream bed. The sediments that are on the bed of the stream for greater periods of time between mobilizations events are able to have increased interaction with their surroundings and allow for greater quantities of phosphorus to adsorb on to the sediments in the stream. Once a large discharge event takes place both large mobilizations and large concentrations of sediments and phosphorus can take place.

There were also cases throughout the study period where figure-eight hysteresis patterns were often observed in the SMC watershed after larger magnitude clockwise events. This can be observed well in the storm ID's 31-34, where ID 31 represents the largest discharge event and a clockwise hysteresis pattern is observed and ID's 32-34 represent small magnitude events where figure eight hysteresis patterns are observed. The pattern between clockwise followed by figure eight hysteresis patterns reflects a change in the relationship between TP and discharge and turbidity and discharge during individual events. Figure-eight hysteresis patterns incorporate both clockwise and counterclockwise loops indicating that the concentration variables reach their peak before or after discharge but remain at higher concentrations for longer or shorter periods of time when compared to discharge. In some cases, figure-eight patterns were a result of single peak discharge events that had more than one concentration peak during the event. Multiple concentration peaks indicate that more than one source or an additional delayed input of sediments and phosphorus is occurring during these events. Most of the documented figure-eight hysteresis patterns were counterclockwise in their behavior due to the peak in the concentration variable taking place on the falling limb of the hydrograph The large magnitude clockwise 
mobilization events where sediments and phosphorus are being rapidly mobilized and sourced from in stream and near stream, where smaller scale counterclockwise figure-eight events where sediment and phosphorus are being sourced from distal sources up stream and out of stream. The change in patterns from clockwise to counterclockwise figure-eight suggest that the large events have flushed the proximal and easily mobile phosphorus and sediments downstream leaving more distal and delayed sources available for transport. These trends have also been observed other studies (Bierozoa and Heathwite 2015; Lloyd et al., 2015; Salent et al., 2008).

The FI values observed for both turbidity and total phosphorus were always positive during single peak storm events except for on one occasion (Figure 14, Table 4, Table ). The prevalence of positive FI values indicate that the concentrations of sediments and phosphorus observed in the SMC watershed were greater at peak discharge then the initial discharge for the event. The positive FI value for turbidity and TP indicates a concentration effect taking place in the SMC watershed and not a dilution effect. The concentrating effect indicates that the sediment and phosphorus delivery in the watershed is being controlled by non-point sources such as agricultural runoff and tile drainage inputs (Bierozoa and Heathwite 2015). Large scale storms tended to have peak concentrations that were closer aligned to peak discharge then smaller scale storms but not on every occasion. Overall, the differences in the means for FI for turbidity and FI for TP were found not to be significantly different from each other, elucidating those concentrations observed at peak discharge for both variables are occurring at similar alignments with discharge and thus between each other (Figure 22). 


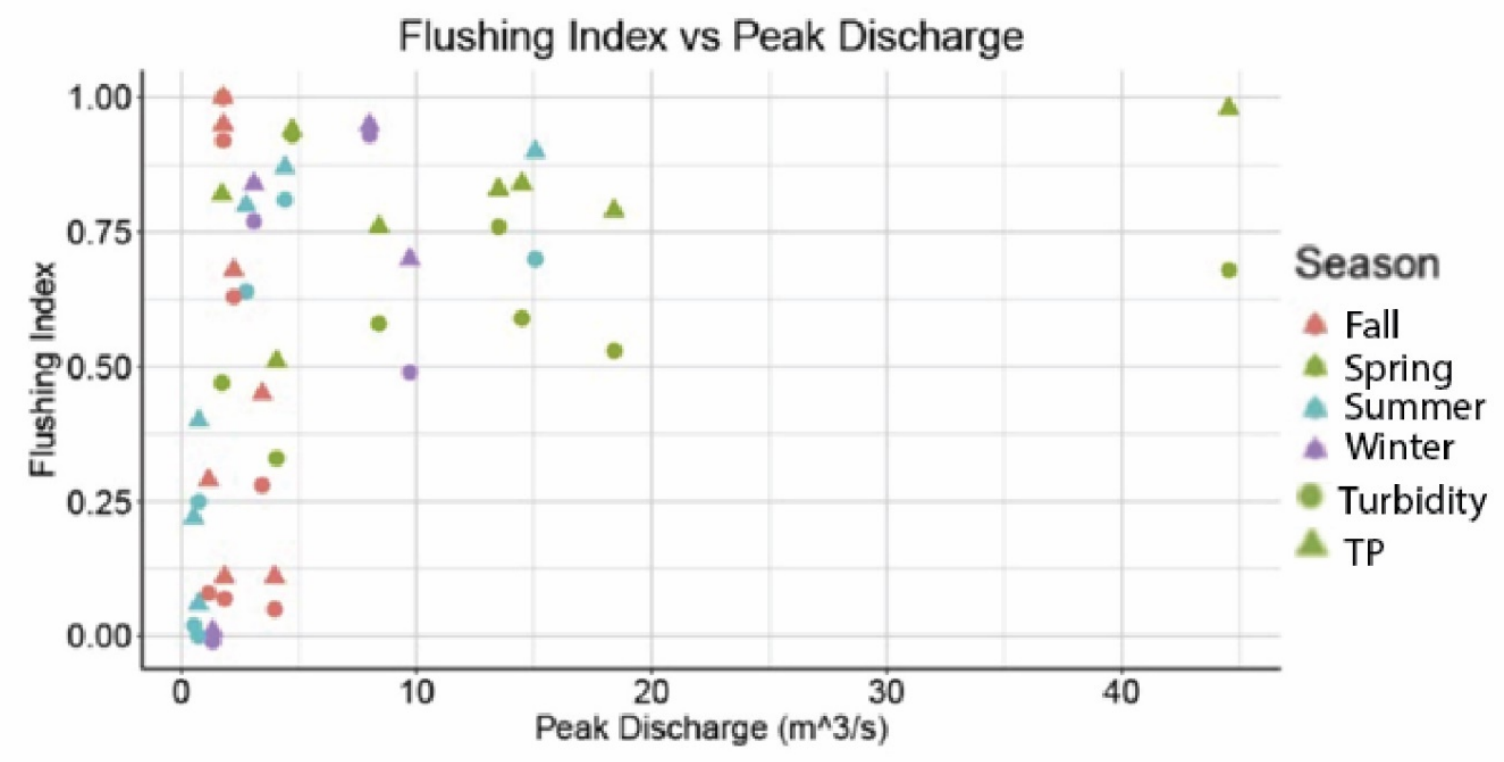

Figure 22: Displays the relationship observed between peak discharge and the flushing index across seasons.

However, it can also be observed that particularly during the spring season the FI value is much greater for TP then it is for turbidity, indicating that there is an increase in tile drainage influence during the spring season (Figure 16). A possibility for the lack of alignment of the peaks between the concentration variables turbidity total phosphorus with peak discharge is pointed out in a study conducted by Wymore et al. (2019). They observed that peak concentration doesn't just align with peak discharge but rather peak storm intensity. The intensity of the storm was not taken into consideration for this research and could allow for further insight between the alignments of peak concentration with peak discharge in the SMC watershed in future studies.

\section{Best Land Management Practices}

The strong relationship between turbidity and total phosphorus (Figure 8) along with similarities in their behaviors (Figure 18) in the SMC watershed suggest that if a reduction of 
sediments being introduced into and mobilized within the watershed might also allow for a reduction in the phosphorus introduced and mobilized. A way to limit the introduction of sediments into watersheds is through the implementation of best land-management practices (BLMP). Examples of BLMP that exhibit sediment reduction from distal and out of stream sources and have shown to be effective are the implementation of cover crops, increased buffer systems and riparian zones and reduced tillage (Hanrahan et al., 2018; Sherriff et al., 2016; Illinois Nutrient Loss Reduction Strategy 2019). The implementation of these practices, especially in the winter and spring, would increase sediment stability and retention in the region allowing for potentially smaller introductions of sediments and therefore phosphorus into the SMC watershed.

The winter and the spring were the times where positive HI values and clockwise patterns were observed, indicating that sourcing of sediment and phosphorus was from instream and near stream and being driven by the large-scale discharge events. Finding a way to reduce the instream mobilization and reduce the stream bank erosion during the winter and the spring would be key steps in reducing sediment and nutrient mobilization during these seasons. It has been documented that at northern latitudes tile flow is greatest during winter and spring due to melt events and greater precipitation amounts (Macrae et al., 2007). It has also been documented that TP exports can be 1.5 times 3 times greater during the spring and winter (King et al., 2016). Thus, finding a way to reduce the influence of tile drainage, particularly in the spring where there was the greatest FI values for TP and when tile drainage has the highest flows would help reduce the rapid mobilization of phosphorus into the SMC Watershed during the spring.

Potential recommendations for ways to address the instream and stream bank introductions of sediments and TP could include future work surveying the SMC watershed for 
areas of increased erosion in the banks as well as tile flow into the stream. These surveys could provide increased insight into the areas that should be of focus for remediation and implementation of BLMP that could address introductions from these sources. An example of BLMP that could be of use in surveyed areas are the installation of riprap or erosion control blankets. The implementation of these practices in higher at-risk areas could provide the reduced introduction of bank sediments and TP that the data in this study suggests is a main contributor to the overall introductions in the SMC watershed. 


\section{CHAPTER V: CONCLUSION}

Overall, the hysteresis patterns, a lack of differences in the HI values for turbidity and TP and a lack of differences in FI values for turbidity and total phosphorus were observed in the SMC Watershed. The similarities in hysteresis patterns and lack of differences among HI and FI values indicated that sediments and total phosphorus are behaving similarly across years, seasons, and events in the SMC Watershed. Seasonally large-scale discharge events occurring in the spring and the winter resulted in hysteresis patterns that displayed clockwise rotational directions and positive HI values. The clockwise patterns and positive HI values indicate that the sourcing of sediments and phosphorus during these seasons are from proximal and in stream sources. It has been well documented that a few large-scale events can account for a majority of sediment and phosphorus loads in a watershed. The majority of sediment and phosphorus loading is also documented to take place during the spring and winter.

The findings of this study also further establish the relationship found between sediments and phosphorus and that there is a strong relationship between both variables in the SMC Watershed. This emphasizes that monitoring of turbidity as a proxy for suspended sediments can allow for a general idea on the behaviors and introductions of phosphorus at the same location. Additionally, the introduction of sediments and phosphorus are largest during the spring and the winter. Finding a way to limit the introduction of sediments and in turn phosphorus during the spring and the winter could allow for a large reduction of these variables entering the watershed and lead to improvements in water quality. Best land management practices that reduce soil loss from agriculture, reduce tile drainage influence, and reduce in stream mobilization and channel bank erosion during high flow should be of primary focus. Examples of these practices that could 
provide improvements to sediment stability include cover crops, buffer zones, riprap and erosion control blankets.

This research was possible due to the availability of high frequency data and emphasizes how monitoring watershed characteristics can clarify their behaviors and dynamics. It was noted that during the study period Six Mile Creek's behavior was flashy and, in many instances, the rising limb rose quickly, and the falling limb fell slowly. This resulted in fewer data points being available for comparison on both limbs and thus even more detailed comparison could be conducted in flashy systems with data being collected on an interval that is a higher frequency than 15-minutes. As this research progresses for future studies, having the availability of both nutrient data and stream characteristic data at 15-minute intervals or higher frequencies may aid in understanding these relationships and ultimately lead to improvements in water quality. 


\section{REFERENCES}

Achim Zeileis and Gabor Grothendieck (2005). zoo: S3 Infrastructure for Regular and Irregular Time Series. Journal of Statistical Software, 14(6), 1-27. doi:10.18637/jss.v014.i06

Allan, J. D., \& Castillo, M. M. (2007). Stream ecology: Structure and function of running waters. Dordrecht: Springer.

Ballantine, D.J., Walling, D.E., Collins, A.L., and Leeks, G.J.L., 2009, The content and storage of phosphorus in fine-grained channel bed sediment in contrasting lowland agricultural catchments in the UK: Geoderma, v. 151, p. 141-149, doi:10.1016/j.geoderma.2009.03.021.

Bieroza, M.Z., and Heathwaite, A.L., 2015, Seasonal variation in phosphorus concentrationdischarge hysteresis inferred from high-frequency in situ monitoring: Journal of Hydrology, v. 524, p. 333-347, doi:10.1016/j.jhydrol.2015.02.036.

Borah, D K, M Bera, and S Shaw. 2003. "Water, Sediment, Nutrient, And Pesticide Measurements in An Agricultural Watershed IN Illinois During Storm Events." 46(3): 65774.

Bowes, M.J., House, W.A., and Hodgkinson, R.A., 2003, Phosphorus dynamics along a river continuum: Science of the Total Environment, v. 313, p. 199-212, doi:10.1016/S00489697(03)00260-2.

Bowes, M.J., House, W.A., Hodgkinson, R.A., and Leach, D. V., 2005, Phosphorus-discharge hysteresis during storm events along a river catchment: The River Swale, UK: Water Research, v. 39, p. 751-762, doi:10.1016/j.watres.2004.11.027. 
Bowes, M.J., Smith, J.T., and Neal, C., 2009, The value of high-resolution nutrient monitoring: A case study of the River Frome, Dorset, UK: Journal of Hydrology, v. 378, p. 82-96, doi:10.1016/j.jhydrol.2009.09.015.

Bowes, M.J., Jarvie, H.P., Halliday, S.J., Skeffington, R.A., Wade, A.J., Loewenthal, M., Gozzard, E., Newman, J.R., and Palmer-Felgate, E.J., 2015, Characterising phosphorus and nitrate inputs to a rural river using high-frequency concentration-flow relationships: Science of the Total Environment, v. 511, p. 608-620, doi:10.1016/j.scitotenv.2014.12.086.

Burns, D.A., Pellerin, B.A., Miller, M.P., Capel, P.D., Tesoriero, A.J., and Duncan, J.M., 2019, Monitoring the riverine pulse: Applying high-frequency nitrate data to advance integrative understanding of biogeochemical and hydrological processes: Wiley Interdisciplinary Reviews: Water, p. e1348, doi:10.1002/wat2.1348.

Calli Gross and Philipp Ottolinger (2016). ggThemeAssist: Add-in to Customize 'ggplot2' Themes. R package version 0.1.5. https://CRAN.R-project.org/package=ggThemeAssist C. Sievert. Interactive Web-Based Data Visualization with R, plotly, and shiny. Chapman and Hall/CRC Florida, 2020.

Diaz, R.J., 2001, Overview of Hypoxia around the World: Journal of Environmental Quality, v. 30, p. 275-281, doi:10.2134/jeq2001.302275x. 
Dinnes, D.L., Karlen, D.L., Jaynes, D.B., Kaspar, T.C., Hatfield, J.L., Colvin, T.S., and Cambardella, C.A., 2002, Nitrogen management strategies to reduce nitrate leaching in tiledrained midwestern soils: Agronomy Journal, v. 94, p. 153-171, doi:10.2134/agronj2002.1530.

Elin Waring, Michael Quinn, Amelia McNamara, Eduardo Arino de la Rubia, Hao Zhu and Shannon Ellis (2021). skimr: Compact and Flexible Summaries of Data. R package version 2.1.3. https://CRAN.R-project.org/package=skimr

Emelko, M.B., Stone, M., Silins, U., Allin, D.O.N., and Adrian, L., 2015, Sediment-phosphorus dynamics can shift aquatic ecology and cause downstream legacy effects after wildfire in large river systems: , p. 1-17, doi:10.1111/gcb.13073.

Emelko, M.B., Stone, M., Silins, U., Allin, D.O.N., and Adrian, L., 2015, Sediment-phosphorus dynamics can shift aquatic ecology and cause downstream legacy effects after wildfire in large river systems: , p. 1-17, doi:10.1111/gcb.13073.

Fang, H., Cui, Z., He, G., Huang, L., and Chen, M., 2017, Phosphorus adsorption onto clay minerals and iron oxide with consideration of heterogeneous particle morphology: Science of the Total Environment, v. 605-606, p. 357-367, doi:10.1016/j.scitotenv.2017.05.133.

Fernandez, C., Wu, J.Q., McCool, D.K., and Stöckle, C.O., 2003, Estimating water erosion and sediment yield with GIS, RUSLE, and SEDD: Journal of Soil and Water Conservation, v. 58 , p. $128-136$. 
Sam Firke (2021). janitor: Simple Tools for Examining and Cleaning Dirty Data. R package version 2.1.0. https://CRAN.R-project.org/package=janitor

Garrett Grolemund, Hadley Wickham (2011). Dates and Times Made Easy with lubridate. Journal of Statistical Software, 40(3), 1-25. URL https://www.jstatsoft.org/v40/i03/.

Garnett Williams, 1989, Sediment Concentration Versus Water Discharge During Single Event.Pdf: Journal of Hydrology, v. 111, p. 89-106, https://www.sciencedirect.com/science/article/pii/0022169489902540.

Gellis, A.C., and Noe, G.B., 2013, Sediment source analysis in the Linganore Creek watershed, Maryland, USA, using the sediment fingerprinting approach: 2008 to 2010: Journal of Soils and Sediments, v. 13, p. 1735-1753, doi:10.1007/s11368-013-0771-6.

Gellis, A.C., Fitzpatrick, F.A., Schubauer-Berigan, J.P., Landy, R.B., and Sanisaca, L.E.G., 2015, Identifying sediment sources in the sediment TMDL process: Proceedings of the 3rd Joint Federal Interagency Conference (10th Federal Interagency Sedimentation Conference and 5th Federal Interagency Hydrologic Modeling Conference), p. 1983-1991.

Gentry, L.E., David, M.B., Royer, T. V., Mitchell, C.A., and Starks, K.M., 2007, Phosphorus Transport Pathways to Streams in Tile-Drained Agricultural Watersheds: Journal of Environmental Quality, v. 36, p. 408-415, doi:10.2134/jeq2006.0098.

Hadley Wickham and Jennifer Bryan (2019). readxl: Read Excel Files. R package version 1.3.1. https://CRAN.R-project.org/package=readxl 
Hadley Wickham, Romain François, Lionel Henry and Kirill Müller (2021). dplyr: A Grammar of Data Manipulation. R package version 1.0.5. https:/CRAN.R-project.org/package=dplyr

Hanna, L.A., 2013, Dissolved and Suspended Sediment Transport Dynamics in Two Agriculturally Dominated Watersheds, Mclean County, Illinois:, https://my.ilstu.edu/ ewpeter/theses/Hanna_2013.pdf.

Hanrahan BR, Tank JL, Christopher SF, Mahl UH, Trentman MT, Royer TV (2018) Winter cover crops reduce nitrate loss in an agricultural watershed in the central US. Agr Ecosyst Environ 265:513-523. https://doi.org/10.1016/j.agee.2018.07.004

Hart, Murray R., Bert F. Quin, and M. Long Nguyen. 2004. "Phosphorus Runoff from Agricultural Land and Direct Fertilizer Effects: A Review.” Journal of Environmental Quality 33(6): 1954-72.

House, W.A., and Warwick, M.S., 1998, Hysteresis of the solute concentration/discharge relationship in rivers during storms: Water Research, v. 32, p. 2279-2290, doi:10.1016/S0043-1354(97)00473-9.

Keesstra, S.D., Davis, J., Masselink, R.H., Casalí, J., Peeters, E.T.H.M., and Dijksma, R., 2019, Coupling hysteresis analysis with sediment and hydrological connectivity in three agricultural catchments in Navarre, Spain: Journal of Soils and Sediments, v. 19, p. 15981612, doi:10.1007/s11368-018-02223-0. 
King, K.W., Williams, M.R., and Fausey, N.R., 2015, Contributions of Systematic Tile Drainage to Watershed-Scale Phosphorus Transport: Journal of Environmental Quality, v. 44, p. 486494, doi:10.2134/jeq2014.04.0149.

King, K.W., Williams, M.R., and Fausey, N.R., 2016, Effect of crop type and season on nutrient leaching to tile drainage under a corn soybean rotation: Journal of Soil and Water Conservation, v. 71, p. 56-68, doi:10.2489/jswc.71.1.56.

Kinley, R.D., R.J. Gordon, G.W. Stratton, G.T. Patterson, and J. Hoyle. 2007. Phosphorus losses through agricultural tile drainage in Nova Scotia, Canada. J. Environ. Qual. 36:469-477. doi:10.2134/jeq2006.0138

Kronvang, B., Andersen, H.E., Larsen, S.E., and Audet, J., 2013, Importance of bank erosion for sediment input, storage and export at the catchment scale: Journal of Soils and Sediments, v. 13, p. 230-241, doi:10.1007/s11368-012-0597-7.

Lake, Evergreen, and Watershed Planning. "Evergreen Lake Watershed Plan."

Lake Bloomington Watershed Plan, Lake Bloomington Watershed Planning Committee, June 22, 2008. Bloomington, IL

Lampo, L., O’Reilly, C., Heath, V.E., Perry, B., Twait, R., Bruening, B., and Hanlin, A., 2017, Dynamics of Nitrate, Phosphorus, and Suspended Sediment Transport in Two Agricultural Streams in Central Illinois:, doi:10.1130/abs/2016nc-275560.

Lawler DM. Spectrophotometry: turbidimetry and nephelometry. En- cyclopedia of analytical science, 2nd edition. Elsevier7 Academic Press; 2005a. p. 343-51 
Lawler, D.M., Petts, G.E., Foster, I.D.L., and Harper, S., 2006, Turbidity dynamics during spring storm events in an urban headwater river system: The Upper Tame, West Midlands, UK: Science of the Total Environment, v. 360, p. 109-126, doi:10.1016/j.scitotenv.2005.08.032.

Lloyd, C.E.M., Freer, J.E., Johnes, P.J., and Collins, A.L., 2016, Using hysteresis analysis of high-resolution water quality monitoring data, including uncertainty, to infer controls on nutrient and sediment transfer in catchments: Science of the Total Environment, v. 543, p. 388-404, doi:10.1016/j.scitotenv.2015.11.028.

Lloyd, C.E.M., Freer, J.E., Johnes, P.J., and Collins, A.L., 2016, Technical Note: Testing an improved index for analysing storm discharge-concentration hysteresis: Hydrology and Earth System Sciences, v. 20, p. 625-632, doi:10.5194/hess-20-625-2016.

Macrae, M.L., English, M.C., Schiff, S.L., and Stone, M., 2007, Intra-annual variability in the contribution of tile drains to basin discharge and phosphorus export in a first-order agricultural catchment: Agricultural Water Management, v. 92, p. 171-182, doi:10.1016/j.agwat.2007.05.015.

Mastrocicco, M., Boz, B., Colombani, N., Carrer, G.M., Bonato, M., and Gumiero, B., 2014, Modelling groundwater residence time in a sub-irrigated buffer zone: Ecohydrology, v. 7, p. 1054-1063, doi:10.1002/eco.1437.

Manual, User., 2020, SDI-PT-KEL:SDI-12 Submersible Pressure Transducer 
Oeurng, C., Sauvage, S., and Sanchez-Perez, J. M., 2010a, Dynamics of suspended sediment transport and yield in a large agricultural catchment, southwest France: Earth Surface Processes and Landforms, v. 35, no. 11, p. 1289-1301.

Piske, J., and Peterson, E.W., 2019, Nitrate Concentrations in Streams as a Function of Crop Cover in Midwestern Agricultural Watersheds: Assessing the Role of Corn and Soybeans:, doi:10.1130/abs/2018am-318148.

Peterson, E.W.; Sickbert, T.B.; Moore, S.L. High frequency stream bed mobility of a lowgradient agricultural stream with implications on the hyporheic zone. Hydrological Processes 2008, 22, 4239-4248, doi:10.1002/hyp.7031.

Rabalais, N.N., Turner, R.E., and Wiseman, W.J., 2002, Gulf of Mexico hypoxia, a.k.a. "The dead zone": Annual Review of Ecology and Systematics, v. 33, p. 235-263, doi:10.1146/annurev.ecolsys.33.010802.150513.

Ramos, T. B., Goncalves, M. C., Branco, M. A., Brito, D., Rodrigues, S., Sanchez-Perez, J. M., Sauvage, S., Prazeres, A., Martins, J. C., Fernandes, M. L., and Pires, F. P., 2015, Sediment and nutrient dynamics during storm events in the Enxoe temporary river, Southern Portugal: Catena, v. 127, p. 177-190.

Reddy, K. R., and DeLaune, R. D. (eds.). (2008). "Phosphorus," in Biogeochemistry of Wetlands: Science and Applications (Boca Raton, FL: CRC Press, Taylor and Francis Group, LLC), 325-404. doi: 10.1201/9780203491454.ch9 
Royer, T. V., David, M.B., and Gentry, L.E., 2006, Timing of riverine export of nitrate and phosphorus from agricultural watersheds in Illinois: Implications for reducing nutrient loading to the Mississippi River: Environmental Science and Technology, v. 40, p. 41264131, doi:10.1021/es052573n.

Sciences, L. IOWA NUTRIENT REDUCTION STRATEGY, 2012:

Schilling, K.E., Streeter, M.T., Seeman, A., Jones, C.S., and Wolter, C.F., 2020, Total phosphorus export from Iowa agricultural watersheds: Quantifying the scope and scale of a regional condition: Journal of Hydrology, v. 581, p. 124397, doi:10.1016/j.jhydrol.2019.124397.

Sharpley, A.N., Kleinman, P.J.A., Heathwaite, A.L., Gburek, W.J., Folmar, G.J., and Schmidt, J.P., 2008, Phosphorus Loss from an Agricultural Watershed as a Function of Storm Size: Journal of Environmental Quality, v. 37, p. 362-368, doi:10.2134/jeq2007.0366.

Sherriff, S.C., Rowan, J.S., Melland, A.R., Jordan, P., Fenton, O., and Huallacháin, D.O., 2015, Investigating suspended sediment dynamics in contrasting agricultural catchments using ex situ turbidity-based suspended sediment monitoring: Hydrology and Earth System Sciences, v. 19, p. 3349-3363, doi:10.5194/hess-19-3349-2015.

Simon, A., and Rinaldi, M., 2006, Disturbance, stream incision, and channel evolution: The roles of excess transport capacity and boundary materials in controlling channel response: Geomorphology, v. 79, p. 361-383, doi:10.1016/j.geomorph.2006.06.037. 
Smith, D.G., and Davies-Colley, R.J., 2002, If Visual Water Clarity Is the Issue, Then Why Not Measure It ? National Water Quality Monitoring Conference, p. 1-10, http://acwi.gov/monitoring/conference/2002/Papers-Alphabetical by First Name/David Smith2.pdf.

Specifications, Technical. 2013. "Technical Specifications." Hydraulic Fill Manual: 433-75.

Sugg, Z., 2007, Assessing U . S . Farm Drainage : Can GIS Lead to Better Estimates of Subsurface Drainage Extent? World Resource Institute, p. 1-8, http://pdf.wri.org/assessing farm drainage.pdf.

Sutherland, A.B., and Meyer, J.L., 2007, Effects of increased suspended sediment on growth rate and gill condition of two southern Appalachian minnows: Environmental Biology of Fishes, v. 80, p. 389-403, doi:10.1007/s10641-006-9139-8.

Thomas Lin Pedersen (2020). patchwork: The Composer of Plots. R package version 1.1.1. https://CRAN.R-project.org/package=patchwork

University of Illinois Extension, IEPA, and IDA, 2019, Illinois nutrient loss reduction strategy: Biennial Report 2019:

Vaughan, M. C. H., Bowden, W. B., Shanley, J. B., Vermilyea, A., Sleeper, R., Gold, A. J., ... Schroth, A. W. (2017). High-frequency dissolved organic carbon and nitrate measurements reveal differences in storm hysteresis and loading in relation to land cover and seasonality. Water Resources Research, 53(7), 5345-5363. doi:10.1002/2017wr020 
Watson, S.B. et al., 2016, The re-eutrophication of Lake Erie: Harmful algal blooms and hypoxia: Harmful Algae, v. 56, p. 44-66, doi:10.1016/j.hal.2016.04.010.

Wickham et al., (2019). Welcome to the tidyverse. Journal of Open Source Software, 4(43), 1686, https://doi.org/10.21105/joss.01686

Wymore, A.S., Leon, M.C., Shanley, J.B., and McDowell, W.H., 2019, Hysteretic response of solutes and turbidity at the event scale across forested tropical montane watersheds:

Frontiers in Earth Science, v. 7, p. 1-13, doi:10.3389/feart.2019.00126.

Zabaleta, A., Martínez, M., Uriarte, J.A., and Antigüedad, I., 2007, Factors controlling suspended sediment yield during runoff events in small headwater catchments of the Basque Country: Catena, v. 71, p. 179-190, doi:10.1016/j.catena.2006.06.007.

Zou, K. H., Tuncali, K., \& Silverman, S. G. (2003). Correlation and simple linear regression. Radiology, 227, 617-628, doi:10.1148/radiol.2273011499. 
APPENDIX: SINGLE PEAK STORM EVENTS

SMC STORM ID 3

\begin{tabular}{|c|c|c|c|c|c|}
\hline \multicolumn{3}{|c|}{ Duration } & \multicolumn{3}{|c|}{$5-28-16$ to $6-6-16$} \\
\hline \multicolumn{3}{|c|}{ Time Since Previous Storm } & \multicolumn{3}{|c|}{11 Days } \\
\hline \multicolumn{3}{|c|}{ Hysteresis Pattern } & \multicolumn{3}{|c|}{ Clockwise } \\
\hline \multicolumn{3}{|c|}{ HI Turbidity } & \multicolumn{3}{|c|}{0.12} \\
\hline \multicolumn{3}{|c|}{ FI Turbidity } & \multicolumn{3}{|c|}{0.76} \\
\hline \multicolumn{3}{|c|}{ HI Total Phosphorus } & \multicolumn{3}{|c|}{0.10} \\
\hline \multicolumn{3}{|c|}{ FI Total Phosphorus } & \multicolumn{3}{|c|}{0.83} \\
\hline Variable & Minimum & Maximum & Range & Mean ( \pm standard deviation) & Units \\
\hline Stage & 0.50 & 1.54 & 1.04 & $0.65( \pm 0.17)$ & $\mathbf{m}$ \\
\hline Discharge & 1.19 & 13.50 & 12.31 & $2.27( \pm 1.83)$ & $\mathbf{m}^{3} / \mathbf{s}$ \\
\hline Turbidity & 17.0 & 2282.0 & 2265 & $128.1( \pm 269.9)$ & NTU \\
\hline Total Phosphorus Model & 101.8 & 1151.2 & 1049.4 & $162.0( \pm 77.7)$ & $\mathbf{m g} / \mathrm{L}$ \\
\hline Mean Absolute Error Model & & & & 117.50 & $\mathrm{mg} / \mathrm{L}$ \\
\hline
\end{tabular}
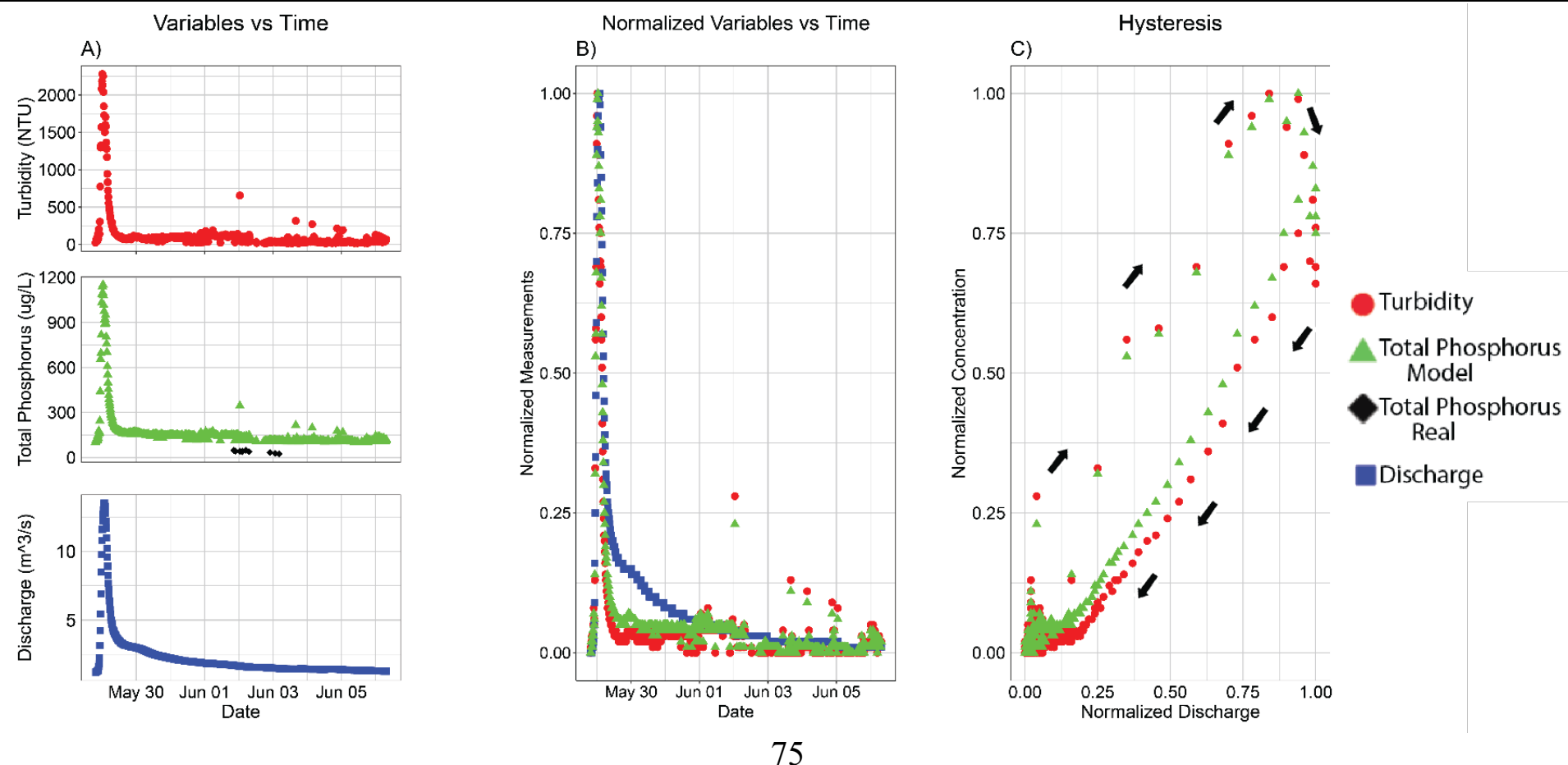


\begin{tabular}{|c|c|c|c|c|c|}
\hline \multicolumn{6}{|c|}{ SMC STORM ID 5} \\
\hline \multicolumn{3}{|c|}{ Duration } & \multicolumn{3}{|c|}{$6-22-16$ to $6-29-16$} \\
\hline \multicolumn{3}{|c|}{ Time Since Previous Storm } & \multicolumn{3}{|c|}{5 Days } \\
\hline \multicolumn{3}{|c|}{ Hysteresis Pattern } & \multicolumn{3}{|c|}{ Clockwise } \\
\hline \multicolumn{3}{|c|}{ HI Turbidity } & \multicolumn{3}{|c|}{0.27} \\
\hline \multicolumn{3}{|c|}{ FI Turbidity } & \multicolumn{3}{|c|}{0.58} \\
\hline \multicolumn{3}{|c|}{ HI Total Phosphorus } & \multicolumn{3}{|c|}{0.23} \\
\hline \multicolumn{3}{|c|}{ FI Total Phosphorus } & \multicolumn{3}{|c|}{0.76} \\
\hline Variable & Minimum & Maximum & Range & Mean ( \pm standard deviation) & Units \\
\hline Stage & 0.43 & 1.24 & 0.81 & $0.60( \pm 0.15)$ & $\mathbf{m}$ \\
\hline Discharge & 0.88 & 8.41 & 7.53 & $1.87( \pm 1.26)$ & $\mathbf{m}^{3} / \mathbf{s}$ \\
\hline Turbidity & 12.0 & 1353.0 & 1341.0 & $78.4( \pm 167.5)$ & NTU \\
\hline Total Phosphorus Model & 95.2 & 670.1 & 575.0 & $135.9( \pm 83.7)$ & $\mathrm{mg} / \mathrm{L}$ \\
\hline Mean Absolute Error Model & & & & 88.9 & $\mathrm{mg} / \mathrm{L}$ \\
\hline
\end{tabular}
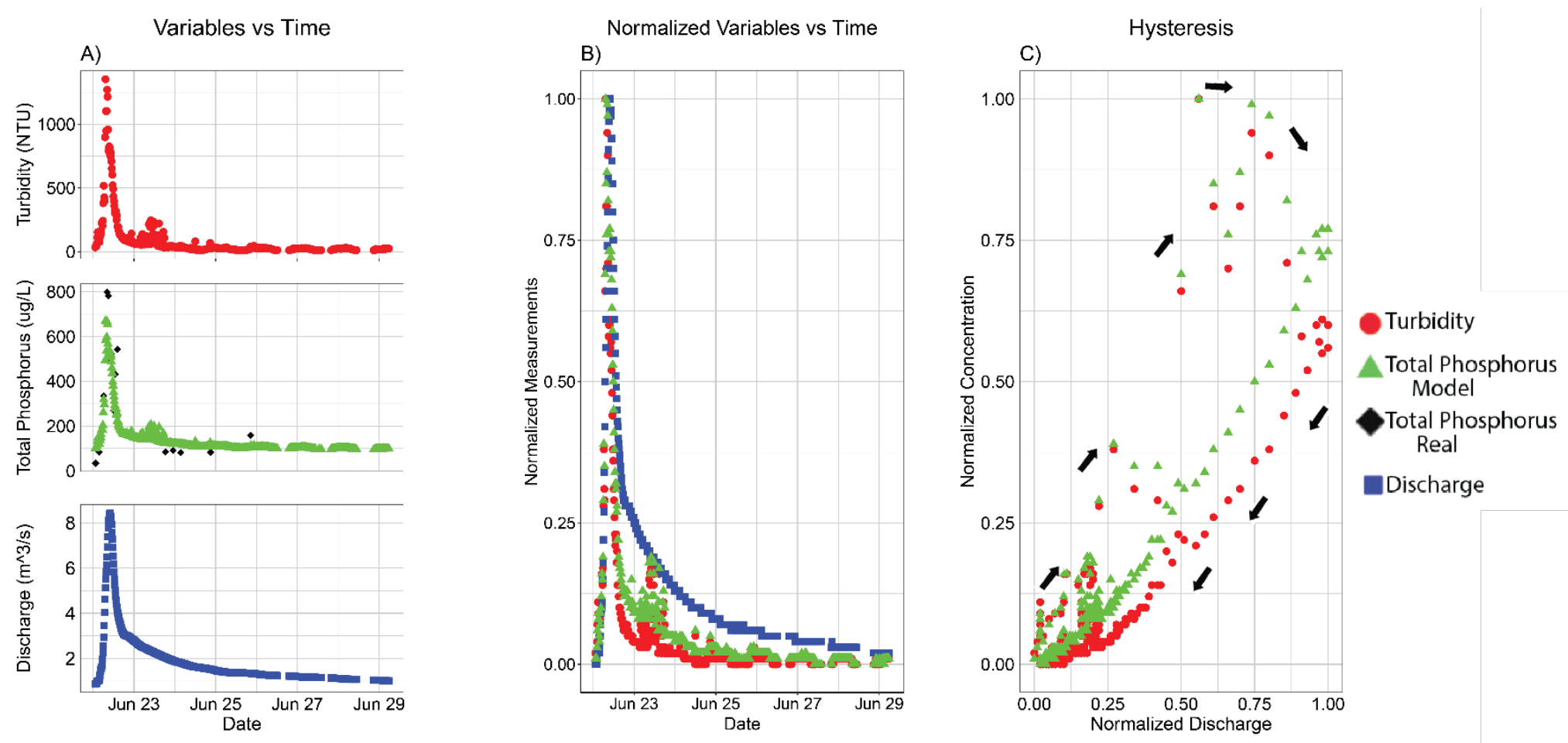


\begin{tabular}{|c|c|c|c|c|c|}
\hline \multicolumn{6}{|c|}{ SMC STORM ID 6} \\
\hline \multicolumn{3}{|c|}{ Duration } & \multicolumn{3}{|c|}{$7-6-16$ to $7-11-16$} \\
\hline \multicolumn{3}{|c|}{ Time Since Previous Storm } & \multicolumn{3}{|c|}{7 Days } \\
\hline \multicolumn{3}{|c|}{ Hysteresis Pattern } & \multicolumn{3}{|c|}{ Clockwise Figure Eight } \\
\hline \multicolumn{3}{|c|}{ HI Turbidity } & \multicolumn{3}{|c|}{0.09} \\
\hline \multicolumn{3}{|c|}{ FI Turbidity } & \multicolumn{3}{|c|}{0.81} \\
\hline \multicolumn{3}{|c|}{ HI Total Phosphorus } & \multicolumn{3}{|c|}{0.07} \\
\hline \multicolumn{3}{|c|}{ FI Total Phosphorus } & \multicolumn{3}{|c|}{0.87} \\
\hline Variable & Minimum & Maximum & Range & Mean ( \pm standard deviation) & Units \\
\hline Stage & 0.53 & 0.92 & 0.39 & $0.63( \pm 0.09)$ & $\mathbf{m}$ \\
\hline Discharge & 0.86 & 4.41 & 3.55 & $1.97( \pm 0.67)$ & $\mathbf{m}^{3} / \mathbf{s}$ \\
\hline Turbidity & 8.0 & 462.0 & 454.0 & $45.84( \pm 68.59)$ & NTU \\
\hline Total Phosphorus Model & 102.81 & 325.35 & 222.55 & $137.40( \pm 46.57)$ & $\mathbf{m g} / \mathrm{L}$ \\
\hline Mean Absolute Error Model & & & & 26.45 & $\mathrm{mg} / \mathrm{L}$ \\
\hline
\end{tabular}
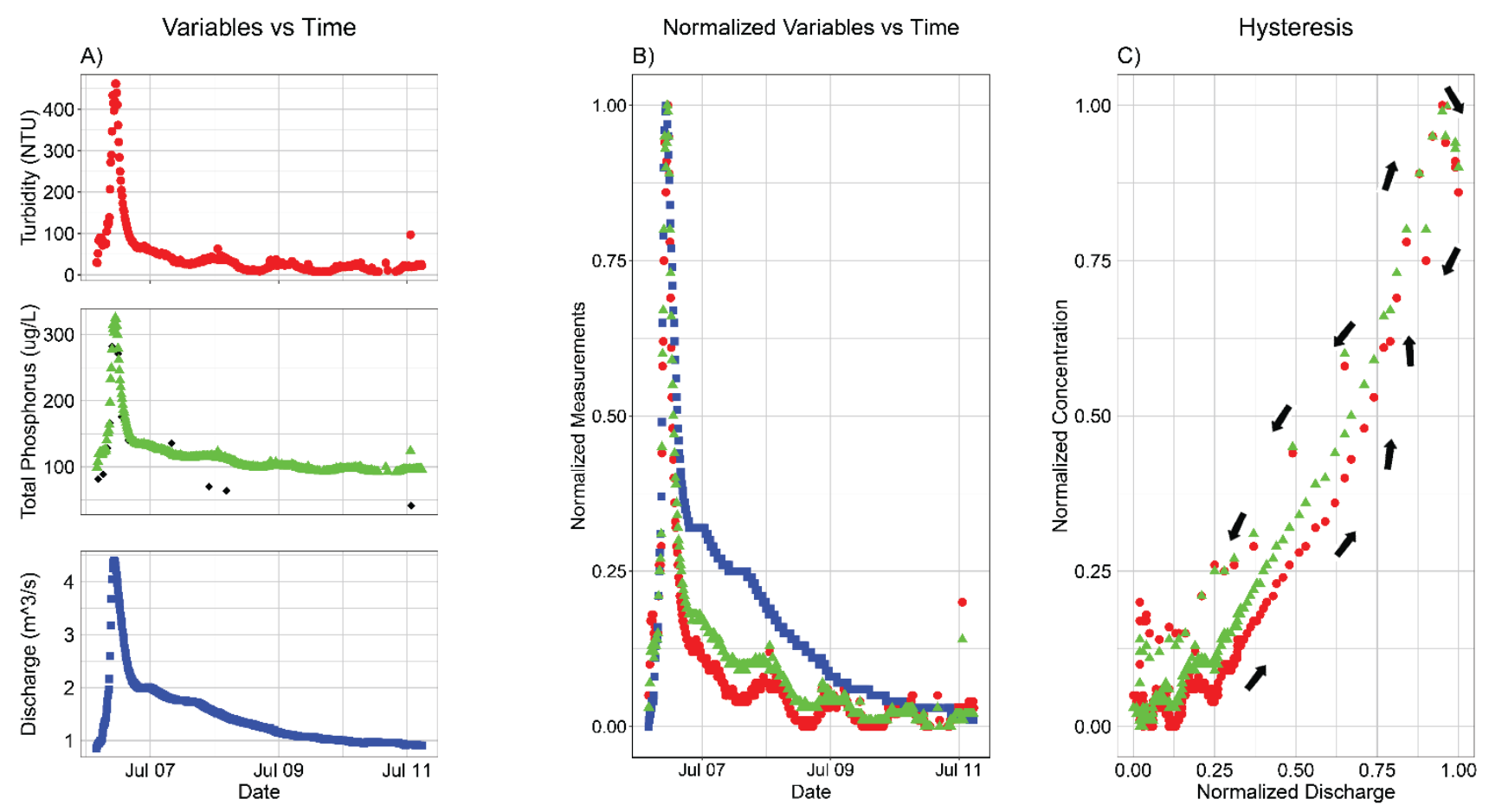

Turbidity

Total Phosphorus Model

Total Phosphorus Real

Discharge 


\begin{tabular}{|c|c|c|c|c|c|}
\hline \multicolumn{6}{|c|}{ SMC STORM ID 9} \\
\hline \multicolumn{3}{|c|}{ Duration } & \multicolumn{3}{|c|}{$7-21-16$ to $7-24-16$} \\
\hline \multicolumn{3}{|c|}{ Time Since Previous Storm } & \multicolumn{3}{|c|}{3 Days } \\
\hline \multicolumn{3}{|c|}{ Hysteresis Pattern } & \multicolumn{3}{|c|}{ Counterclockwise Figure Eight } \\
\hline \multicolumn{3}{|c|}{ HI Turbidity } & \multicolumn{3}{|c|}{0.07} \\
\hline \multicolumn{3}{|c|}{ FI Turbidity } & \multicolumn{3}{|c|}{0.64} \\
\hline \multicolumn{3}{|c|}{ HI Total Phosphorus } & \multicolumn{3}{|c|}{0.05} \\
\hline \multicolumn{3}{|c|}{ FI Total Phosphorus } & \multicolumn{3}{|c|}{0.80} \\
\hline Variable & Minimum & Maximum & Range & Mean ( \pm standard deviation) & Units \\
\hline Stage & 0.39 & 0.74 & 0.35 & $0.51( \pm 0.07)$ & $\mathbf{m}$ \\
\hline Discharge & 0.69 & 2.76 & 2.07 & $1.27( \pm 0.41)$ & $\mathrm{m}^{3} / \mathbf{s}$ \\
\hline Turbidity & 8.0 & 321.0 & 313.0 & $50.5( \pm 62.6)$ & NTU \\
\hline Total Phosphorus Model & 89.1 & 233.2 & 144.2 & $113.7( \pm 30.1)$ & $\mathrm{mg} / \mathrm{L}$ \\
\hline Mean Absolute Error Model & & & & 39.63 & $\mathrm{mg} / \mathrm{L}$ \\
\hline
\end{tabular}
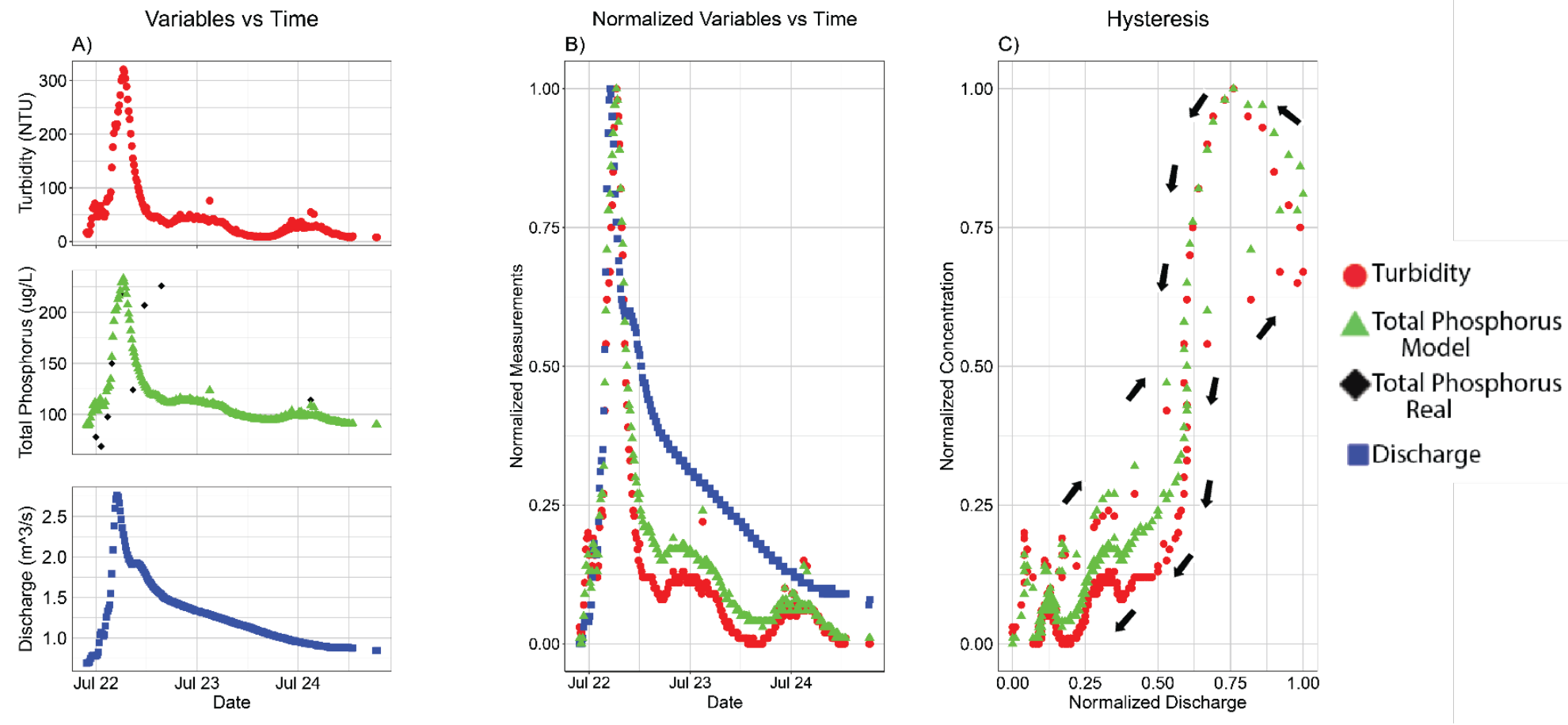


\begin{tabular}{|c|c|c|c|c|c|}
\hline \multicolumn{6}{|c|}{ SMC STORM ID 10} \\
\hline \multicolumn{3}{|c|}{ Duration } & \multicolumn{3}{|c|}{$7-24-16$ to $7-31-16$} \\
\hline \multicolumn{3}{|c|}{ Time Since Previous Storm } & \multicolumn{3}{|c|}{1 Day } \\
\hline \multicolumn{3}{|c|}{ Hysteresis Pattern } & \multicolumn{3}{|c|}{ Clockwise } \\
\hline \multicolumn{3}{|c|}{ HI Turbidity } & \multicolumn{3}{|c|}{0.06} \\
\hline \multicolumn{3}{|c|}{ FI Turbidity } & \multicolumn{3}{|c|}{0.70} \\
\hline \multicolumn{3}{|c|}{ HI Total Phosphorus } & \multicolumn{3}{|c|}{0.04} \\
\hline \multicolumn{3}{|c|}{ FI Total Phosphorus } & \multicolumn{3}{|c|}{0.90} \\
\hline Variable & Minimum & Maximum & Range & Mean ( \pm standard deviation) & Units \\
\hline Stage & 0.45 & 1.62 & 1.18 & $0.65( \pm 0.23)$ & $\mathbf{m}$ \\
\hline Discharge & 0.95 & 15.06 & 14.11 & $2.44( \pm 2.32)$ & $\mathbf{m}^{3} / \mathbf{s}$ \\
\hline Turbidity & 22.0 & 815.0 & 793.0 & $127.8( \pm 269.9)$ & NTU \\
\hline Total Phosphorus Model & 93.2 & 631.8 & 538.7 & $141.0( \pm 77.7)$ & $\mathrm{mg} / \mathrm{L}$ \\
\hline Mean Absolute Error Model & & & & 26.84 & $\mathrm{mg} / \mathrm{L}$ \\
\hline
\end{tabular}
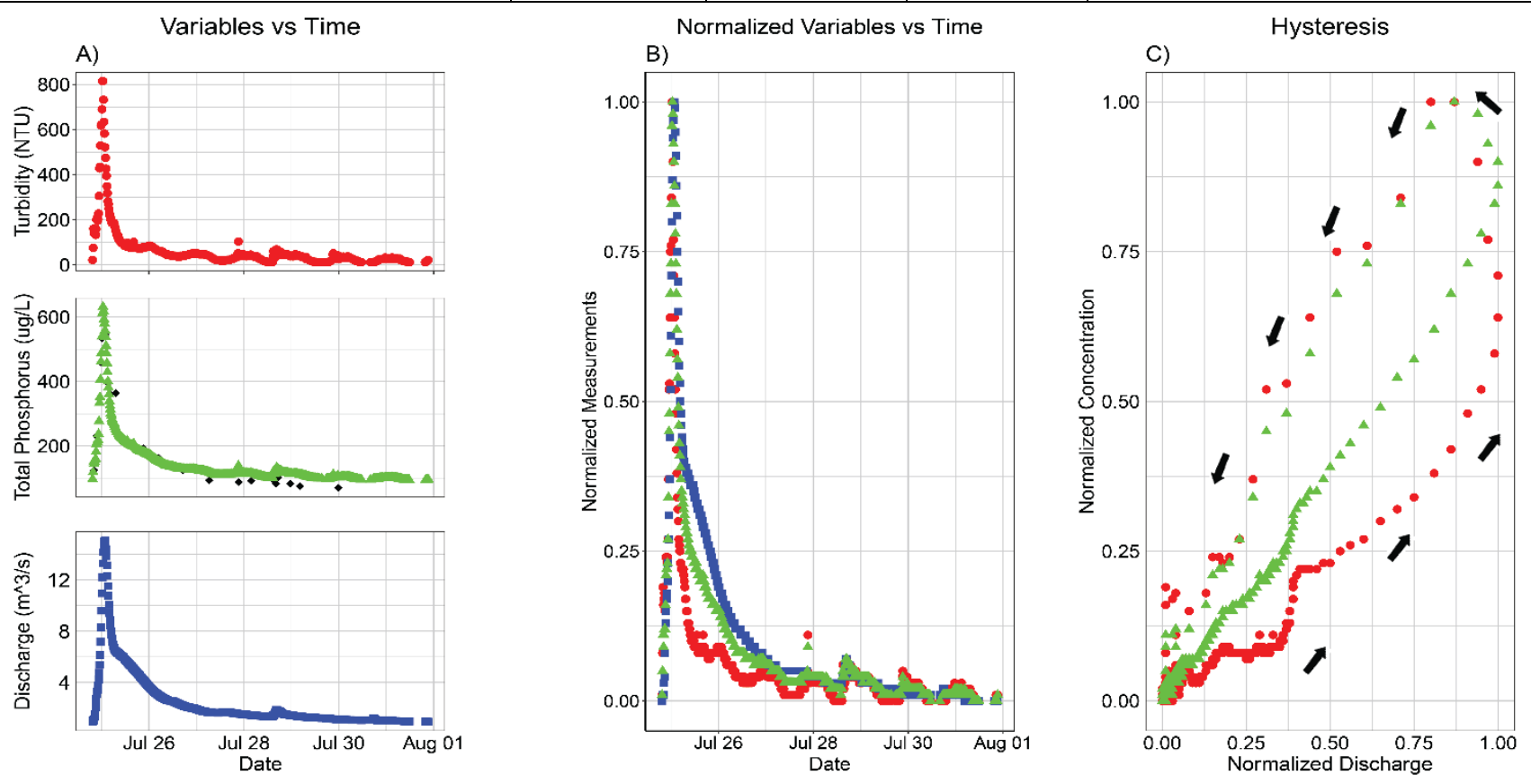

Turbidity

Total Phosphorus Model

Total Phosphorus Real

Discharge 


\begin{tabular}{|c|c|c|c|c|c|}
\hline \multicolumn{6}{|c|}{ SMC STORM ID 16} \\
\hline \multicolumn{3}{|c|}{ Duration } & \multicolumn{3}{|c|}{$10-6-16$ to $10-12-16$} \\
\hline \multicolumn{3}{|c|}{ Time Since Previous Storm } & \multicolumn{3}{|c|}{17 Days } \\
\hline \multicolumn{3}{|c|}{ Hysteresis Pattern } & \multicolumn{3}{|c|}{ Counterclockwise Figure Eight } \\
\hline \multicolumn{3}{|c|}{ HI Turbidity } & \multicolumn{3}{|c|}{0.02} \\
\hline \multicolumn{3}{|c|}{ FI Turbidity } & \multicolumn{3}{|c|}{0.05} \\
\hline \multicolumn{3}{|c|}{ HI Total Phosphorus } & \multicolumn{3}{|c|}{0.02} \\
\hline \multicolumn{3}{|c|}{ FI Total Phosphorus } & \multicolumn{3}{|c|}{0.11} \\
\hline Variable & Minimum & Maximum & Range & Mean ( \pm standard deviation) & Units \\
\hline Stage & 0.38 & 0.88 & 0.49 & $0.63( \pm 0.11)$ & $\mathbf{m}$ \\
\hline Discharge & 0.67 & 3.97 & 3.30 & $2.02( \pm 0.79)$ & $\mathrm{m}^{3} / \mathbf{s}$ \\
\hline Turbidity & 16.0 & 2604.0 & 2588.0 & $76.4( \pm$ 199.6) & NTU \\
\hline Total Phosphorus Model & 89.3 & 1051.1 & 961.8 & $138.1( \pm 77.5)$ & $\mathrm{mg} / \mathrm{L}$ \\
\hline Mean Absolute Error Model & & & & 196.82 & $\mathrm{mg} / \mathrm{L}$ \\
\hline
\end{tabular}
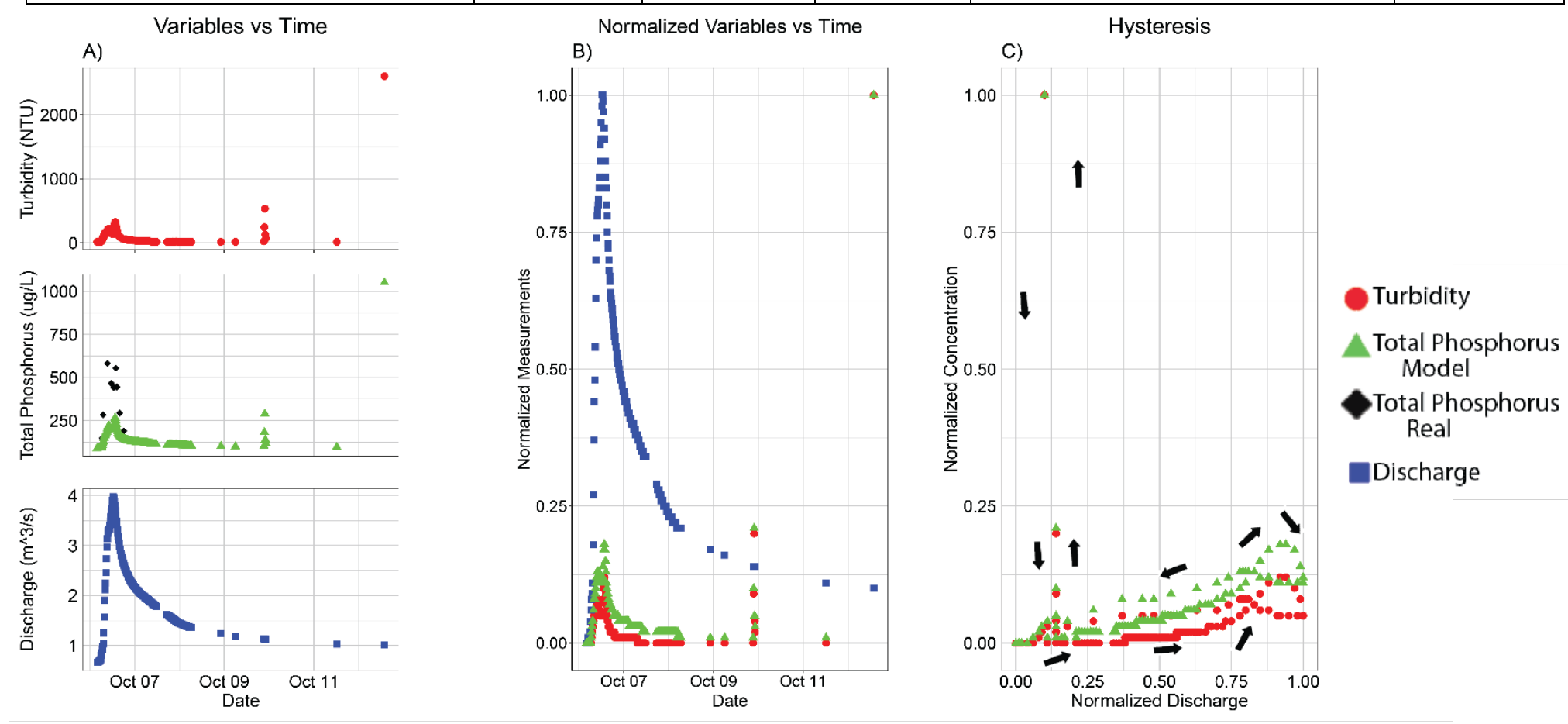


\begin{tabular}{|c|c|c|c|c|c|}
\hline \multicolumn{6}{|c|}{ SMC STORM ID 18} \\
\hline \multicolumn{3}{|c|}{ Duration } & \multicolumn{3}{|c|}{$11-2-16$ to $11-12-16$} \\
\hline \multicolumn{3}{|c|}{ Time Since Previous Storm } & \multicolumn{3}{|c|}{3 Days } \\
\hline \multicolumn{3}{|c|}{ Hysteresis Pattern } & \multicolumn{3}{|c|}{ Counterclockwise Figure Eight } \\
\hline \multicolumn{3}{|c|}{ HI Turbidity } & \multicolumn{3}{|c|}{-0.08} \\
\hline \multicolumn{3}{|c|}{ FI Turbidity } & \multicolumn{3}{|c|}{0.28} \\
\hline \multicolumn{3}{|c|}{ HI Total Phosphorus } & \multicolumn{3}{|c|}{-0.06} \\
\hline \multicolumn{3}{|c|}{ FI Total Phosphorus } & \multicolumn{3}{|c|}{0.45} \\
\hline Variable & Minimum & Maximum & Range & Mean ( \pm standard deviation) & Units \\
\hline Stage & 0.41 & 0.82 & 0.41 & $0.54( \pm 0.09)$ & $\mathbf{m}$ \\
\hline Discharge & 0.78 & 3.44 & 2.66 & $1.46( \pm 0.55)$ & $\mathbf{m}^{3} / \mathbf{s}$ \\
\hline Turbidity & 5.0 & 504.0 & 499.0 & $25.9( \pm 58.3)$ & NTU \\
\hline Total Phosphorus Model & 87.5 & 319.6 & 232.2 & $108.4( \pm 30.3)$ & $\mathrm{mg} / \mathrm{L}$ \\
\hline Mean Absolute Error Model & & & & 139.14 & $\mathrm{mg} / \mathrm{L}$ \\
\hline
\end{tabular}
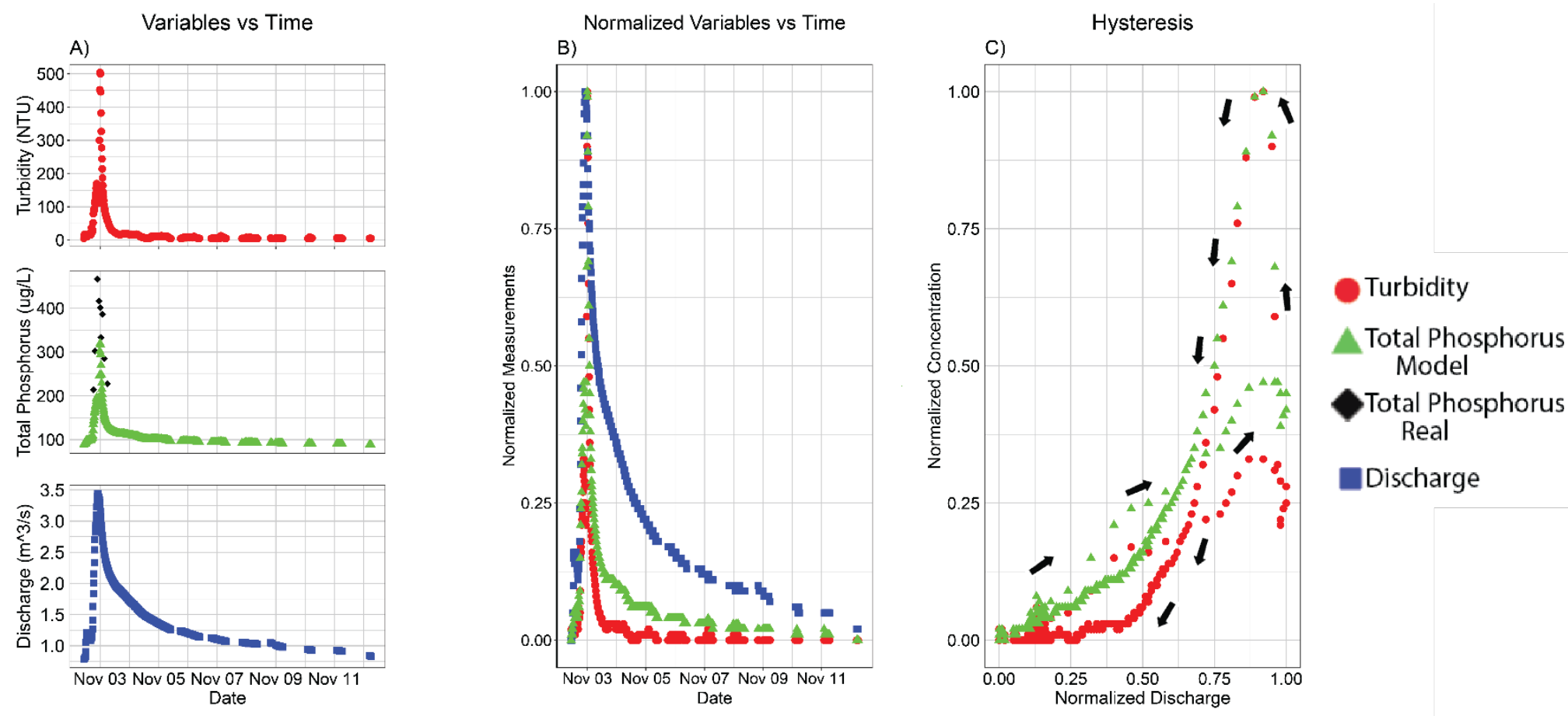


\begin{tabular}{|c|c|c|c|c|c|}
\hline \multicolumn{6}{|c|}{ SMC STORM ID 19} \\
\hline \multicolumn{3}{|c|}{ Duration } & \multicolumn{3}{|c|}{$11-22-16$ to $11-26-16$} \\
\hline \multicolumn{3}{|c|}{ Time Since Previous Storm } & \multicolumn{3}{|c|}{10 Days } \\
\hline \multicolumn{3}{|c|}{ Hysteresis Pattern } & \multicolumn{3}{|c|}{ Counterclockwise } \\
\hline \multicolumn{3}{|c|}{ HI Turbidity } & \multicolumn{3}{|c|}{-0.16} \\
\hline \multicolumn{3}{|c|}{ FI Turbidity } & \multicolumn{3}{|c|}{0.08} \\
\hline \multicolumn{3}{|c|}{ HI Total Phosphorus } & \multicolumn{3}{|c|}{-0.13} \\
\hline \multicolumn{3}{|c|}{ FI Total Phosphorus } & \multicolumn{3}{|c|}{0.29} \\
\hline Variable & Minimum & Maximum & Range & Mean ( \pm standard deviation) & Units \\
\hline Stage & 0.39 & 0.50 & 0.11 & $0.43( \pm 0.03)$ & $\mathbf{m}$ \\
\hline Discharge & 0.68 & 1.17 & 0.48 & $0.85( \pm 0.14)$ & $\mathbf{m}^{3} / \mathbf{s}$ \\
\hline Turbidity & 3.0 & 92.0 & 89.0 & $14.6( \pm 15.4)$ & NTU \\
\hline Total Phosphorus Model & 84.9 & 126.4 & 41.6 & $92.4( \pm 7.4)$ & $\mathrm{mg} / \mathrm{L}$ \\
\hline Mean Absolute Error Model & & & & 30.24 & $\mathrm{mg} / \mathrm{L}$ \\
\hline
\end{tabular}
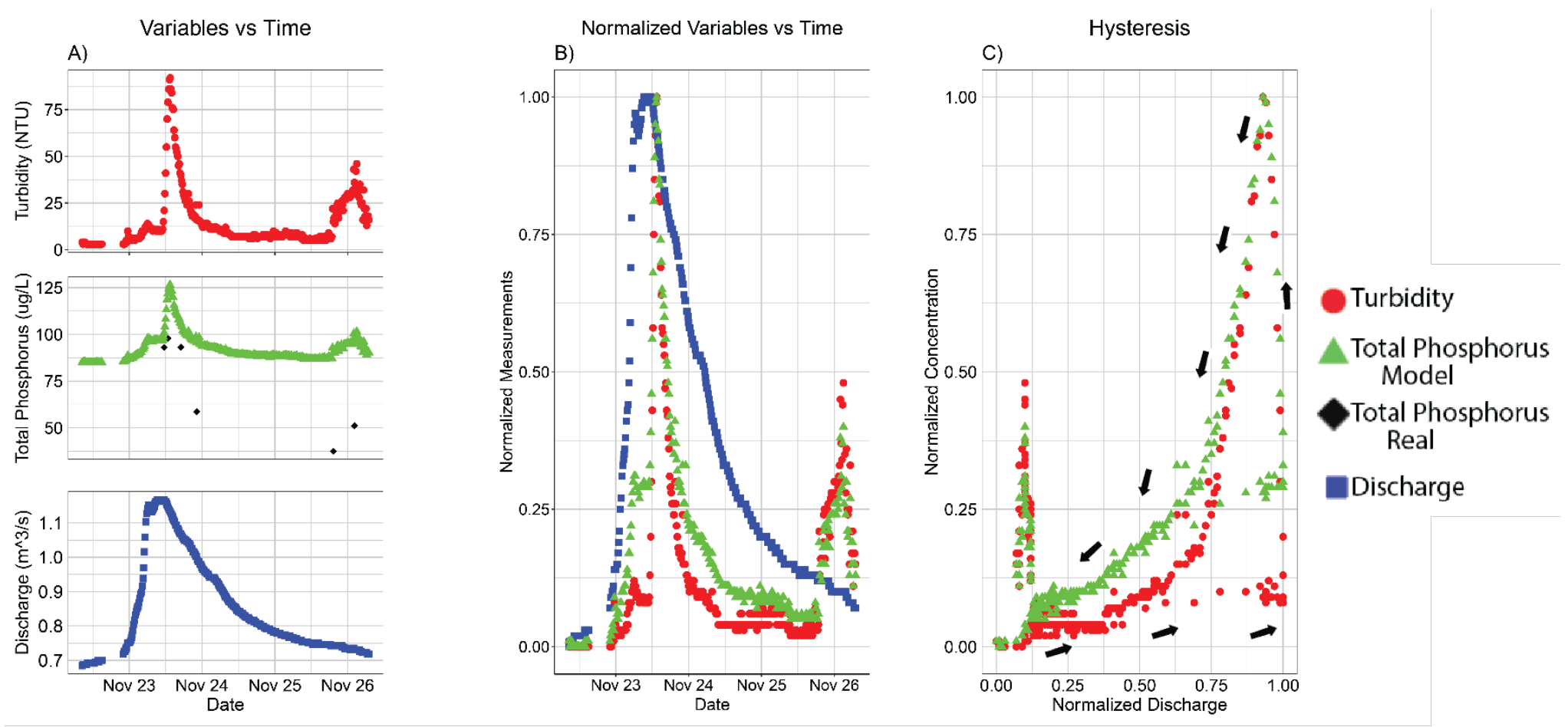


\begin{tabular}{|c|c|c|c|c|c|}
\hline \multicolumn{6}{|c|}{ SMC STORM ID 21} \\
\hline \multicolumn{3}{|c|}{ Duration } & \multicolumn{3}{|c|}{$12-26-16$ to $12-31-16$} \\
\hline \multicolumn{3}{|c|}{ Time Since Previous Storm } & \multicolumn{3}{|c|}{23 Days } \\
\hline \multicolumn{3}{|c|}{ Hysteresis Pattern } & \multicolumn{3}{|c|}{ Counterclockwise } \\
\hline \multicolumn{3}{|c|}{ HI Turbidity } & \multicolumn{3}{|c|}{-0.02} \\
\hline \multicolumn{3}{|c|}{ FI Turbidity } & \multicolumn{3}{|c|}{0.07} \\
\hline \multicolumn{3}{|c|}{ HI Total Phosphorus } & \multicolumn{3}{|c|}{-0.01} \\
\hline \multicolumn{3}{|c|}{ FI Total Phosphorus } & \multicolumn{3}{|c|}{0.11} \\
\hline Variable & Minimum & Maximum & Range & Mean ( \pm standard deviation) & Units \\
\hline Stage & 0.43 & 0.61 & 0.18 & $0.50( \pm 0.05)$ & $\mathbf{m}$ \\
\hline Discharge & 0.85 & 1.84 & 0.99 & $1.20( \pm 0.29)$ & $\mathbf{m}^{3} / \mathbf{s}$ \\
\hline Turbidity & 9.0 & 1081.0 & 1072.0 & $57.7( \pm 150.8)$ & NTU \\
\hline Total Phosphorus Model & 90.2 & 504.2 & 414.0 & $115.1( \pm 58.8)$ & $\mathrm{mg} / \mathrm{L}$ \\
\hline Mean Absolute Error Model & & & & 66.04 & $\mathrm{mg} / \mathrm{L}$ \\
\hline
\end{tabular}
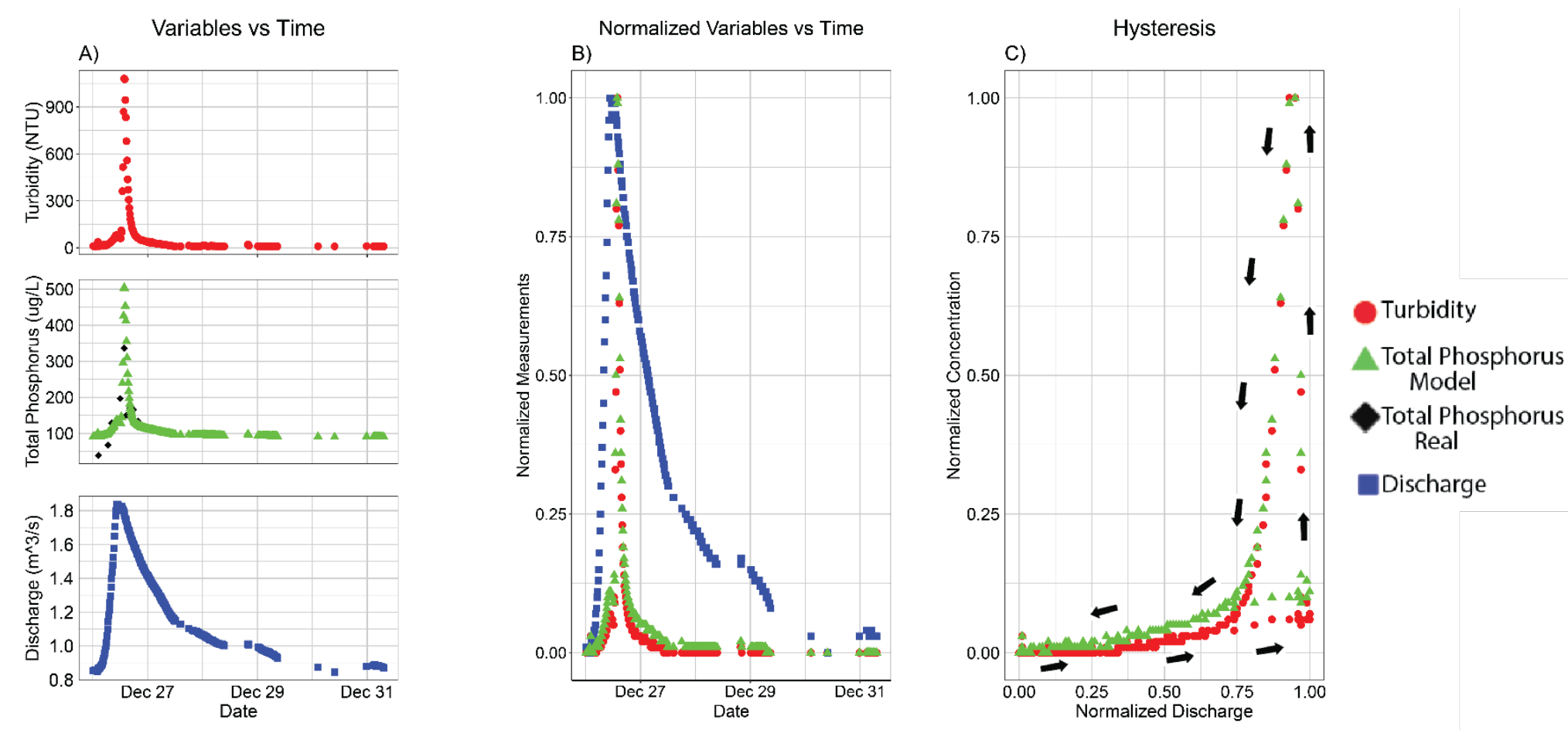


\begin{tabular}{|c|c|c|c|c|c|}
\hline \multicolumn{6}{|c|}{ SMC STORM ID 23} \\
\hline \multicolumn{3}{|c|}{ Duration } & \multicolumn{3}{|c|}{$3-6-17$ to $3-8-17$} \\
\hline \multicolumn{3}{|c|}{ Time Since Previous Storm } & \multicolumn{3}{|c|}{3 Days } \\
\hline \multicolumn{3}{|c|}{ Hysteresis Pattern } & \multicolumn{3}{|c|}{ Complex } \\
\hline \multicolumn{3}{|c|}{ HI Turbidity } & \multicolumn{3}{|c|}{-0.16} \\
\hline \multicolumn{3}{|c|}{ FI Turbidity } & \multicolumn{3}{|c|}{-0.01} \\
\hline \multicolumn{3}{|c|}{ HI Total Phosphorus } & \multicolumn{3}{|c|}{-0.16} \\
\hline \multicolumn{3}{|c|}{ FI Total Phosphorus } & \multicolumn{3}{|c|}{0.01} \\
\hline Variable & Minimum & Maximum & Range & Mean ( \pm standard deviation) & Units \\
\hline Stage & 0.42 & 0.53 & 0.11 & $0.46( \pm 0.03)$ & $\mathbf{m}$ \\
\hline Discharge & 0.82 & 1.34 & 0.52 & $1.00( \pm 0.15)$ & $\mathbf{m}^{3} / \mathbf{s}$ \\
\hline Turbidity & 11.0 & 1352.0 & 1341.0 & $151.4( \pm 212.3)$ & NTU \\
\hline Total Phosphorus Model & 90.6 & 588.1 & 497.5 & $145.6( \pm 78.2)$ & $\mathrm{mg} / \mathrm{L}$ \\
\hline Mean Absolute Error Model & & & & 71.89 & $\mathrm{mg} / \mathrm{L}$ \\
\hline
\end{tabular}
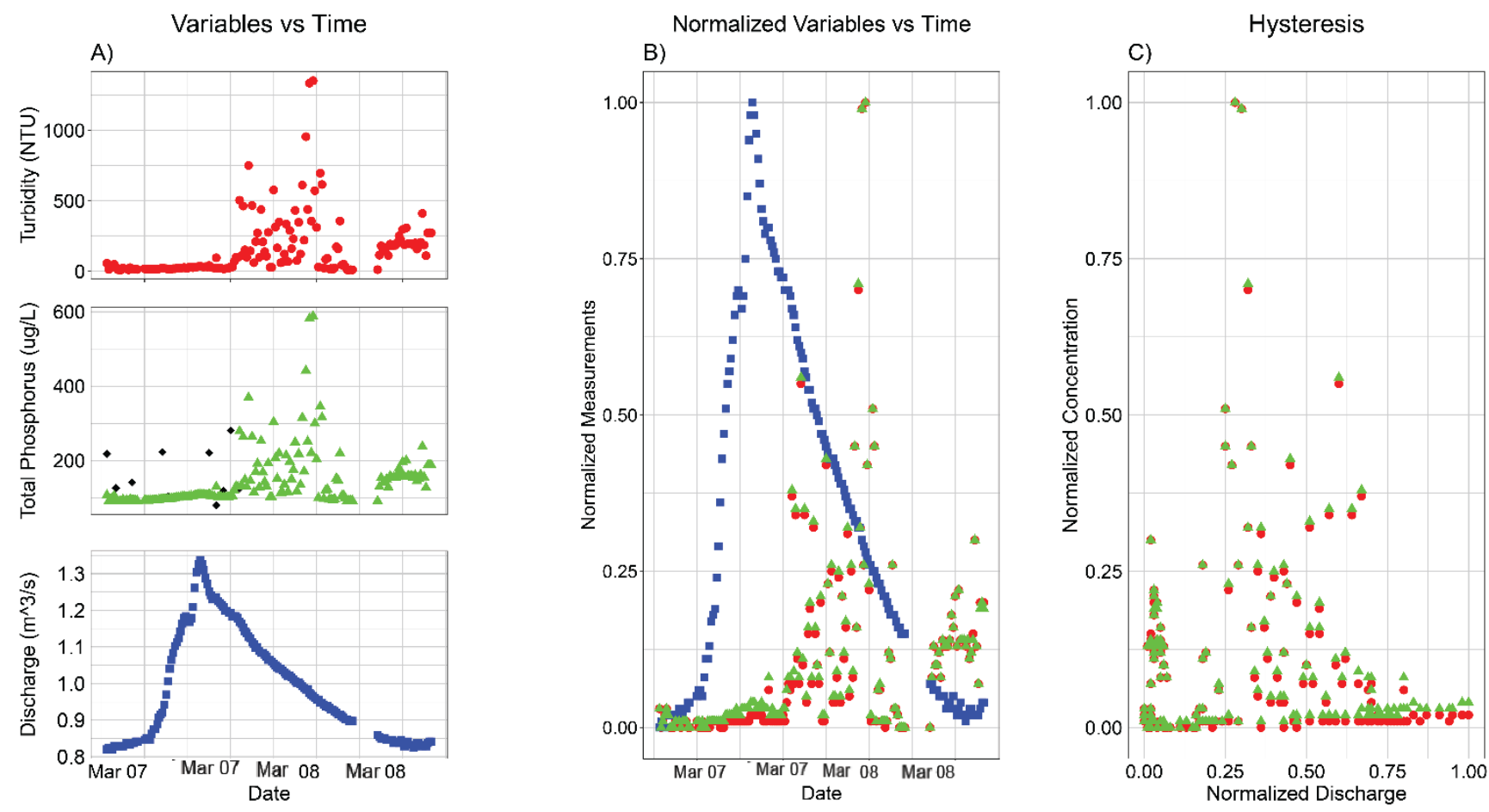

Turbidity

Total Phosphorus Model

Total Phosphorus Real

Discharge 


\begin{tabular}{|c|c|c|c|c|c|}
\hline \multicolumn{6}{|c|}{ SMC STORM ID 25} \\
\hline \multicolumn{3}{|c|}{ Duration } & \multicolumn{3}{|c|}{$4-3-17$ to $4-5-17$} \\
\hline \multicolumn{3}{|c|}{ Time Since Previous Storm } & \multicolumn{3}{|c|}{26 Days } \\
\hline \multicolumn{3}{|c|}{ Hysteresis Pattern } & \multicolumn{3}{|c|}{ Counterclockwise Figure Eight } \\
\hline \multicolumn{3}{|c|}{ HI Turbidity } & \multicolumn{3}{|c|}{-0.04} \\
\hline \multicolumn{3}{|c|}{ FI Turbidity } & \multicolumn{3}{|c|}{0.33} \\
\hline \multicolumn{3}{|c|}{ HI Total Phosphorus } & \multicolumn{3}{|c|}{-0.03} \\
\hline \multicolumn{3}{|c|}{ FI Total Phosphorus } & \multicolumn{3}{|c|}{0.51} \\
\hline Variable & Minimum & Maximum & Range & Mean ( \pm standard deviation) & Units \\
\hline Stage & 0.69 & 0.88 & 0.19 & $0.7( \pm 0.04)$ & $\mathbf{m}$ \\
\hline Discharge & 2.38 & 4.05 & 1.67 & $3.07( \pm 0.39)$ & $\mathbf{m}^{3} / \mathbf{s}$ \\
\hline Turbidity & 29.0 & 302.0 & 273.0 & $63.8( \pm 52.6)$ & NTU \\
\hline Total Phosphorus Model & 127.7 & 256.4 & 128.8 & $153.9( \pm 25.8)$ & $\mathbf{m g} / \mathrm{L}$ \\
\hline Mean Absolute Error Model & & & & 49.87 & $\mathrm{mg} / \mathrm{L}$ \\
\hline
\end{tabular}
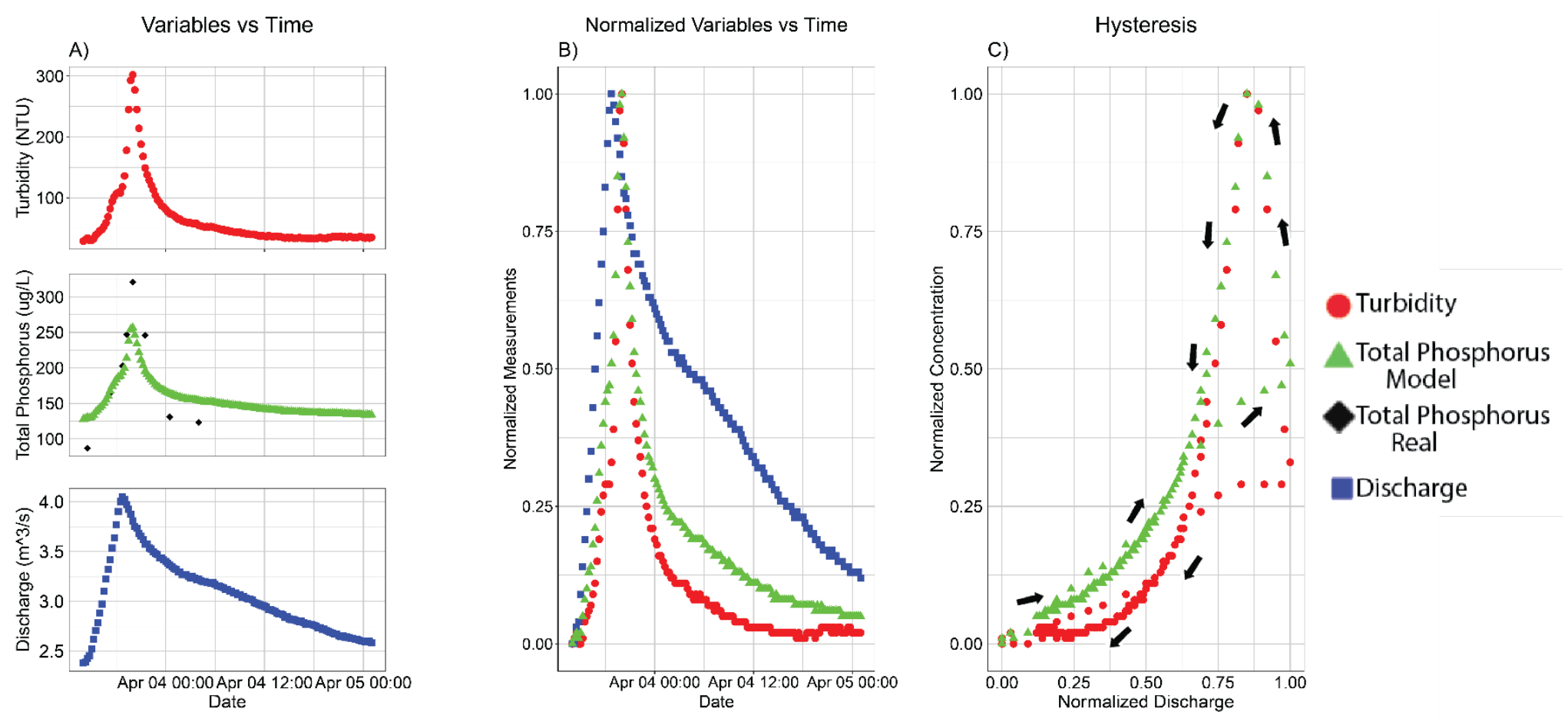


\begin{tabular}{|c|c|c|c|c|c|}
\hline \multicolumn{6}{|c|}{ SMC STORM ID 28} \\
\hline \multicolumn{3}{|c|}{ Duration } & \multicolumn{3}{|c|}{$4-16-17$ to $4-17-17$} \\
\hline \multicolumn{3}{|c|}{ Time Since Previous Storm } & \multicolumn{3}{|c|}{1 Day } \\
\hline \multicolumn{3}{|c|}{ Hysteresis Pattern } & \multicolumn{3}{|c|}{ Counterclockwise Figure Eight } \\
\hline \multicolumn{3}{|c|}{ HI Turbidity } & \multicolumn{3}{|c|}{0.05} \\
\hline \multicolumn{3}{|c|}{ FI Turbidity } & \multicolumn{3}{|c|}{0.47} \\
\hline \multicolumn{3}{|c|}{ HI Total Phosphorus } & \multicolumn{3}{|c|}{0.03} \\
\hline \multicolumn{3}{|c|}{ FI Total Phosphorus } & \multicolumn{3}{|c|}{0.82} \\
\hline Variable & Minimum & Maximum & Range & Mean ( \pm standard deviation) & Units \\
\hline Stage & 0.52 & 0.60 & 0.08 & $0.55( \pm 0.02)$ & $\mathbf{m}$ \\
\hline Discharge & 1.34 & 1.73 & 0.39 & $1.44( \pm 0.12)$ & $\mathbf{m}^{3} / \mathbf{s}$ \\
\hline Turbidity & 5.0 & 37.0 & 32.0 & $13.6( \pm 6.5)$ & NTU \\
\hline Total Phosphorus Model & 97.3 & 114.7 & 17.5 & $103.6( \pm 4.2)$ & $\mathrm{mg} / \mathrm{L}$ \\
\hline Mean Absolute Error Model & & & & NA & $\mathrm{mg} / \mathrm{L}$ \\
\hline
\end{tabular}
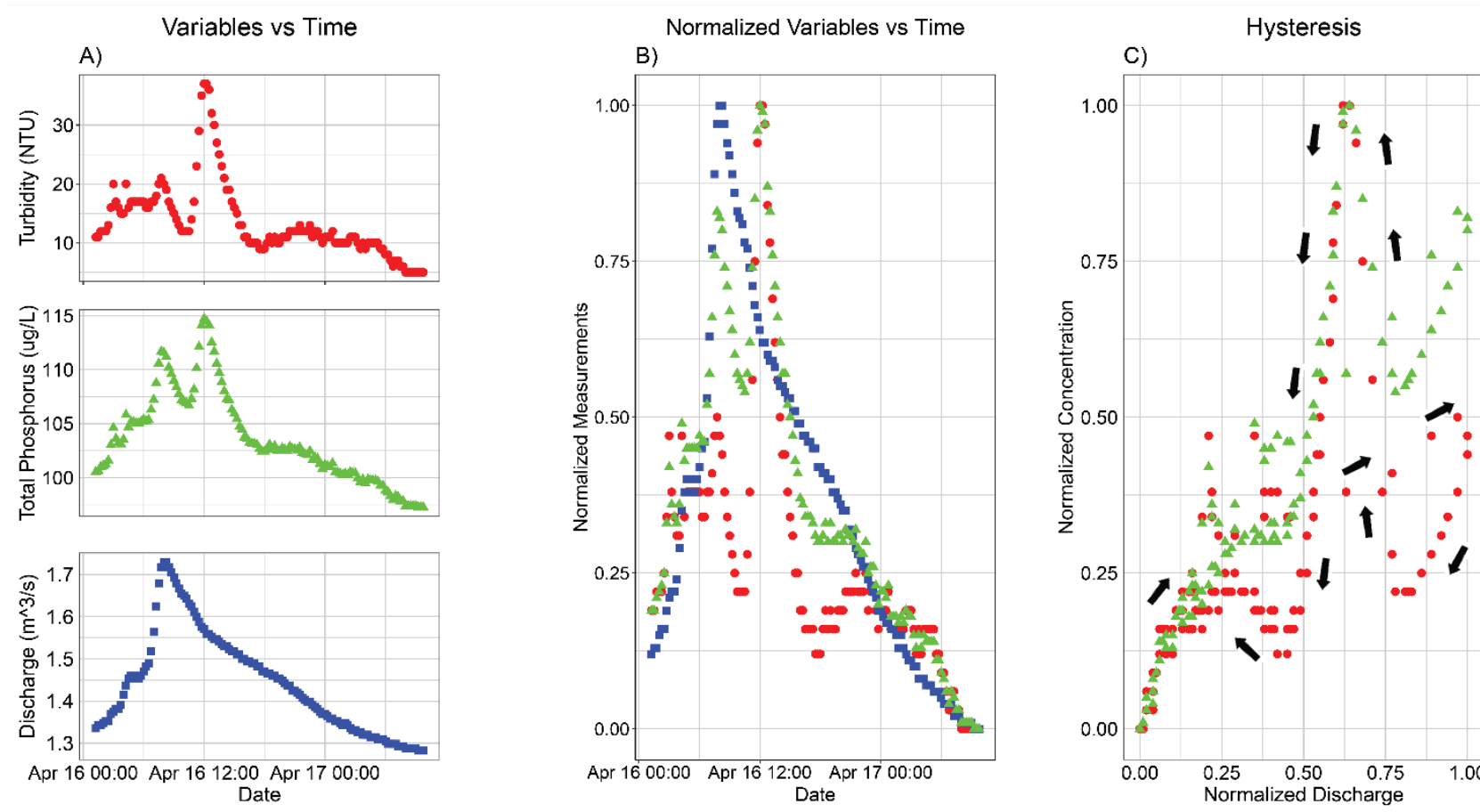

Turbidity

Total Phosphorus Model

Total Phosphorus Real

Discharge 


\begin{tabular}{|c|c|c|c|c|c|}
\hline \multicolumn{6}{|c|}{ SMC STORM ID 31} \\
\hline \multicolumn{3}{|c|}{ Duration } & \multicolumn{3}{|c|}{$6-17-17$ to $6-23-17$} \\
\hline \multicolumn{3}{|c|}{ Time Since Previous Storm } & \multicolumn{3}{|c|}{20 Days } \\
\hline \multicolumn{3}{|c|}{ Hysteresis Pattern } & \multicolumn{3}{|c|}{ Clockwise } \\
\hline \multicolumn{3}{|c|}{ HI Turbidity } & \multicolumn{3}{|c|}{0.33} \\
\hline \multicolumn{3}{|c|}{ FI Turbidity } & \multicolumn{3}{|c|}{0.68} \\
\hline \multicolumn{3}{|c|}{ HI Total Phosphorus } & \multicolumn{3}{|c|}{0.16} \\
\hline \multicolumn{3}{|c|}{ FI Total Phosphorus } & \multicolumn{3}{|c|}{0.98} \\
\hline Variable & Minimum & Maximum & Range & Mean ( \pm standard deviation) & Units \\
\hline Stage & 0.34 & 2.69 & 2.34 & $0.88( \pm 0.54)$ & $\mathbf{m}$ \\
\hline Discharge & 0.53 & 44.55 & 44.03 & $6.00( \pm 9.63)$ & $\mathbf{m}^{3} / \mathbf{s}$ \\
\hline Turbidity & 16.0 & 1756.0 & 1740.0 & $177.4( \pm 323.8)$ & NTU \\
\hline Total Phosphorus Model & 100.4 & 1428.6 & 1328.1 & $253.5( \pm 301.3)$ & $\mathrm{mg} / \mathrm{L}$ \\
\hline Mean Absolute Error Model & & & & 183.36 & $\mathrm{mg} / \mathrm{L}$ \\
\hline
\end{tabular}
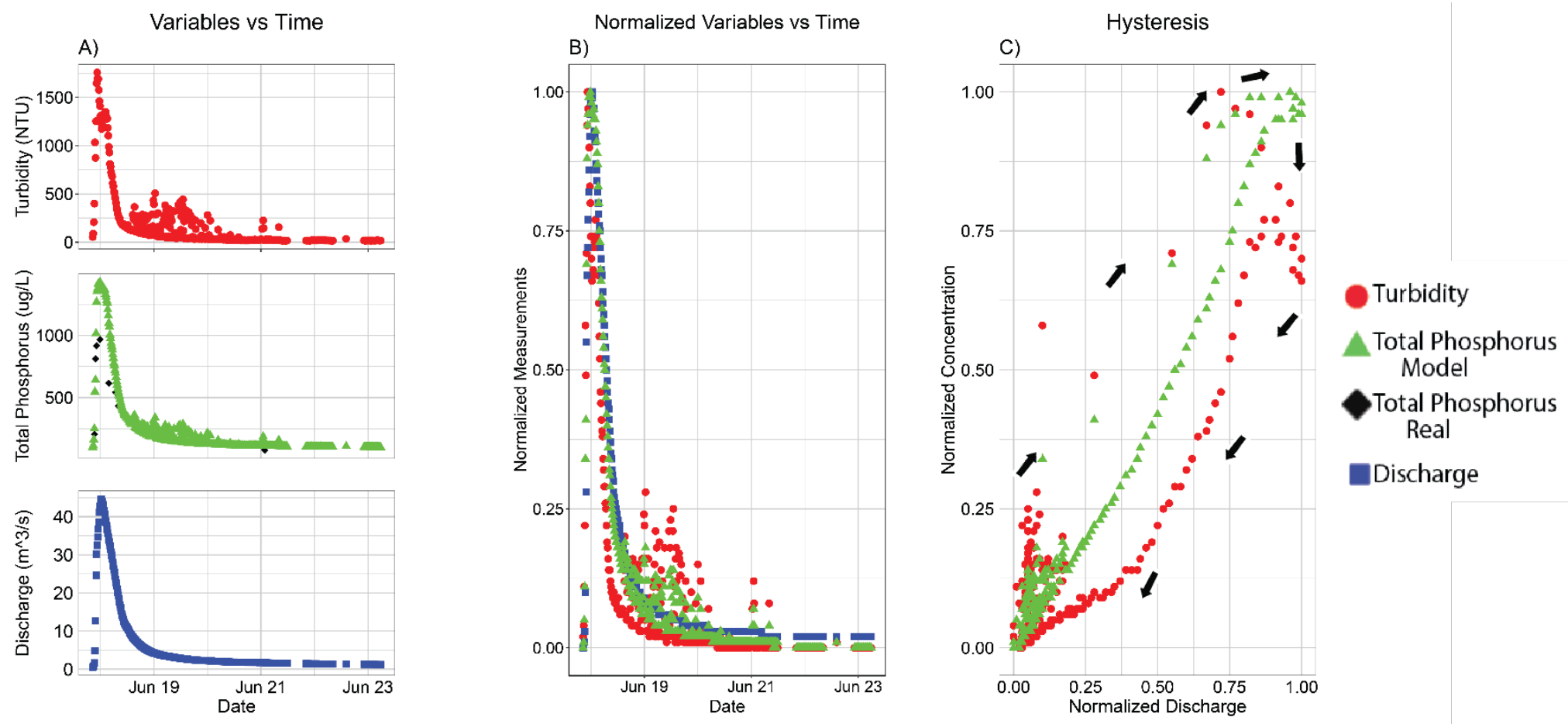


\begin{tabular}{|c|c|c|c|c|c|}
\hline \multicolumn{6}{|c|}{ SMC STORM ID 32} \\
\hline \multicolumn{3}{|c|}{ Duration } & \multicolumn{3}{|c|}{$7-11-17$ to $7-13-17$} \\
\hline \multicolumn{3}{|c|}{ Time Since Previous Storm } & \multicolumn{3}{|c|}{18 Days } \\
\hline \multicolumn{3}{|c|}{ Hysteresis Pattern } & \multicolumn{3}{|c|}{ Counterclockwise Figure Eight } \\
\hline \multicolumn{3}{|c|}{ HI Turbidity } & \multicolumn{3}{|c|}{-0.04} \\
\hline \multicolumn{3}{|c|}{ FI Turbidity } & \multicolumn{3}{|c|}{0.00} \\
\hline \multicolumn{3}{|c|}{ HI Total Phosphorus } & \multicolumn{3}{|c|}{-0.04} \\
\hline \multicolumn{3}{|c|}{ FI Total Phosphorus } & \multicolumn{3}{|c|}{0.06} \\
\hline Variable & Minimum & Maximum & Range & Mean ( \pm standard deviation) & Units \\
\hline Stage & 0.32 & 0.40 & 0.08 & $0.34( \pm 0.02)$ & $\mathbf{m}$ \\
\hline Discharge & 0.45 & 0.73 & 0.28 & $0.53( \pm 0.07)$ & $\mathbf{m}^{3} / \mathbf{s}$ \\
\hline Turbidity & 4.0 & 228.0 & 224.0 & $17.7( \pm 24.4)$ & NTU \\
\hline Total Phosphorus Model & 81.0 & 166.1 & 85.1 & $87.1( \pm 9.2)$ & $\mathrm{mg} / \mathrm{L}$ \\
\hline Mean Absolute Error Model & & & & 32.30 & $\mathrm{mg} / \mathrm{L}$ \\
\hline
\end{tabular}
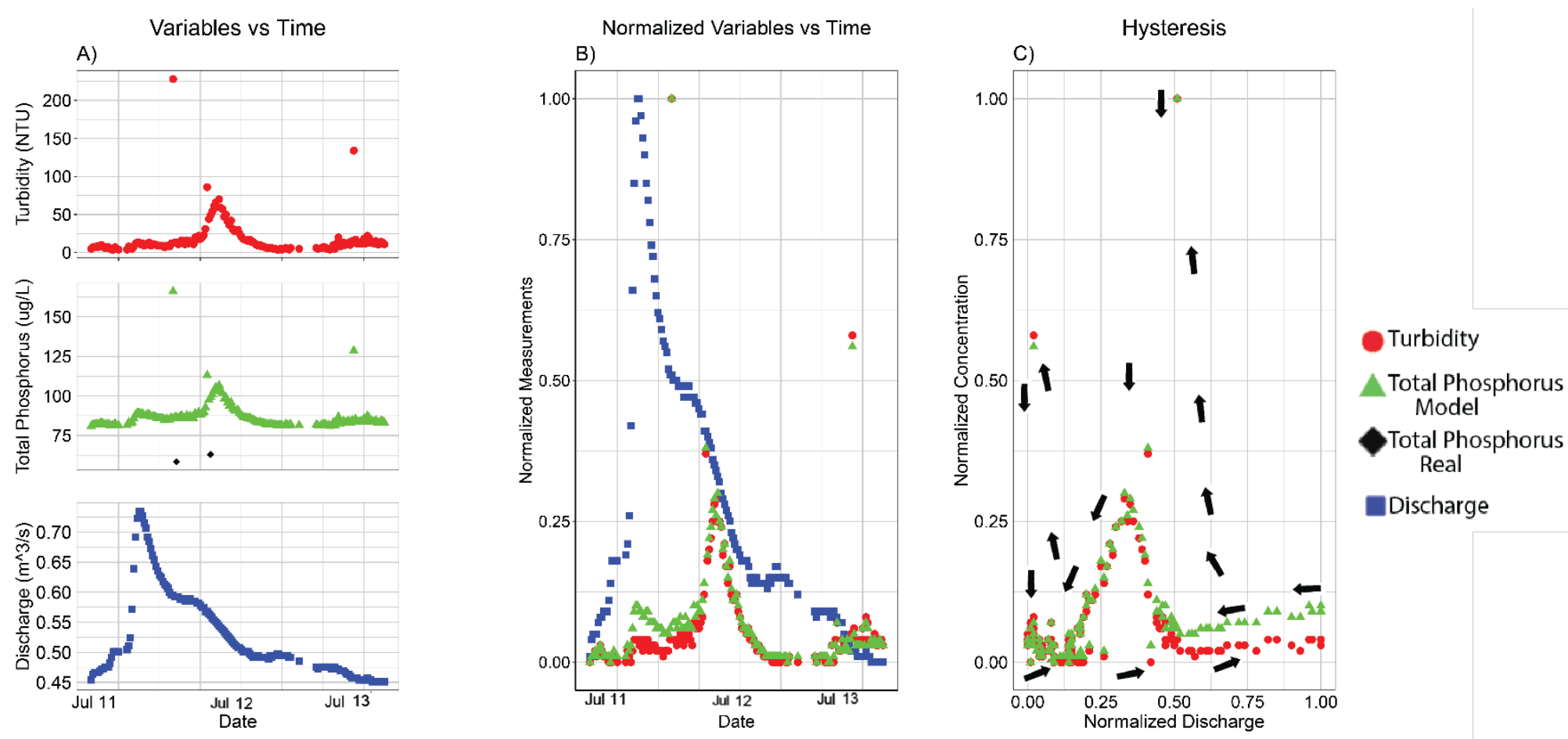


\begin{tabular}{|c|c|c|c|c|c|}
\hline \multicolumn{6}{|c|}{ SMC STORM ID 33} \\
\hline \multicolumn{3}{|c|}{ Duration } & \multicolumn{3}{|c|}{$7-22-17$ to $7-24-17$} \\
\hline \multicolumn{3}{|c|}{ Time Since Previous Storm } & \multicolumn{3}{|c|}{11 Days } \\
\hline \multicolumn{3}{|c|}{ Hysteresis Pattern } & \multicolumn{3}{|c|}{ Clockwise } \\
\hline \multicolumn{3}{|c|}{ HI Turbidity } & \multicolumn{3}{|c|}{0.12} \\
\hline \multicolumn{3}{|c|}{ FI Turbidity } & \multicolumn{3}{|c|}{0.76} \\
\hline \multicolumn{3}{|c|}{ HI Total Phosphorus } & \multicolumn{3}{|c|}{0.10} \\
\hline \multicolumn{3}{|c|}{ FI Total Phosphorus } & \multicolumn{3}{|c|}{0.83} \\
\hline Variable & Minimum & Maximum & Range & Mean ( \pm standard deviation) & Units \\
\hline Stage & 0.26 & 0.35 & 0.09 & $0.29( \pm 0.02)$ & $\mathbf{m}$ \\
\hline Discharge & $\mathbf{0 . 3 0}$ & 0.54 & 0.24 & $0.36( \pm 0.06)$ & $\mathbf{m}^{3} / \mathbf{s}$ \\
\hline Turbidity & 2.0 & 64.0 & 62.0 & $7.2( \pm 6.1)$ & NTU \\
\hline Total Phosphorus Model & 76.7 & 100.2 & 23.5 & $80.0( \pm 2.3)$ & $\mathrm{mg} / \mathrm{L}$ \\
\hline Mean Absolute Error Model & & & & 19.61 & $\mathrm{mg} / \mathrm{L}$ \\
\hline
\end{tabular}
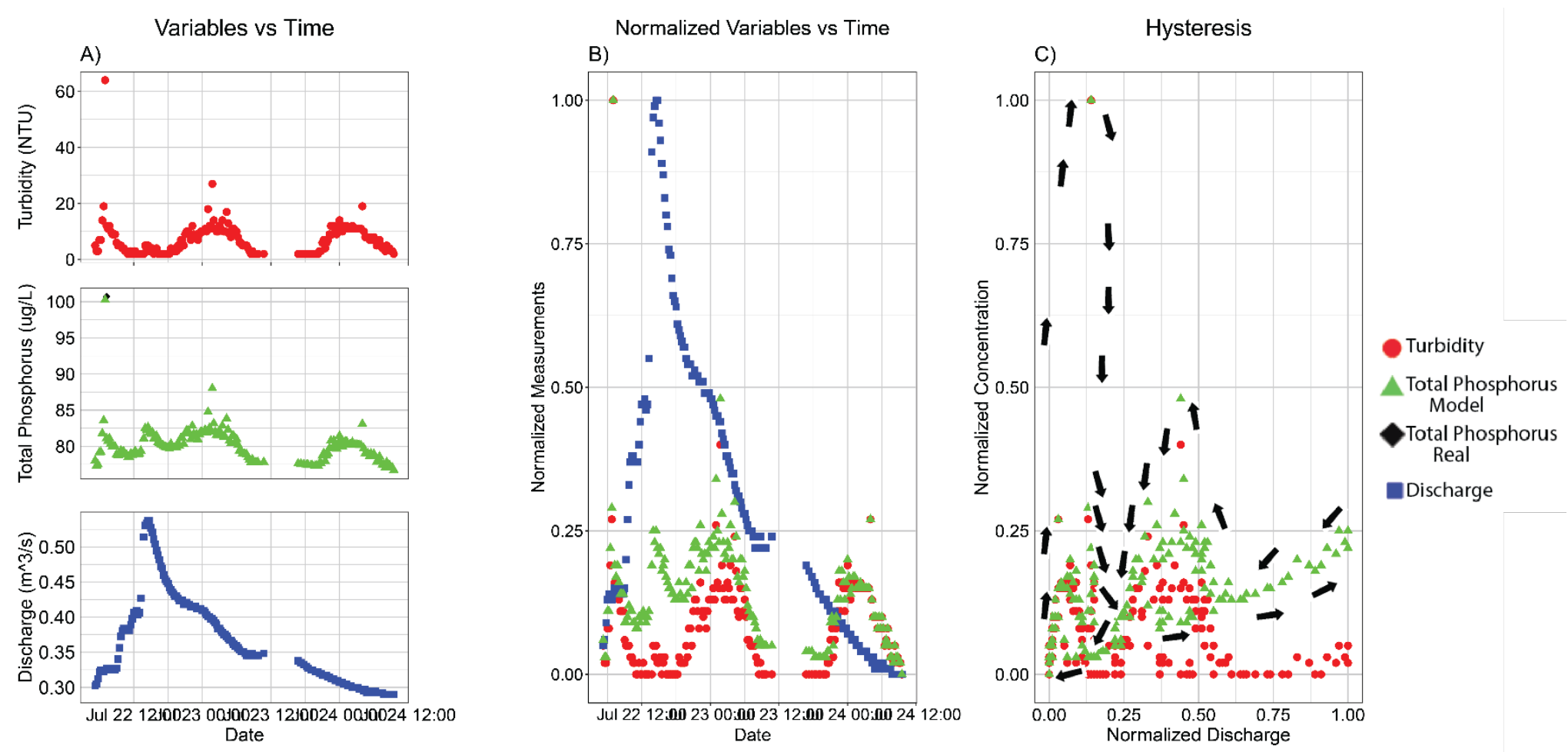


\begin{tabular}{|c|c|c|c|c|c|}
\hline \multicolumn{6}{|c|}{ SMC STORM ID 34} \\
\hline \multicolumn{3}{|c|}{ Duration } & \multicolumn{3}{|c|}{$7-26-17$ to $7-29-17$} \\
\hline \multicolumn{3}{|c|}{ Time Since Previous Storm } & \multicolumn{3}{|c|}{2 Days } \\
\hline \multicolumn{3}{|c|}{ Hysteresis Pattern } & \multicolumn{3}{|c|}{ Counterclockwise Figure Eight } \\
\hline \multicolumn{3}{|c|}{ HI Turbidity } & \multicolumn{3}{|c|}{-0.12} \\
\hline \multicolumn{3}{|c|}{ FI Turbidity } & \multicolumn{3}{|c|}{0.25} \\
\hline \multicolumn{3}{|c|}{ HI Total Phosphorus } & \multicolumn{3}{|c|}{-0.11} \\
\hline \multicolumn{3}{|c|}{ FI Total Phosphorus } & \multicolumn{3}{|c|}{0.40} \\
\hline Variable & Minimum & Maximum & Range & Mean ( \pm standard deviation) & Units \\
\hline Stage & 0.25 & 0.40 & 0.14 & $0.29( \pm 0.04)$ & $\mathbf{m}$ \\
\hline Discharge & 0.29 & 0.75 & 0.46 & $0.38( \pm 0.11)$ & $\mathbf{m}^{3} / \mathbf{s}$ \\
\hline Turbidity & 5.0 & 144.0 & 139.0 & $30.6( \pm 32.8)$ & NTU \\
\hline Total Phosphorus Model & 77.2 & 132.7 & 55.5 & $89.1( \pm 13.0)$ & $\mathrm{mg} / \mathrm{L}$ \\
\hline Mean Absolute Error Model & & & & 22.71 & $\mathrm{mg} / \mathrm{L}$ \\
\hline
\end{tabular}
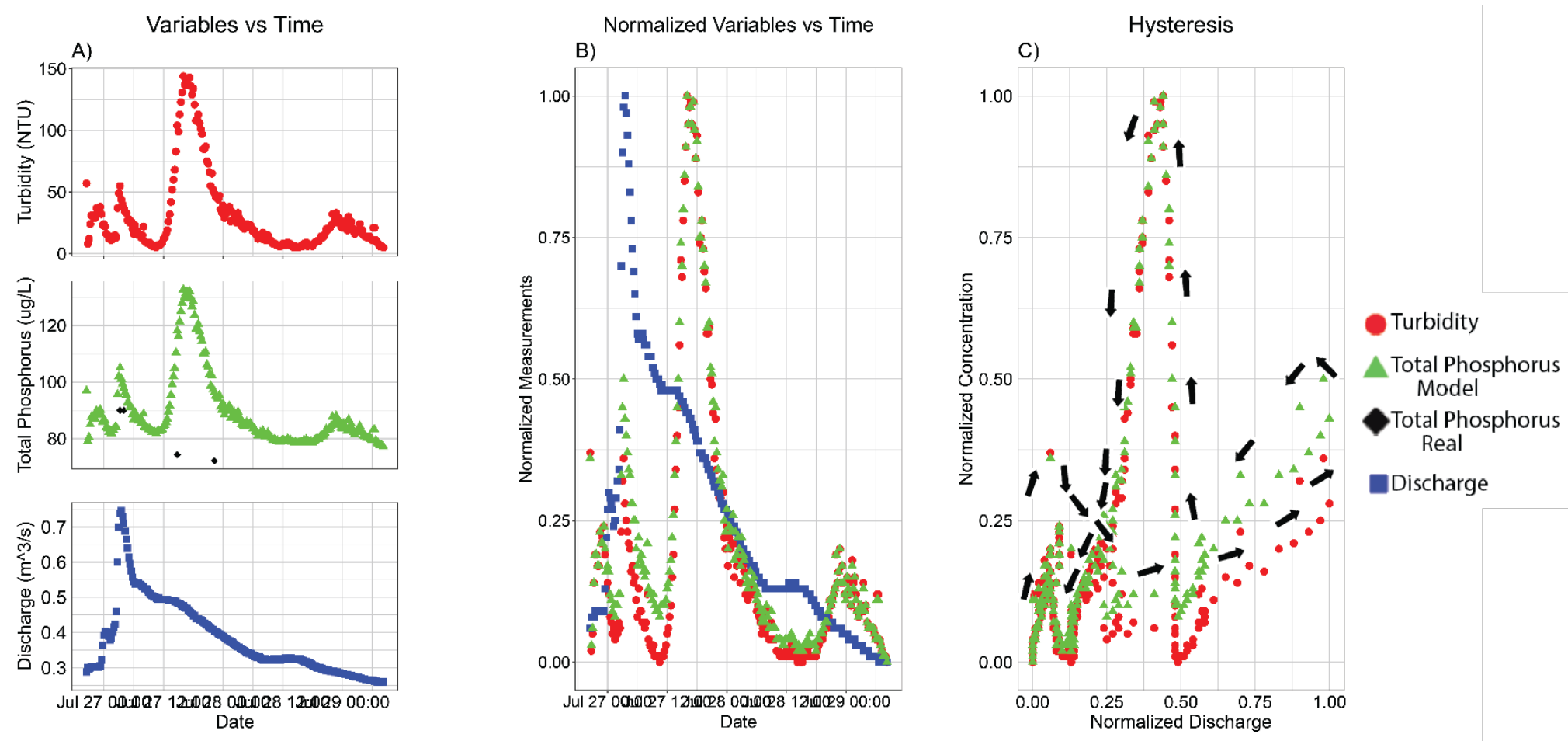


\begin{tabular}{|c|c|c|c|c|c|}
\hline \multicolumn{6}{|c|}{ SMC STORM ID 42} \\
\hline \multicolumn{3}{|c|}{ Duration } & \multicolumn{3}{|c|}{$11-18-17$ to $11-20-17$} \\
\hline \multicolumn{3}{|c|}{ Time Since Previous Storm } & \multicolumn{3}{|c|}{2 Days } \\
\hline \multicolumn{3}{|c|}{ Hysteresis Pattern } & \multicolumn{3}{|c|}{ Counterclockwise } \\
\hline \multicolumn{3}{|c|}{ HI Turbidity } & \multicolumn{3}{|c|}{-0.17} \\
\hline \multicolumn{3}{|c|}{ FI Turbidity } & \multicolumn{3}{|c|}{0.63} \\
\hline \multicolumn{3}{|c|}{ HI Total Phosphorus } & \multicolumn{3}{|c|}{-0.15} \\
\hline \multicolumn{3}{|c|}{ FI Total Phosphorus } & \multicolumn{3}{|c|}{0.68} \\
\hline Variable & Minimum & Maximum & Range & Mean ( \pm standard deviation) & Units \\
\hline Stage & 0.21 & 0.67 & 0.46 & $0.38( \pm 0.11)$ & $\mathbf{m}$ \\
\hline Discharge & 0.17 & 2.23 & 2.06 & $0.75( \pm 0.51)$ & $\mathbf{m}^{3} / \mathbf{s}$ \\
\hline Turbidity & 9.0 & 1011.0 & 1002.0 & $134.9( \pm 209.3)$ & NTU \\
\hline Total Phosphorus Model & 77.0 & 482.7 & 405.7 & $134.7( \pm 86.0)$ & $\mathrm{mg} / \mathrm{L}$ \\
\hline Mean Absolute Error Model & & & & 72.63 & $\mathrm{mg} / \mathrm{L}$ \\
\hline
\end{tabular}
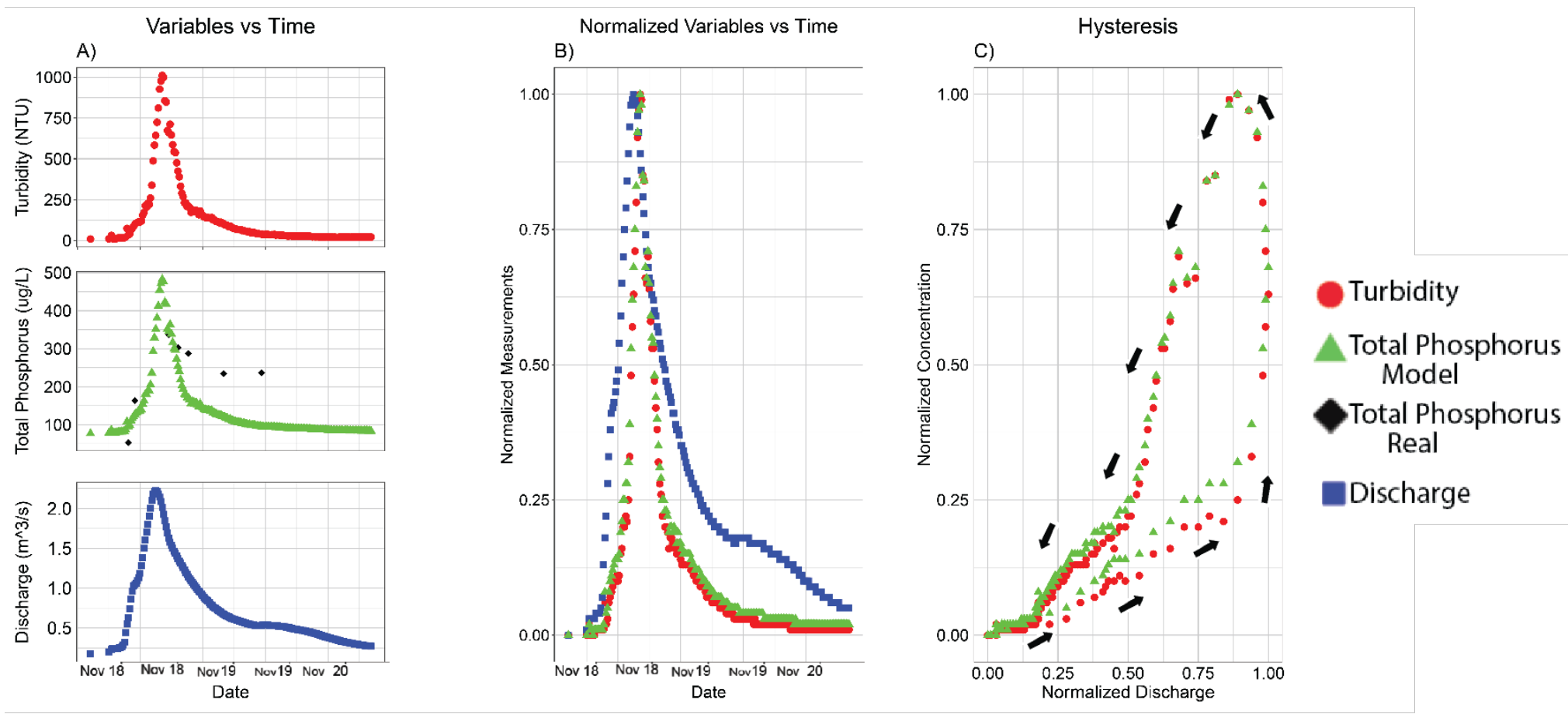


\begin{tabular}{|c|c|c|c|c|c|}
\hline \multicolumn{6}{|c|}{ SMC STORM ID 44} \\
\hline \multicolumn{3}{|c|}{ Duration } & \multicolumn{3}{|c|}{$3-1-18$ to $3-4-18$} \\
\hline \multicolumn{3}{|c|}{ Time Since Previous Storm } & \multicolumn{3}{|c|}{86 Days } \\
\hline \multicolumn{3}{|c|}{ Hysteresis Pattern } & \multicolumn{3}{|c|}{ Counterclockwise Figure Eight } \\
\hline \multicolumn{3}{|c|}{ HI Turbidity } & \multicolumn{3}{|c|}{0.03} \\
\hline \multicolumn{3}{|c|}{ FI Turbidity } & \multicolumn{3}{|c|}{0.77} \\
\hline \multicolumn{3}{|c|}{ HI Total Phosphorus } & \multicolumn{3}{|c|}{0.00} \\
\hline \multicolumn{3}{|c|}{ FI Total Phosphorus } & \multicolumn{3}{|c|}{0.84} \\
\hline Variable & Minimum & Maximum & Range & Mean ( \pm standard deviation) & Units \\
\hline Stage & 0.43 & 0.78 & 0.35 & $0.54( \pm 0.08)$ & $\mathbf{m}$ \\
\hline Discharge & 0.85 & 3.09 & 2.24 & $1.42( \pm 0.48)$ & $\mathbf{m}^{3} / \mathbf{s}$ \\
\hline Turbidity & 17.0 & 465.0 & 448 & $61.9( \pm 82.1)$ & NTU \\
\hline Total Phosphorus Model & 94.8 & 297.4 & 202.6 & $120.9( \pm 38.8)$ & $\mathrm{mg} / \mathrm{L}$ \\
\hline Mean Absolute Error Model & & & & 43.25 & $\mathrm{mg} / \mathrm{L}$ \\
\hline
\end{tabular}
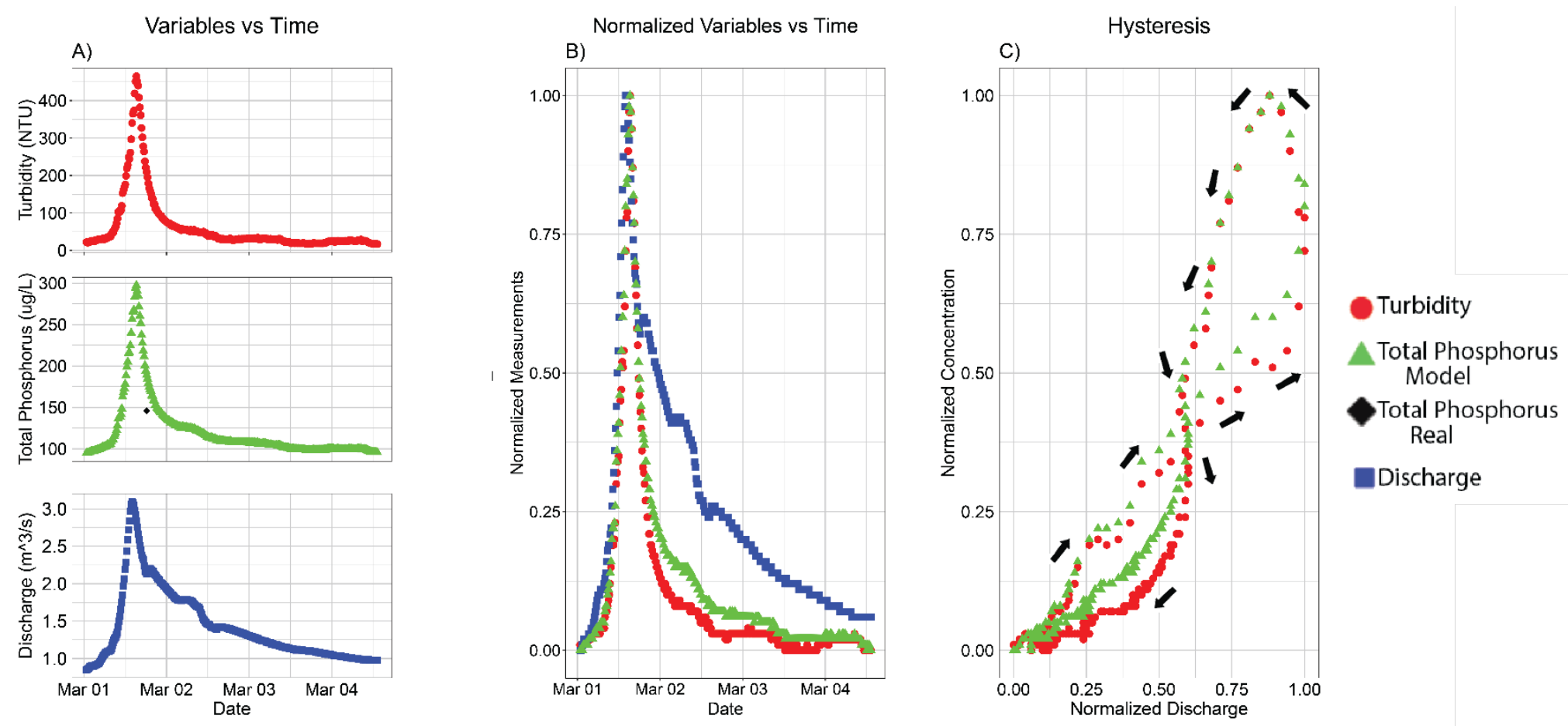


\begin{tabular}{|c|c|c|c|c|c|}
\hline \multicolumn{6}{|c|}{ SMC STORM ID 45} \\
\hline \multicolumn{3}{|c|}{ Duration } & \multicolumn{3}{|c|}{$3-26-18$ to $4-1-18$} \\
\hline \multicolumn{3}{|c|}{ Time Since Previous Storm } & \multicolumn{3}{|c|}{22 Days } \\
\hline \multicolumn{3}{|c|}{ Hysteresis Pattern } & \multicolumn{3}{|c|}{ Clockwise } \\
\hline \multicolumn{3}{|c|}{ HI Turbidity } & \multicolumn{3}{|c|}{0.34} \\
\hline \multicolumn{3}{|c|}{ FI Turbidity } & \multicolumn{3}{|c|}{0.49} \\
\hline \multicolumn{3}{|c|}{ HI Total Phosphorus } & \multicolumn{3}{|c|}{0.24} \\
\hline \multicolumn{3}{|c|}{ FI Total Phosphorus } & \multicolumn{3}{|c|}{0.34} \\
\hline Variable & Minimum & Maximum & Range & Mean ( \pm standard deviation) & Units \\
\hline Stage & 0.44 & 1.33 & 0.89 & $0.73( \pm 0.23)$ & $\mathbf{m}$ \\
\hline Discharge & 0.89 & 9.72 & 8.83 & $3.07( \pm 2.31)$ & $\mathbf{m}^{3} / \mathbf{s}$ \\
\hline Turbidity & 14.0 & 949.0 & 935.0 & $99.3( \pm 150.6)$ & NTU \\
\hline Total Phosphorus Model & 92.9 & 580.3 & 487.4 & $167.1( \pm 95.9)$ & $\mathbf{m g} / \mathrm{L}$ \\
\hline Mean Absolute Error Model & & & & 128.28 & $\mathrm{mg} / \mathrm{L}$ \\
\hline
\end{tabular}
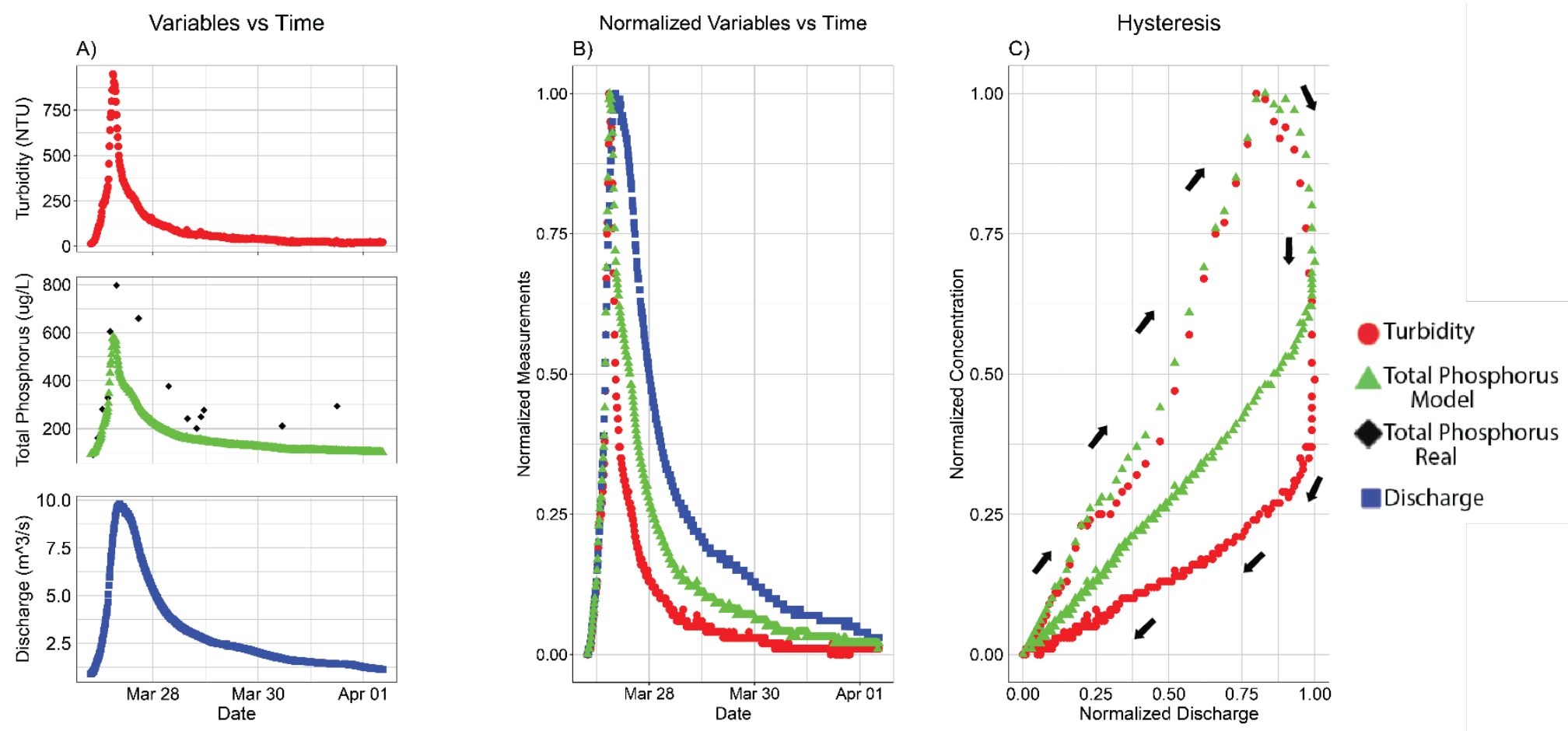


\begin{tabular}{|c|c|c|c|c|c|}
\hline \multicolumn{6}{|c|}{ SMC STORM ID 47} \\
\hline \multicolumn{3}{|c|}{ Duration } & \multicolumn{3}{|c|}{$5-30-18$ to $6-2-18$} \\
\hline \multicolumn{3}{|c|}{ Time Since Previous Storm } & \multicolumn{3}{|c|}{41 Days } \\
\hline \multicolumn{3}{|c|}{ Hysteresis Pattern } & \multicolumn{3}{|c|}{ Counterclockwise Figure Eight } \\
\hline \multicolumn{3}{|c|}{ HI Turbidity } & \multicolumn{3}{|c|}{0.00} \\
\hline \multicolumn{3}{|c|}{ FI Turbidity } & \multicolumn{3}{|c|}{0.93} \\
\hline \multicolumn{3}{|c|}{ HI Total Phosphorus } & \multicolumn{3}{|c|}{-0.01} \\
\hline \multicolumn{3}{|c|}{ FI Total Phosphorus } & \multicolumn{3}{|c|}{0.94} \\
\hline Variable & Minimum & Maximum & Range & Mean ( \pm standard deviation) & Units \\
\hline Stage & 0.33 & 0.95 & 0.62 & $0.49( \pm 0.11)$ & $\mathbf{m}$ \\
\hline Discharge & $\mathbf{0 . 5 0}$ & 4.71 & 4.21 & $1.23( \pm 0.73)$ & $\mathbf{m}^{3} / \mathbf{s}$ \\
\hline Turbidity & 13.0 & 1052.0 & 1039.0 & $89.7( \pm 191.2)$ & NTU \\
\hline Total Phosphorus Model & 85.4 & 549.6 & 464.2 & $127.4( \pm 84.3)$ & $\mathrm{mg} / \mathrm{L}$ \\
\hline Mean Absolute Error Model & & & & 5.77 & $\mathrm{mg} / \mathrm{L}$ \\
\hline
\end{tabular}
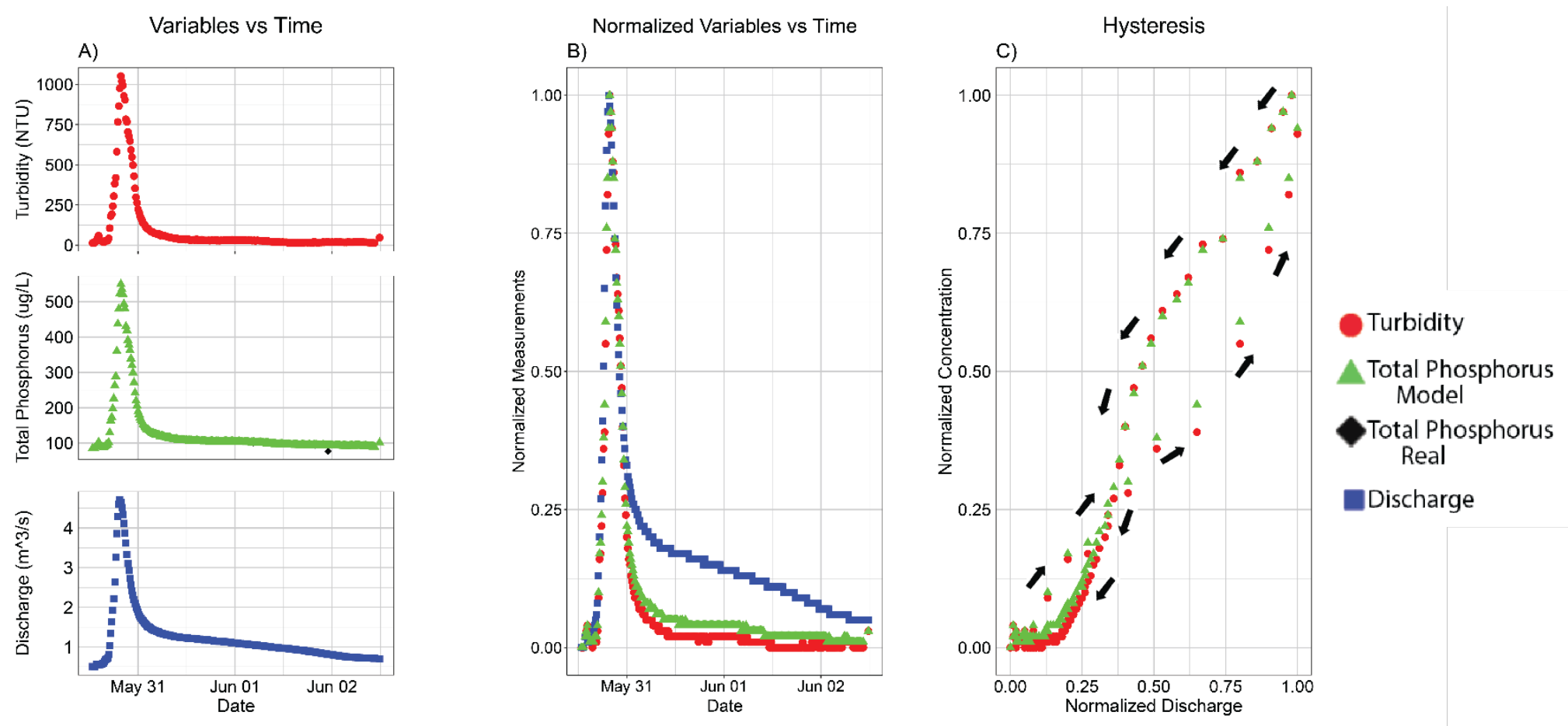


\begin{tabular}{|c|c|c|c|c|c|}
\hline \multicolumn{6}{|c|}{ SMC STORM ID 48} \\
\hline \multicolumn{3}{|c|}{ Duration } & \multicolumn{3}{|c|}{$6-10-18$ to $6-17-18$} \\
\hline \multicolumn{3}{|c|}{ Time Since Previous Storm } & \multicolumn{3}{|c|}{8 Days } \\
\hline \multicolumn{3}{|c|}{ Hysteresis Pattern } & \multicolumn{3}{|c|}{ Clockwise } \\
\hline \multicolumn{3}{|c|}{ HI Turbidity } & \multicolumn{3}{|c|}{0.28} \\
\hline \multicolumn{3}{|c|}{ FI Turbidity } & \multicolumn{3}{|c|}{0.59} \\
\hline \multicolumn{3}{|c|}{ HI Total Phosphorus } & \multicolumn{3}{|c|}{0.20} \\
\hline \multicolumn{3}{|c|}{ FI Total Phosphorus } & \multicolumn{3}{|c|}{0.84} \\
\hline Variable & Minimum & Maximum & Range & Mean ( \pm standard deviation) & Units \\
\hline Stage & 0.36 & 1.59 & 1.23 & $0.67( \pm 0.27)$ & $\mathbf{m}$ \\
\hline Discharge & 0.58 & 14.48 & 13.90 & $2.70( \pm 2.82)$ & $\mathbf{m}^{3} / \mathbf{s}$ \\
\hline Turbidity & 17.0 & 1316.0 & 1299.0 & $90.1( \pm 192.5)$ & NTU \\
\hline Total Phosphorus Model & 89.4 & 751.9 & 662.5 & $156.4( \pm 122.3)$ & $\mathrm{mg} / \mathrm{L}$ \\
\hline Mean Absolute Error Model & & & & 77.75 & $\mathrm{mg} / \mathrm{L}$ \\
\hline
\end{tabular}
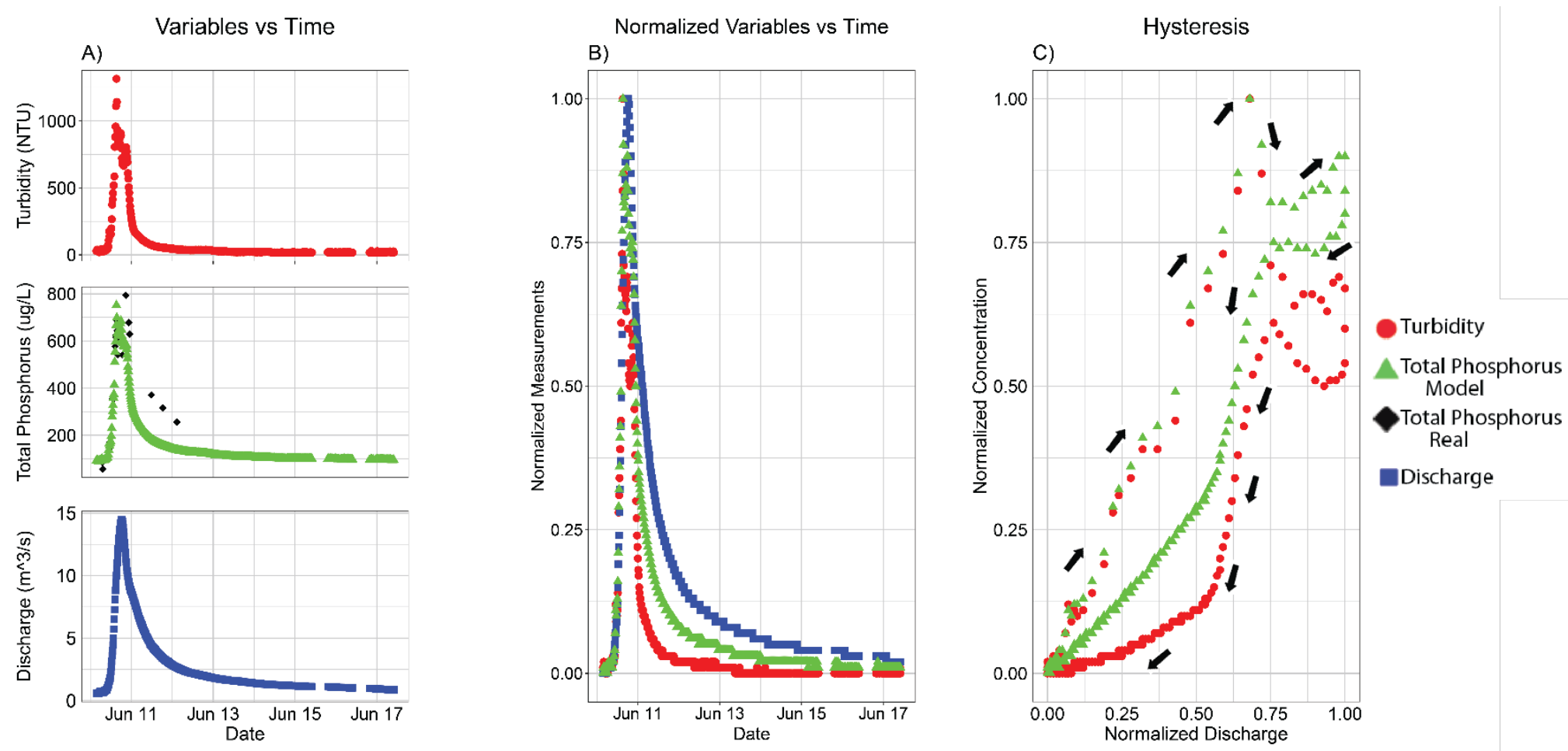


\begin{tabular}{|c|c|c|c|c|c|}
\hline \multicolumn{6}{|c|}{ SMC STORM ID 49} \\
\hline \multicolumn{3}{|c|}{ Duration } & \multicolumn{3}{|c|}{$6-20-18$ to $6-28-18$} \\
\hline \multicolumn{3}{|c|}{ Time Since Previous Storm } & \multicolumn{3}{|c|}{3 Days } \\
\hline \multicolumn{3}{|c|}{ Hysteresis Pattern } & \multicolumn{3}{|c|}{ Clockwise } \\
\hline \multicolumn{3}{|c|}{ HI Turbidity } & \multicolumn{3}{|c|}{0.29} \\
\hline \multicolumn{3}{|c|}{ FI Turbidity } & \multicolumn{3}{|c|}{0.53} \\
\hline \multicolumn{3}{|c|}{ HI Total Phosphorus } & \multicolumn{3}{|c|}{0.19} \\
\hline \multicolumn{3}{|c|}{ FI Total Phosphorus } & \multicolumn{3}{|c|}{0.79} \\
\hline Variable & Minimum & Maximum & Range & Mean ( \pm standard deviation) & Units \\
\hline Stage & 0.39 & 1.78 & 1.39 & $0.64( \pm 0.30)$ & $\mathbf{m}$ \\
\hline Discharge & 0.71 & 18.42 & 17.71 & $2.62( \pm 3.48)$ & $\mathbf{m}^{3} / \mathbf{s}$ \\
\hline Turbidity & 16.0 & 1416.0 & 1400.0 & $77.1( \pm 175.5)$ & NTU \\
\hline Total Phosphorus Model & 90.4 & 882.3 & 791.1 & $150.2( \pm 128.2)$ & $\mathrm{mg} / \mathrm{L}$ \\
\hline Mean Absolute Error Model & & & & 84.69 & $\mathrm{mg} / \mathrm{L}$ \\
\hline
\end{tabular}
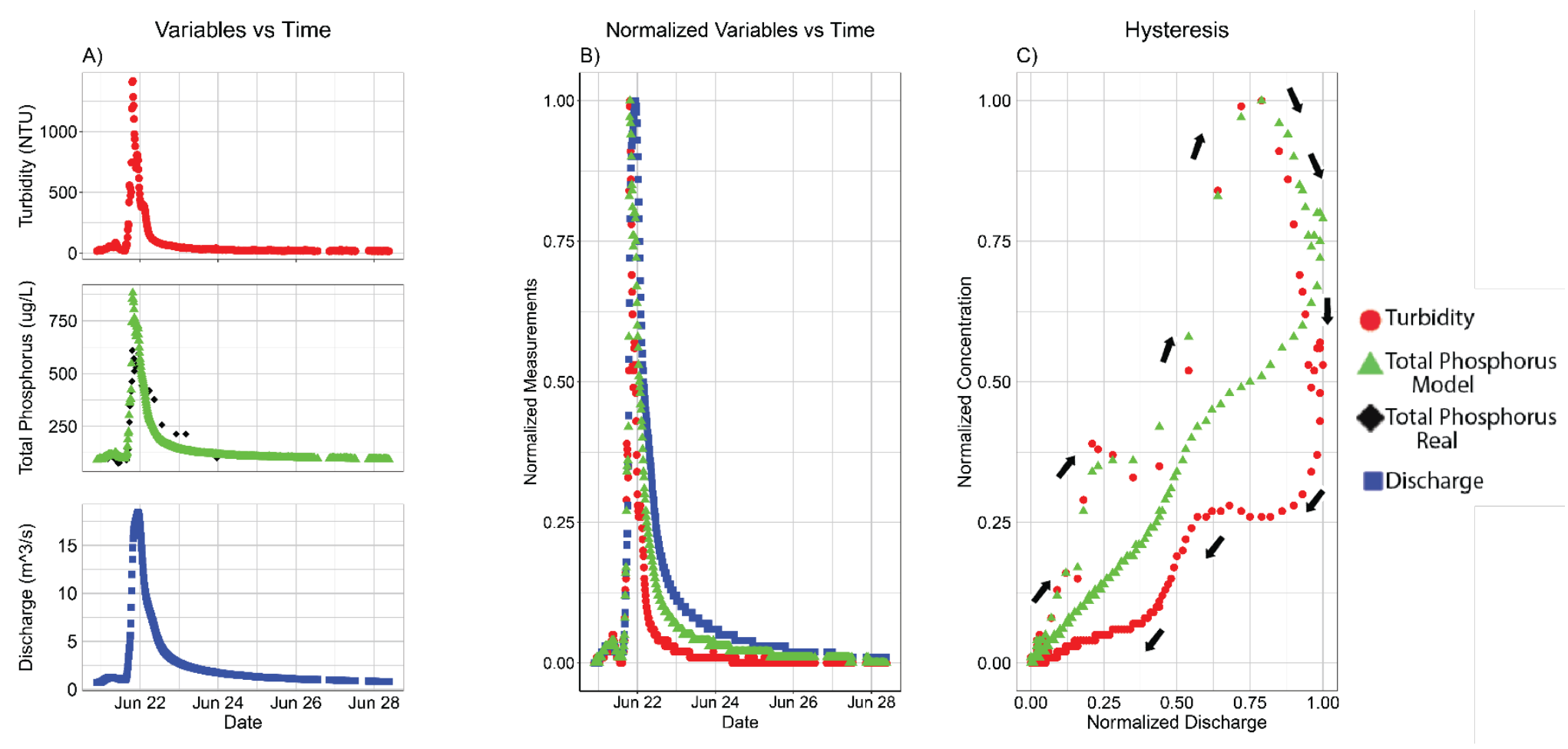


\begin{tabular}{|c|c|c|c|c|c|}
\hline \multicolumn{6}{|c|}{ SMC STORM ID 51} \\
\hline \multicolumn{3}{|c|}{ Duration } & \multicolumn{3}{|c|}{$10-30-18$ to $11-4-18$} \\
\hline \multicolumn{3}{|c|}{ Time Since Previous Storm } & \multicolumn{3}{|c|}{15 Days } \\
\hline \multicolumn{3}{|c|}{ Hysteresis Pattern } & \multicolumn{3}{|c|}{ Clockwise Figure Eight } \\
\hline \multicolumn{3}{|c|}{ HI Turbidity } & \multicolumn{3}{|c|}{-0.09} \\
\hline \multicolumn{3}{|c|}{ FI Turbidity } & \multicolumn{3}{|c|}{0.92} \\
\hline \multicolumn{3}{|c|}{ HI Total Phosphorus } & \multicolumn{3}{|c|}{-0.05} \\
\hline \multicolumn{3}{|c|}{ FI Total Phosphorus } & \multicolumn{3}{|c|}{0.95} \\
\hline Variable & Minimum & Maximum & Range & Mean ( \pm standard deviation) & Units \\
\hline Stage & 0.19 & 0.60 & 0.42 & $0.34( \pm 0.08)$ & $\mathbf{m}$ \\
\hline Discharge & 0.15 & 1.79 & 1.64 & $0.55( \pm 0.32)$ & $\mathbf{m}^{3} / \mathbf{s}$ \\
\hline Turbidity & 11.0 & 131.0 & 120.0 & $23.8( \pm 17.2)$ & NTU \\
\hline Total Phosphorus Model & 77.2 & 153.6 & 76.4 & $89.9( \pm 11.8)$ & $\mathrm{mg} / \mathrm{L}$ \\
\hline Mean Absolute Error Model & & & & 202.65 & $\mathrm{mg} / \mathrm{L}$ \\
\hline
\end{tabular}

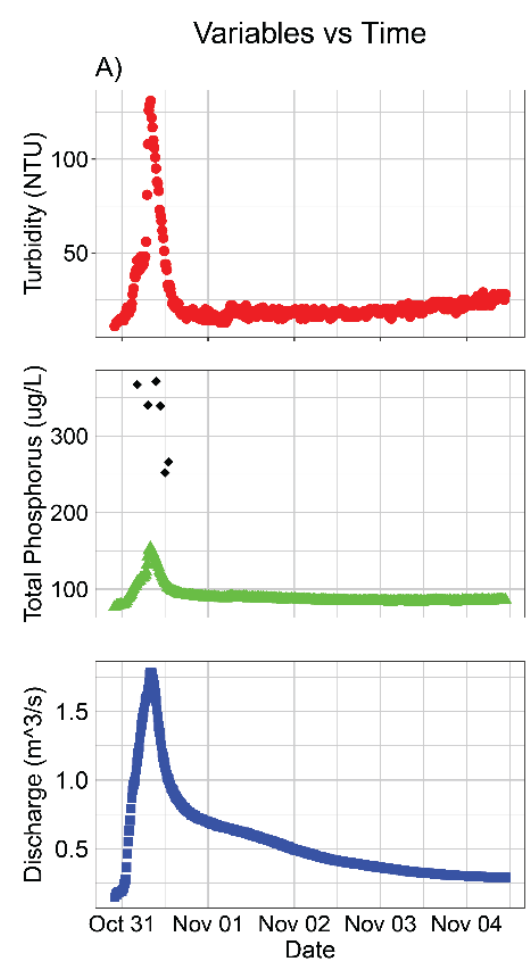

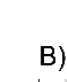

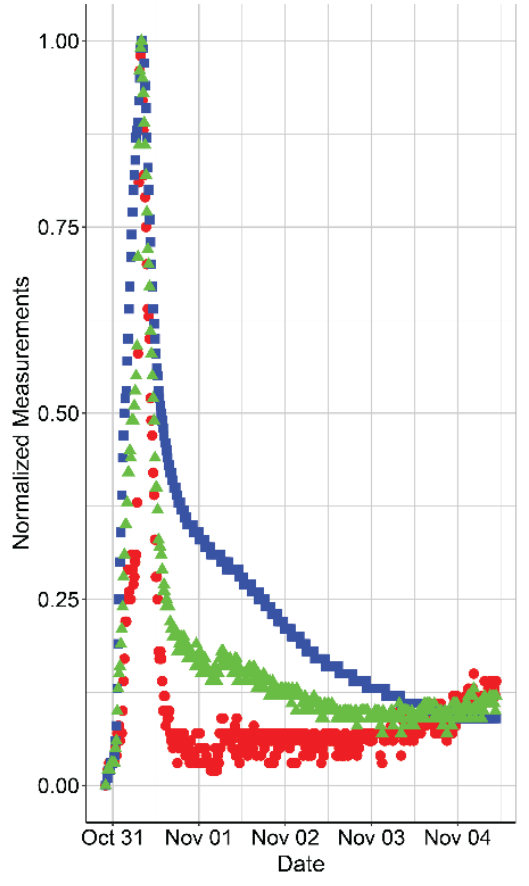




\begin{tabular}{|c|c|c|c|c|c|}
\hline \multicolumn{6}{|c|}{ SMC STORM ID 54} \\
\hline \multicolumn{3}{|c|}{ Duration } & \multicolumn{3}{|c|}{$12-27-18$ to $12-30-18$} \\
\hline \multicolumn{3}{|c|}{ Time Since Previous Storm } & \multicolumn{3}{|c|}{20 Days } \\
\hline \multicolumn{3}{|c|}{ Hysteresis Pattern } & \multicolumn{3}{|c|}{ Counterclockwise Figure Eight } \\
\hline \multicolumn{3}{|c|}{ HI Turbidity } & \multicolumn{3}{|c|}{-0.06} \\
\hline \multicolumn{3}{|c|}{ FI Turbidity } & \multicolumn{3}{|c|}{1.00} \\
\hline \multicolumn{3}{|c|}{ HI Total Phosphorus } & \multicolumn{3}{|c|}{-0.05} \\
\hline \multicolumn{3}{|c|}{ FI Total Phosphorus } & \multicolumn{3}{|c|}{1.00} \\
\hline Variable & Minimum & Maximum & Range & Mean ( \pm standard deviation) & Units \\
\hline Stage & 0.32 & 0.60 & 0.28 & $0.46( \pm 0.06)$ & $\mathbf{m}$ \\
\hline Discharge & 0.45 & 1.77 & 1.32 & $1.04( \pm 0.29)$ & $\mathbf{m}^{3} / \mathbf{s}$ \\
\hline Turbidity & 10.0 & 366.0 & 356.0 & $47.5( \pm 63.4)$ & NTU \\
\hline Total Phosphorus Model & 82.8 & 240.2 & 157.4 & $108.1( \pm 28.1)$ & $\mathrm{mg} / \mathrm{L}$ \\
\hline Mean Absolute Error Model & & & & 27.52 & $\mathrm{mg} / \mathrm{L}$ \\
\hline
\end{tabular}
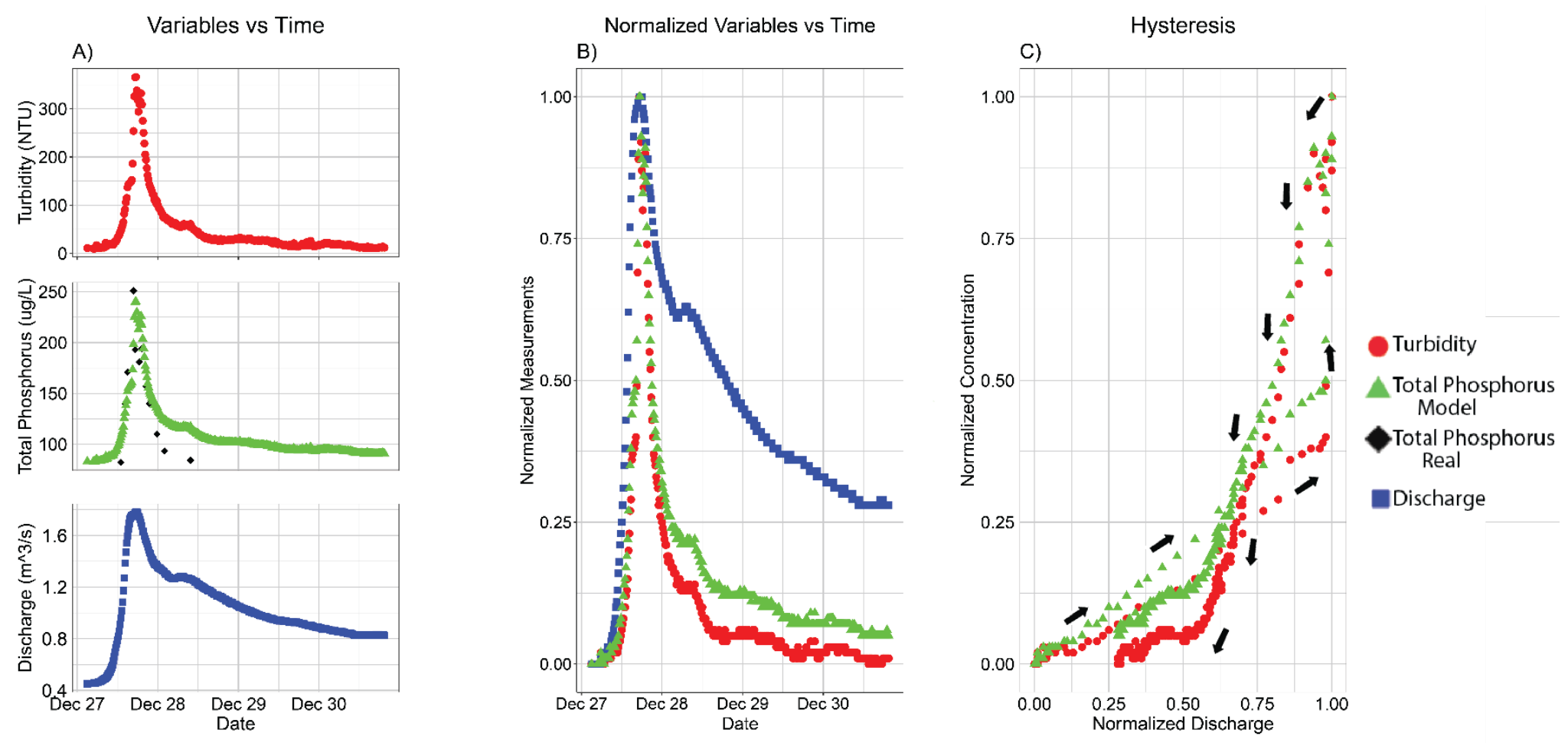


\begin{tabular}{|c|c|c|c|c|c|}
\hline \multicolumn{6}{|c|}{ SMC STORM ID 55} \\
\hline \multicolumn{3}{|c|}{ Duration } & \multicolumn{3}{|c|}{$12-31-18$ to $1-6-19$} \\
\hline \multicolumn{3}{|c|}{ Time Since Previous Storm } & \multicolumn{3}{|c|}{1 Day } \\
\hline \multicolumn{3}{|c|}{ Hysteresis Pattern } & \multicolumn{3}{|c|}{ Clockwise } \\
\hline \multicolumn{3}{|c|}{ HI Turbidity } & \multicolumn{3}{|c|}{0.16} \\
\hline \multicolumn{3}{|c|}{ FI Turbidity } & \multicolumn{3}{|c|}{0.93} \\
\hline \multicolumn{3}{|c|}{ HI Total Phosphorus } & \multicolumn{3}{|c|}{0.13} \\
\hline \multicolumn{3}{|c|}{ FI Total Phosphorus } & \multicolumn{3}{|c|}{0.95} \\
\hline Variable & Minimum & Maximum & Range & Mean ( \pm standard deviation) & Units \\
\hline Stage & 0.43 & 1.21 & .78 & $0.66( \pm 0.20)$ & $\mathbf{m}$ \\
\hline Discharge & 0.85 & 8.01 & 7.14 & $2.41( \pm 1.68)$ & $\mathbf{m}^{3} / \mathbf{s}$ \\
\hline Turbidity & 19.0 & 1378.0 & 1359.0 & $97.7( \pm 181.1)$ & NTU \\
\hline Total Phosphorus Model & 94.4 & 734.7 & 640.3 & $153.7( \pm 95.8)$ & $\mathbf{m g} / \mathrm{L}$ \\
\hline Mean Absolute Error Model & & & & 136.29 & $\mathrm{mg} / \mathrm{L}$ \\
\hline
\end{tabular}
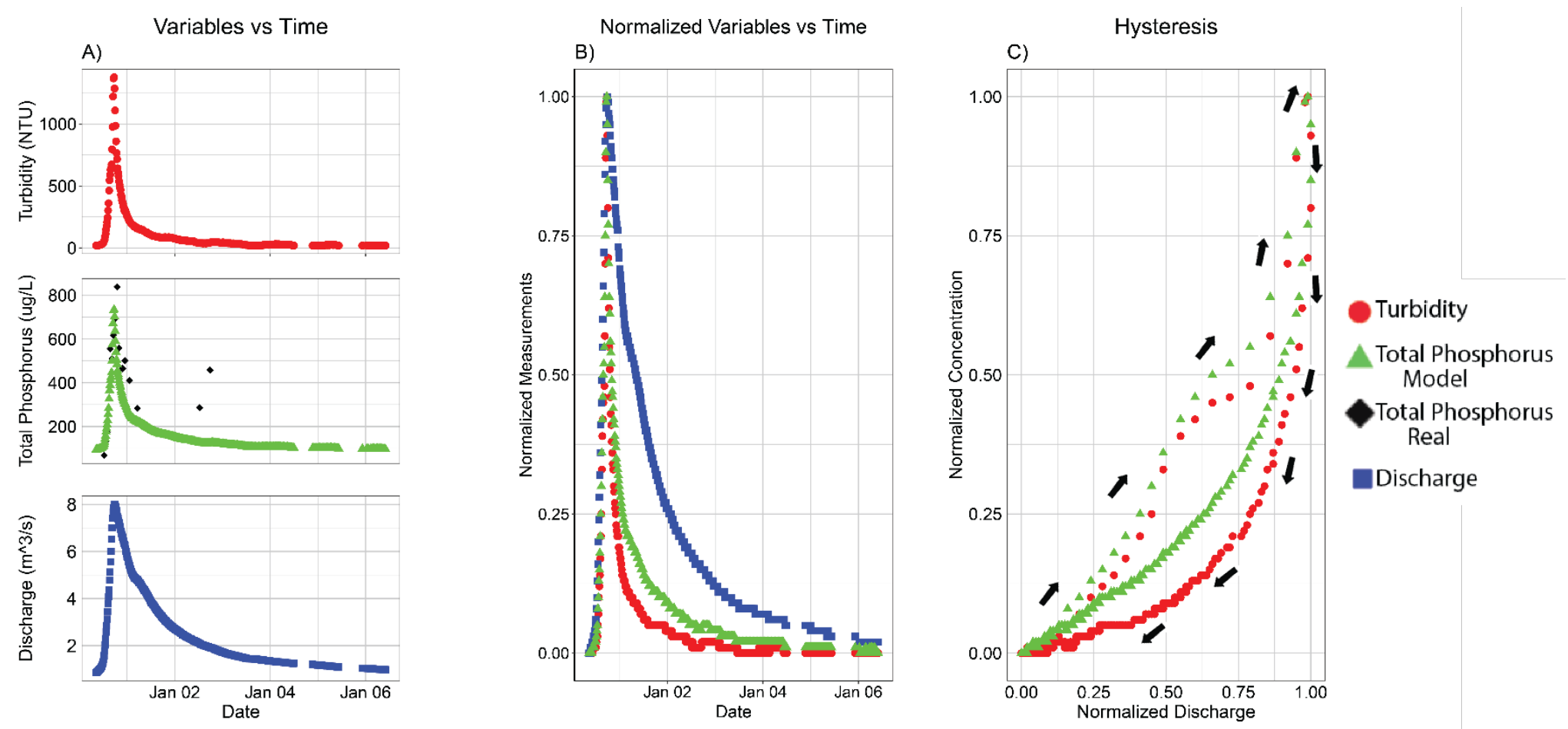